University of Louisville

ThinkIR: The University of Louisville's Institutional Repository

Electronic Theses and Dissertations

$12-2016$

\title{
"We weren't created to do it by ourselves" : good mothering and maternal support across race, class, and family structure.
}

Cheryl Lynn Crane

University of Louisville

Follow this and additional works at: https://ir.library.louisville.edu/etd

Part of the Family, Life Course, and Society Commons, Gender and Sexuality Commons, Inequality and Stratification Commons, and the Race and Ethnicity Commons

\section{Recommended Citation}

Crane, Cheryl Lynn, "'We weren't created to do it by ourselves" : good mothering and maternal support across race, class, and family structure." (2016). Electronic Theses and Dissertations. Paper 2605. https://doi.org/10.18297/etd/2605

This Doctoral Dissertation is brought to you for free and open access by ThinkIR: The University of Louisville's Institutional Repository. It has been accepted for inclusion in Electronic Theses and Dissertations by an authorized administrator of ThinkIR: The University of Louisville's Institutional Repository. This title appears here courtesy of the author, who has retained all other copyrights. For more information, please contact thinkir@louisville.edu. 


\title{
"WE WEREN'T CREATED TO DO IT BY OURSELVES": GOOD MOTHERING AND MATERNAL SUPPORT ACROSS RACE, CLASS, AND FAMILY STRUCTURE
}

\author{
By \\ Cheryl Lynn Crane \\ B.A., University of Washington, 1996 \\ M.A., University of Washington, 1998

\begin{abstract}
A Dissertation
Submitted to the Faculty of the

College of Arts and Sciences of the University of Louisville in Partial Fulfillment of the Requirements

for the Degree of
\end{abstract}

Doctor of Philosophy in Applied Sociology

Department of Sociology
University of Louisville
Louisville, Kentucky

December 2016 
(C) Copyright 2016 by Cheryl Lynn Crane

All rights reserved. 



\title{
"WE WEREN'T CREATED TO DO IT BY OURSELVES": GOOD MOTHERING AND MATERNAL SUPPORT ACROSS RACE, CLASS, AND FAMILY STRUCTURE
}

\section{By}

\section{Cheryl Lynn Crane}

B.A., University of Washington, 1996

M.A., University of Washington, 1998

A Dissertation Approved on

November 17, 2016

by the following Dissertation Committee:

Karen Christopher, PhD, Director

\author{
Patricia Gagné, PhD
}

Gül Aldikaçti Marshall, PhD

Robin Högnäs, $\mathrm{PhD}$

Nancy Theriot, $\mathrm{PhD}$ 


\section{DEDICATION}

This dissertation is the culmination of years

of support and encouragement from family members and friends.

I dedicate this to Matt

for never letting me give up and

for being the partner I've always needed and co-parent I've always wanted.

I dedicate this to my mother, Ann, for her countless readings of drafts

and for seamlessly filling in the voids I left in my family's daily life.

I dedicate this to Heidi

for celebrating and commiserating with me throughout this program.

Finally, I dedicate this to Katie

for being my inspiration and my motivation

for this, and everything, I do.

I would not have started nor finished this if not for you. 


\section{ACKNOWLEDGEMENTS}

This project took a village, and I am so thankful for mine. Thank you to the Department of Sociology and the School of Interdisciplinary and Graduate Studies for years of academic and financial support. Thank you to Ryan Schroeder and Cynthia Negrey for leading a department so committed to its graduate students and their successes. To my peers and colleagues, thank you for making this journey challenging and enjoyable. I've learned so much from each of you and am thankful to count you as friends.

My dissertation committee was second to none. Thank you to my chair, Karen Christopher, for her academic insight and pragmatic advice; her edits and feedback made me a stronger writer and better researcher, and her encouragement kept me going. Thank you to Patricia Gagné for helping to make my dream of returning to school a reality, and for teaching me compassion for myself throughout this process. Thank you to Gül Aldikaçti Marshall for her strengths in combining gender and social movements theories, and for inspiring me to do the same. Thank you to Robin Högnäs for making me draft (multiple!) proposals of my research early in the program. Thank you to Nancy Theriot for working with me my first summer in residence, and for her professional support since then. Most importantly, each member of my committee-whether she knew it or notmodeled the way she worked to be a fierce, feminist researcher, a deeply committed teacher/mentor, and a mother. I learned to set boundaries, practice self-care, and find my voice to negotiate the messy and exquisite challenges that arise when combining motherhood and academia. Thank you.

I am so grateful to have worked with the dedicated and impassioned maternal advocates and activists in this community. Thank you so much, Shannon, for vouching for me and connecting mothers to this project. Thank you, Emily, for letting me observe and learn from you and your commitment to supporting others. Thank you, both, for your unyielding devotion to social justice and community. I hope you never doubt the influence your work has on others. Thank you.

My most sincere thank you to the mothers who shared their stories with me. I heard you. You trusted me with the sorrows, frustrations, celebrations, fears, and joy you've experienced on your motherhood journeys and I am deeply humbled. I promise to continue working for you and alongside you to expand maternal resources and support for all mothers. Thank you. 


\author{
ABSTRACT \\ “WE WEREN'T CREATED TO DO IT BY OURSELVES": \\ GOOD MOTHERING AND MATERNAL SUPPORT \\ ACROSS RACE, CLASS, AND FAMILY STRUCTURE \\ Cheryl Lynn Crane
}

November 17, 2016

Maternal support contributes to maternal and child well-being, yet not all mothers incorporate support into their maternal practices. Most research on mothering standards and practices in the U.S. focuses on white, middle-class, married mothers. This study expands upon this research by incorporating an intersectional lens to explore how mothers interpret standards of "good mothering" across race, class, and family structure. I conducted a mixed-method evaluation of a nonprofit program offering peer-based maternal support to mothers of color, lower-income mothers, and single mothers; 41 indepth interviews with mothers to learn why maternal support resonated with some, but not all, mothers; and an in-depth focus group interview with the founders of the peerbased support program. Employing systems-centered intersectionality (Choo and Ferree 2010) and multi-institutional politics (Armstrong and Bernstein 2008), I found that some lower-income, single mothers practiced the parenting style "nurtured growth," allowing them to supplement their limited income and physical and emotional presence with free and low-cost resources from public institutions (e.g., schools, churches, parks). Some other lower-income, single, mothers of color resisted normative parenting practices 
rooted in self-sacrifice by practicing "empowered mothering." This practice incorporated self-care and mother-centric support systems to challenge race-based interpretations of good mothering. Finally, the theme "cultural mismatch" explains the difficulty faced by the nonprofit organization in attracting mothers of color and single mothers. I argue that racial, economic, and marital variations in maternal standards, practices, and support rendered the program's curriculum incompatible with its intended participants. I conclude by offering recommendations for this and other maternal support programs. 


\section{TABLE OF CONTENTS}

PAGE

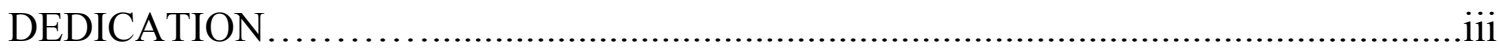

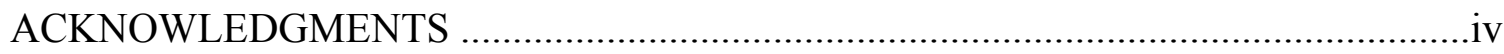

ABSTRACT

CHAPTER I: INTRODUCTION ...............................................

Intensive Mothering Ideology and Its Limitations...........................2

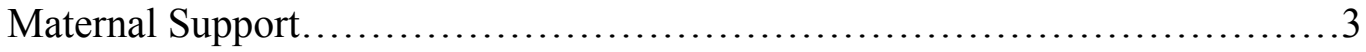

Research Questions...................................................

Preview of Findings and Contributions.....................................

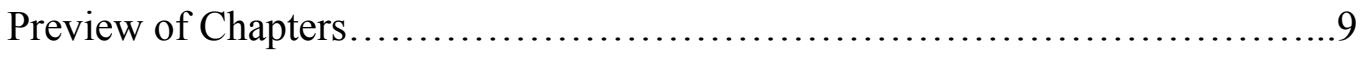

CHAPTER II: REVIEW OF LITERATURE \& THEORETICAL FRAMES....................12

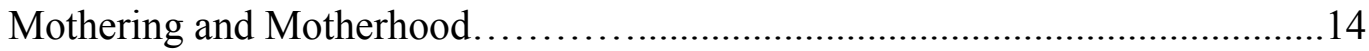

Good Mothering and Intensive Mothering Ideology...................16

Good Mothers versus Bad Mothers....................................19

Challenging the Good Mother......................................23

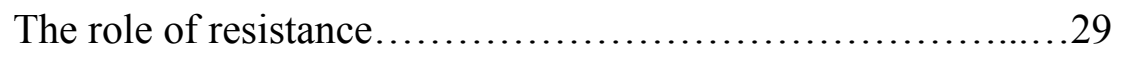

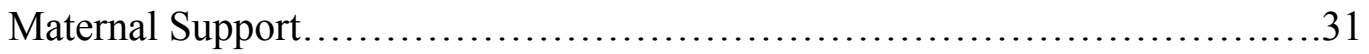

Maternal Support and Well-Being....................................31

Expanding Maternal Support.......................................32 


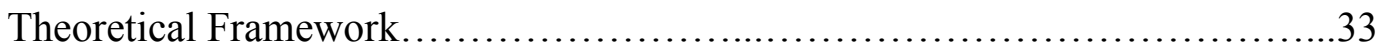

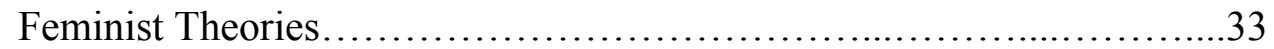

Intersectionality and Motherhood.......................................

Cultural Feminism.................................................... 38

Multi-Institutional Politics Approach to Social Movements..................41

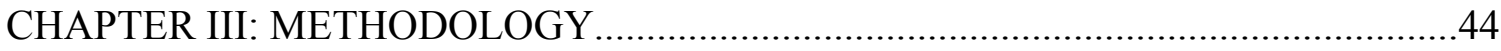

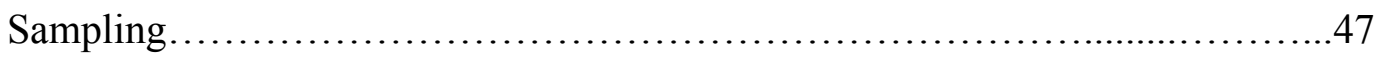

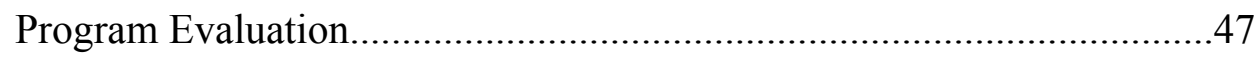

In-depth Interviews............................................... 47

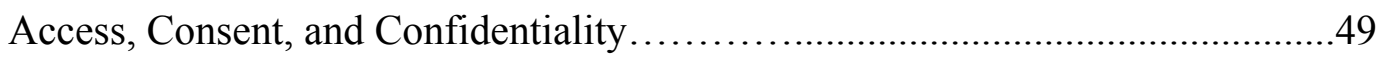

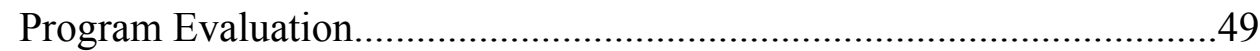

In-depth Interviews.................................................50

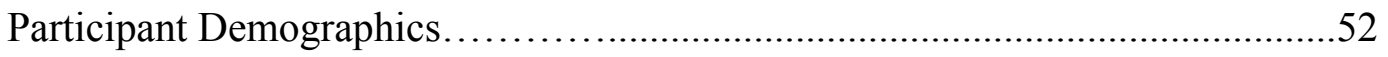

Program Evaluation..........................................................................52

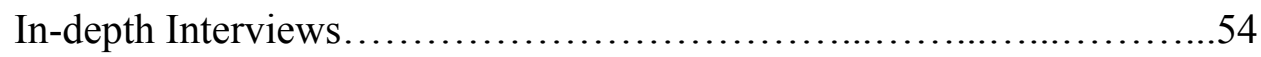

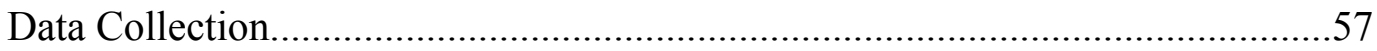

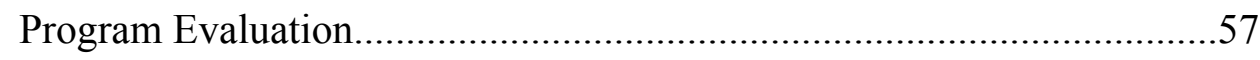

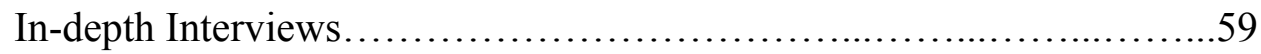

Focus Group Interview.................................................

Methodological Strengths and Weaknesses.................................66

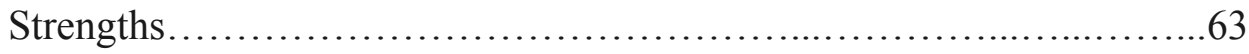

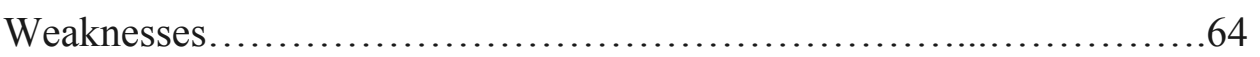

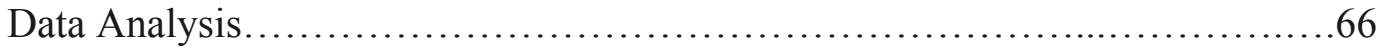


Grounded Theory.

Intersectionality ....................................................

Researcher Subjectivity........................................69

Generalizability of Findings.....................................71

Conclusion......................................................... 72

CHAPTER IV: MOTHERS HELPING MOTHERS AND PEER-BASED SUPPORT...74

Mothers Helping Mothers............................................... 76

The Organization's Origins..................................................76

Peer-based Support Group Programming...................................81

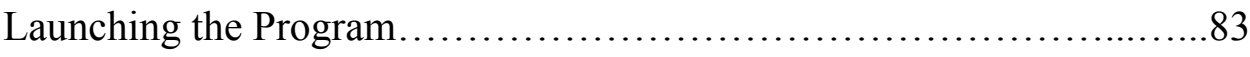

Evaluation Findings................................................ 87

Pre- and Post-Tests......................................... 87

Parenting Skills Self-Confidence............................90

Sense of Community.................................92

Risk of Postpartum Depression...........................93

Participant Observation Findings..................................95

Maternal Ideology......................................97

Cultural Competency.........................................103

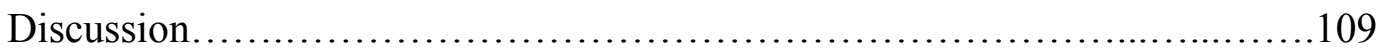

Challenging the Institution of Motherhood:

Framing and maternal ideology...................................111

CHAPTER V: WHAT IS GOOD MOTHERING? ................................................. 115

Perceptions of Good Mothering............................................................116

Affluent, Partnered, Black Mothers: Concerted cultivation...............117 
Lower-Middle Class, Partnered, Stay-at-Home Mothers:

Being there and simple mothering...

Good Mothering and Public Surveillance

Single, Lower-Income Mothers and Public Scrutiny:

Modifying standards, debunking stereotypes, and

maintaining appearances

Debunking perceptions of single mothers

Image maintenance: Lower-income mothers..................128

Image maintenance: Affluent black mothers..................130

Image maintenance and racial privilege.....................130

Modifying Maternal Standards and Practices:

Lower- and lower-middle income mothers

Good Mothers and Self-Sacrifice.

Self-Sacrifice: Work life

Self-Sacrifice: Social life

Self-Sacrifice: Concerted cultivation

Self-Sacrifice: Personal maintenance

Self-Sacrifice: Shifting priorities

Good Mothers and Self-Care........................................... 143

Self-Care: Stay-at-home-mothers...............................143

Self-Care: Working mothers................................. 145

Combining Self-Sacrifice and Self-Care ..................................147

Discussion.......................................................... 150 


\section{CHAPTER VI: WHAT IS MATERNAL SUPPORT?:}

Privileged and Less-Privileged Mothering and Support.

Privileged Mothering and Support

Less-Privileged Mothering and Support.

Less-privileged mothering:

Affluent, married, black mothers and child-centric support......162

Less-privileged mothering:

Child-centric support and "nurtured growth"

Less-privileged mothering:

Single, lower-income, black mothers and child-centric support.

Challenging Racial and Maternal Ideologies

Less-Privileged Mothering:

Self-care as resistance and "parenting white"

Less-Privileged Mothering:

Formal mother-centric support and "parenting white"

Less-Privileged Mothering:

Normalizing mother-centric support and self-care

Less-Privileged Mothering: Redefining good mothering. ...

Less-Privileged Mothering: Accepting mother-centric support.

Less-Privileged Mothering: Maternal support and skepticism.

Discussion.

Privileged Mothering, Less-Privileged Mothering, and Concerted Cultivation

Less-Privileged Mothering:

Simple mothering, being there, and nurtured growth

Empowered Mothering:

Self-care as racial and maternal resistance. 


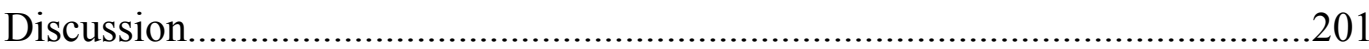

Maternal Practices, Maternal Support, and Child Outcomes..................201

Culturally Mismatched Uses of Maternal Support.....................202

Amended Maternal Practices: Nurtured growth and maternal support...204

Empowered Mothering and Maternal Support.......................205

Implications for Maternal Support Programs and

Mother-Centric Self-Care.......................................207

Becoming "that bridge" for mothers:

Systems-centered intersectionality and frame bridging..........207

Study Limitations and Future Research.................................212

Study Limitations............................................... 212

Future Research.............................................214

Conclusion....................................................216

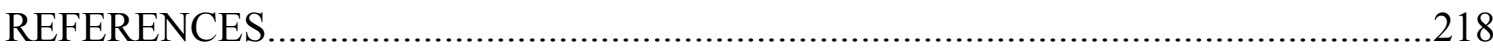

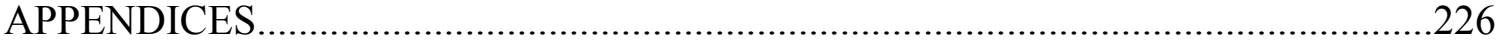

Appendix I: Program Evaluation Surveys..................................2227

Comprehensive Program Evaluation Surveys......................228

Topic-specific Parenting Self-Efficacy Subscale......................232

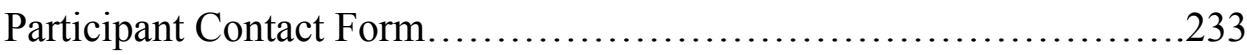

Confidential Demographic Form...................................235

Appendix II: Program Evaluation Outcome Report Forms...................238

Urban Locations...............................................239

Rural Location..................................................240 
Appendix III: Participant Demographics.

Peer-based Support Group Participant Demographics \& Discussion.....242

In-depth Interview Participant Demographics......................245

Appendix IV: In-depth Interview Guides................................246

Interview Guide: All mothers..................................247

Supplemental Interview Guide: MHM/MV participants...............248

Interview Guide: Focus group..............................249

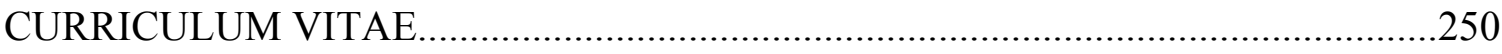




\section{CHAPTER I: \\ INTRODUCTION}

Sociologists have identified socially constructed standards of good mothering that influence how women in the U.S. mother. These stringent standards inform and guide maternal practices. Through media, images of "good" and "bad" mothers are recognizable. Books on parenting serve as reference manuals for how to meet these clearly defined standards (Hays 1996), as do websites, blogs, and more conventional media forms such as television and film (Douglas and Michaels 2007). A sociological approach to understanding mothering explores the relationships between social forces and individuals' experience of motherhood, including mothers' agency to challenge existing social structures and norms.

In this dissertation, I draw from the sociology literatures on motherhood to explore how diverse groups of mothers define good mothering and access maternal support. I first use a program evaluation, participant observation, and focus group to explore the successes and limitations of a maternal support group attempting to decrease the risk of postpartum depression and to increase mothers' parenting self-confidence and sense of community. Then, in-depth interviews with a group of 41 diverse mothers find race- and class-based differences in how mothers construct narratives of good mothering and how they define and employ maternal support. These variations help explain the limitations of the maternal support group in attempting to reach mothers across race and class divides. 
This study's findings also indicate cultural shifts in maternal practices, standards, and support. Programs to support mothers, although flawed in some ways, reflect broader efforts to shift maternal culture and to reframe the act of mothering from a solitary venture to a more communal practice; other mothers are altering the boundaries of acceptable mothering and self-care. I argue that these findings should be considered within the context of a broader cultural shift to redefine the institution of motherhood.

I incorporate an intersectional framework to guide this dissertation, from the formulation of my research questions to my data collection, analysis, and interpretation of the findings. Doing so illuminates the intersections of race, class, and family structure and situates these various influences within maternal ideologies and practices. By including evaluation findings and mothers' voices on good mothering, maternal practices, and maternal support, this intersectional dissertation contributes to the sociological literatures on motherhood and has practical implications for programs supporting diverse mothers.

\section{Intensive Mothering Ideology and Its Limitations}

Intensive mothering ideology (Hays 1996) shapes current perceptions of good mothering in the U.S. This ideology — most visible in white, middle-income, married mothers' practices — constructs mothering as an all-consuming, emotionally-exhausting, labor-and time-intensive venture that requires substantial resources; furthermore, under intensive mothering, the mother is assumed to be most capable of providing these services (Hays 1996). Mothers with racial, economic, and marital privilege are more likely to realize intensive mothering's standard of good mothering; for other mothers, this 
exclusive ideology restricts space for diverse maternal practices. The result is a societal standard that is incompatible with maternal practices in large groups of the population.

Applying a narrowly defined standard of good mothering to all mothers has broad implications, especially as it informs societal norms and social policy (Hays 1996;

Correll, Bernard, and Paik 2007; Hays 2007; Stone 2007; Crowley 2014). Violating this maternal norm through diverse parenting practices or forming alternative family compositions may constitute "bad mothering" and lead to social and legal penalties (e.g., Rich 1976; Rothman 1989; hooks 1984; Collins 1990; Bobel 2002; Edin and Kefalas 2005; Correll et al. 2007; hooks 2007b; Stone 2007; Roberts 2007; Springer 2010; Press 2012; Reich 2014). Though often overlooked, interpretations of and approaches to good mothering differ based on mothers' social contexts (e.g., Collins 1990; hooks 1984; Hays 1996; Edin and Kefalas 2005; hooks 2007b; Roberts 2007; Stone 2007).

\section{Maternal Support}

By 2015, nearly 70 percent of mothers participated in the workforce; 75 percent of single mothers were employed (BLS 2016). Even as workforce participation has become the norm for mothers, women continue to perform the majority of household and childcare duties (Hochschild 1989; Bianchi, Sayer, Milkie, and Robinson 2012; Raley, Bianchi, and Wang 2012). White, middle-class, married mothers adhering to an intensive mothering ideology are often exhausted by their family and work demands (Hochschild 1989).

But while white, middle-income, married mothers often rely on partners' financial and parenting support (e.g., Levitt, Weber, and Clark 1986), black, lower-income, single 
mothers have traditionally constructed extensive kin-based parenting support systems (e.g., Stack 1974; Martin and Martin 1978; Dow 2016a; Dow 2016c). Black mothers have historically constructed informal support networks to overcome legal, economic, and cultural barriers; even now, mothering is often a communal effort in which various blood relatives and "othermothers" (e.g., family members, fictive kin, community members) provide various forms of childrearing support (Stack 1974; Martin and Martin 1978; Collins 1990; hooks 2007).

Beyond the tangible implications of financial support, social and emotional support benefits both mothers and children. Research details the relationship between maternal support systems (comprised of spouses, families, or fictive kin) and children's psychological well-being (e.g., Taylor and Roberts 1995). In recent years, public health research has increasingly focused on mothers' psychological well-being, above and beyond child outcomes (Balaji, Claussen, Smith, Visser, Morales, and Perou 2007). Social and emotional support decreases mothers' likelihood of postpartum depression, anxiety, and toxic stress which can lead to physical illness, mental illness, and child abuse (e.g., Balaji et al. 2007; Taylor and Roberts 1995). Social and emotional support can alleviate maternal tension, reducing the risk of aggressive and abusive parenting (Balaji et al. 2007).

Social connections expanding mothers' support can provide additional parenting resources and assistance. New research finds that maternal support is not only beneficial to new mothers as they transition into parenthood; evidence of ongoing maternal support is also connected to children's positive physical and emotional development (Luther and Ciciolla 2016). Peer-based, maternal support can unite mothers who may be struggling 
with the all-consuming nature of intensive mothering in practice (Hays 1996); connecting with other mothers may grant women permission to reclaim facets of their identities outside of the role of mother.

\section{Research Questions}

Mothers' perceptions, practices, and standards are affected by macro-level structural forces and micro-level dynamics. Guided by sociological literatures on mothering, I emphasize how social forces such as race, class, and family structure affect women's experiences of motherhood. I maintained this intersectional approach to collect and analyze my data. While this project began as a program evaluation, those findings led to my subsequent research questions; an intersectional approach guided me throughout this entire study.

Intensive mothering's exhaustive standards and practices lead some, but not all, mothers to seek maternal support. Yet, mothers have differential access to support. A local nonprofit organization, Mothers Helping Mothers (MHM), created peer-based support group (PSG) programming to increase mothers' accessibility to maternal support; MHM offered free PSG programs in racially and economically marginalized neighborhoods. The regular gatherings provided pregnancy and parenting resources for new and expecting mothers, and connected mothers to community programs and other mothers to construct social and emotional support systems, especially for single mothers, lower-income mothers, and black mothers.

Given this, I pose two sets of research questions. First, was MHM's PSG program successful in reaching its goals, and did the program serve participants across race, class, 
and family structure? After exploring these initial questions, I go on to ask, how and why MHM's work appeals to some_-but not all—mothers. I found that MHM's programming was successful in limited ways, but that the PSG did not ultimately reach the targeted groups, specifically black mothers and single mothers. This finding - that MHM's program appealed mostly to white, partnered mothers informed the remainder of my study.

I posited that how mothers defined good mothering and perceived maternal support would help explain why MHM's program did not reach a broad group of women with regards to race, class, and family structure. First, given that intensive mothering ideology (Hays 1996) overlooks racial, economic, and marital diversity in maternal standards and practices, and that these practices have legal and policy-based implications, I posed the following research questions. First, what is good mothering, and how do mothers' definitions of good mothering vary by race, class, and family structure? Second, how do mothers' views of good mothering inform their maternal practices, and how do these vary by race, class, and family structure?

Next, to understand why MHM did not attract a variety of participants, I explored mothers' perceptions of maternal support. I posed two research questions: one, how do mothers talk about maternal support across race, class, and family structure? Second, how do women incorporate maternal support into their maternal practices? This study examines how mothers view maternal support and how they use it across race, class, and family structure. Recognizing that women's use of maternal support is related to their interpretations of good mothering, and that their maternal practices are influenced by 
race, class, and family structure helps to explain why MHM's PSG program was limited in its appeal.

\section{Preview of Findings and Contributions}

First, I evaluated MHM's efforts to expand support to mothers marginalized by race, class, and family structure. Pre- and post-test surveys revealed that MHM's PSG program generated some positive outcomes for participants, but struggled to attract black mothers and single mothers. Participant observation found that the maternal ideology guiding the PSG program assumed economic and marital privilege, resulting in a disconnect between its facilitators and targeted participants. An in-depth focus group with MHM's founders and their intentions for the PSG program illuminated inequalities and complexities embedded in mothers' views about maternal standards and practices.

Second, I conducted 41 semi-structured, in-depth interviews with mothers to learn how they talk about good mothering and maternal practices, and how these narratives varied by race, class, and family structure. Participants include an over-representation of mothers of color, lower-income mothers, and single mothers. My intersectional approach to analyzing mothers' narratives revealed the contradictions mothers encounter as they struggle to make sense of good mothering standards and their own maternal practices.

Mothers defined good mothering as self-sacrifice; some mothers discussed selfcare, as well. I argue that mothers' perceptions of good mothering standards informed their maternal practices and how they incorporated maternal support; race, class, and family structure influenced three distinctive patterns within these narratives. First, mothers differentiate between support as a child-centric resource or a mother-centric 
resource. Second, whether mothers' maternal practices include self-care informs if and how mothers incorporate mother-centric support. These narratives demonstrate that how mothers perceive good mothering influences how they implement support into their maternal practices. Finally, black mothers often made sense of maternal support by connecting it to maternal and racial ideologies.

These findings help explain why MHM's peer-based, mother-centric support was well-suited for some, but not all, mothers. Narratives provided insight into why some mothers regarded the program as an asset, while others found it incompatible with their maternal—and even racial—ideologies.

This study also contributes to the sociological literatures on motherhood and maternal support. I contribute mothers' diverse voices to a literature that has mainly focused on the mothering standards and practices of white, middle-class women. ${ }^{1}$ An intersectional perspective demonstrates the variation in how mothers internalize maternal standards, practice good mothering, and challenge ideologies of good mothering. To the existing motherhood literature, I contribute a detailed examination of how mothers across race, class, and family structure construct scripts about good mothering.

These findings are also an important resource for MHM and organizations like it working to support lower-income mothers, single mothers, and black mothers. Ultimately, this research demonstrates that mothers' perceptions of good mothering influence their willingness or resistance to access mother-centric support, and the influence of race, class, and family structure on these perceptions. These findings suggest that mothers who may benefit from maternal support may not use it, even when

\footnotetext{
${ }^{1}$ Edin and Kefalas (2005); Collins (1990); and hooks (2007) are important exceptions. Their works provide economically and racially diverse perspectives to the mothering literature.
} 
programming is offered. Mothers who attempt to connect with maternal support programs may encounter curricula embedded with racial, economic, and marital privilege, broadening the gap between privileged and less-privileged mothers.

Preview of Chapters

This dissertation is divided into seven chapters. Chapter II situates the research questions around good mothering and maternal support within the extant sociological literatures on mothering and support. A cultural feminist perspective places Mothers Helping Mothers (MHM) and its underlying ideology within the context of mothering and privilege. Extending this gender-based perspective, I incorporate an intersectional framework to guide this dissertation, from data collection to analysis and interpretation of the findings. Doing so illuminates the intersections of race, class, and family structure and situates these various influences within maternal ideologies and practices.

Chapter III outlines my methodological approach to answering these research questions. I began by conducting a comprehensive, mixed-methods evaluation of MHM's peer-based support group program, relying on pre- and post-test surveys, evaluative indexes, and participant observation. To more deeply explore the program's challenges, I analyzed and interpreted field notes from participant observations, and conducted a semistructured focus group with three of MHM's founders. Next, to better understand why some mothers access external support systems while others do not, I conducted 41 indepth, semi-structured interviews with local mothers. I asked about perceptions of good mothering, maternal practices, the meanings of maternal support, and if/how they sought 
maternal support, rejected it, or were unaware of it. Interviews were recorded and transcribed verbatim, and then analyzed using grounded theory.

This study's findings are presented in three chapters. First, Chapter IV provides the results of the formal evaluation of an organization's peer-based support program. Difference of means tests from pre- and post-tests surveys revealed an increase in program participants' parenting self-confidence, a decrease in participants' risk of postpartum depression, and an increase in participants' sense of community. Demographically, however, the program failed to attract many participants from its targeted communities, especially mothers of color and single mothers. To address this shortcoming, field notes from extensive participant observation were coded and analyzed using a grounded theory approach. Additionally, a semi-structured focus group with MHM's founders revealed the racial and economic complexities embedded in their views of maternal practices and maternal support. I discuss the program's success as demonstrated by the quantitative findings; the program's short-comings are revealed through qualitative analysis. The findings from the semi-structured focus group with the organization's founding members provide additional depth and context to these findings. Specifically, the underlying intentions of the program and inherent biases embedded within are elucidated and explored.

Next, Chapter V expands the scope of this study to incorporate women's narratives on good mothering. Findings from 41 in-depth, semi-structured interviews demonstrate how variations in good mothering ideologies led to narratives about selfsacrifice and self-care. Mothers' scripts reveal complex maternal standards and practices which have implications for participation in the support groups offered by MHM. 
Finally, Chapter VI spotlights mothers' interpretations and applications of maternal support. Mothers' narratives demonstrate the relationship between perceptions of good mothering and maternal support. Mothers of color construct scripts about maternal practices and support related to racial and maternal ideologies. The chapter includes counter-narratives from a group of black mothers who challenge these ideologies by incorporating self-care as a revolutionary act (e.g., Lorde 1988).

A comprehensive and in-depth discussion of these findings is in Chapter VII. This chapter delves into the racial, economic, and familial variations in mothering standards, practices, and uptake of maternal support. I situate these findings and this study's contribution - an intersectional analysis of good mothering and maternal support - within the sociological literature. I then discuss this study's limitations and make recommendations for future research. I propose an examination of MHM's ongoing efforts within the context of a social movement, and recommend a multi-institutional politics approach (Armstrong and Bernstein 2008) to frame MHM's work to redefine culturally acceptable maternal practices. I conclude by suggesting additional projects to extend this intersectional dialogue about mothering and the dangers of a one-size-fits-all maternal ideology. Cumulatively, this sociological study reveals how mothers' narratives about maternal standards, practices, and support are affected by social forces (e.g., race, class, and family structure), and women's agency in resisting and challenging oppressive mothering ideologies. 


\section{CHAPTER II: \\ LITERATURE REVIEW AND THEORETICAL FRAMEWORK}

This study incorporates sociological literatures on mothering (e.g., Rich 1976; Collins 1990; Hays 1996; Bobel 2002; Lareau 2003; Edin and Kefalas 2005; Bobel 2007; hooks 2007a; O’Reilly 2007; Roberts 2007; Walker 2007; Kinzer 2008; Christopher 2012; O’Reilly 2014; Story 2014), feminist theories (e.g., Rich 1976; hooks 1984; Collins 1990; Collins 2007; Rothman 2007; Snitow 2007; Walker 2007; Kinser 2008; Hallstein 2008; O’Reilly 2008; Story 2014), familial support (e.g., Stack 1974; Martin and Martin 1978; Collins 1990; Collins 2007; hooks 2007b; O’Reilly 2007; Cherlin 2010; Raley, Bianachi, and Wang 2012; O'Reilly 2012; O'Reilly 2014), and the multi-institutional politics (MIP) approach to exploring cultural social movements (Armstrong and Bernstein 2008). Together, they provide the study's intersectional theoretical lens. These literatures also inform the evaluation of Mothers Helping Mothers' (MHM) work to expand maternal support, and the exploration of women's perceptions of good mothering and maternal support.

The prevailing standard of good mothering influences how women perceive maternal responsibilities and expectations, informing how they navigate both the institution of motherhood and the experiences of mothering through daily acts of parenting. Rich (1976) first distinguished between these social forces and their ability to oppress or empower women. The institution of motherhood, she argued, is a "maledefined and controlled" (O'Reilly 2004:2) construct to perpetuate women's oppression 
(Rich 1976:13). In contrast, individual experiences of mothering, as "female-defined and centered" (O'Reilly 2004:2) practices, have the potential to empower women (Rich 1976: 13). In this study, I demonstrate how mothers negotiate the institution of motherhood, and variations in mothers' narratives and experiences of empowerment by race, class, and family structure.

Through narratives from racially, economically, and maritally diverse mothers, I explore how some women's maternal practices confront the institution of motherhood by challenging the standard of good mothering in their everyday practices and uses of maternal support. My evaluation of Mothers Helping Mothers' (MHM) peer-based support group (PSG), however, demonstrates how difficult it can be to successfully challenge the many ways in which the institution of motherhood is embedded in maternal norms and culture.

Whether or not the standard of good mothering is reasonable, most mothers strive to attain it. This chapter reviews the sociological research on mothering, providing context for society's expectations for good mothering. Though based upon a specific group's maternal ideology (i.e., white, middle-class, married mothers), good motheringwhich equates mothering to an all-consuming, resource-intensive, isolated venture-is acknowledged across racial/ethnic groups, economic classes, and familial structures. Society holds all mothers to this same stringent measure; concessions are not granted for mothers with few financial, social, and familial resources. Thus, I also explore how these groups adhere to or reject aspects of good mothering.

The application of a one-size-fits-all approach to good mothering means that some - if not most — mothers fall short of this accepted expectation. Some mothers seek 
social and emotional support to cope with these frustrations. Other mothers have pushed to redefine the limited boundaries of acceptable parenting to account for societal variations. This chapter reviews collective efforts for cultural change and the research on social support, including its implications for maternal and child well-being. Altogether, this review provides a rationale for my intersectional focus on racially, economically, and maritally diverse groups' responses to the good mothering ideology, and my justification to consider MHM's maternal support programming and advocacy within the context of a larger social movement using Armstrong and Bernstein's (2008) multi-institutional politics (MIP) theory. This study seeks to extend existing research by examining the role of race/ethnicity, class, and family structure in how mothers define and discuss support, challenge maternal norms, and engage in resistance. After synthesizing these theoretical frames, I go on to explore how mothers' narratives contribute a unique perspective to the sociology of mothering literature in findings Chapters IV, V, and VI.

\section{Mothering and Motherhood}

A sociological approach to examining the institution of motherhood and the practice of mothering blends the personal, micro-level issues with institutional, macrolevel forces. This perspective weaves social characteristics with institutional power and reveals how they interact to privilege some and marginalize others. Employing an intersectional approach (e.g., Collins 1990; Arrendale 2000; Collins 2007; hooks 2007b; Fouquier 2011) magnifies the influence of race/ethnicity, economic class, and marital status, among other social factors on mothering. This lens exposes the complexities shaping the practice of mothering and the institution of motherhood, and the ways in 
which women's experiences differ across groups. Notably, an intersectionality perspective acknowledges both the disadvantages and benefits women experience based on their complex social locations.

This study examines the sociological construction of motherhood through race, class, and family structure. Scholars reveal the importance of intersectionality (e.g., hooks 1984; Collins 1990; Collins 2007; Choo and Ferree 2010). As discussed below, living under racist institutions for centuries led to significantly diverse experiences for African American women as compared to White women within the U.S. For example, women's family structure and familial support systems, paid and unpaid work, and expressions of gender and sexuality vary substantially by race and ethnicity (e.g., hooks 1984; Collins 1990; Roberts 2007). Class-based inequalities influence familial structures, parenting practices, modes of familial support, job security, and economic stability (Lareau 2003); daily practices are often in tension with existing institutional forces (Williams 2010). Intersectionality recognizes and highlights the complexities in groups' experiences and how they inform mothers' perceptions. When examined comprehensively, some women experience challenges in providing and obtaining maternal support based on their social locations. Incorporating marginalized mothers' perspectives uncovered themes limited to certain groups' experiences, and others shared by all mothers. Thus, this study's intersectional lens explores the racial, economic, and marital privilege embedded in normative standards of mothering, and how these locations influence women's standards of good mothering and views of maternal support. 
Good Mothering and the Intensive Mothering Ideology

Good mothering — as a socially constructed standard — shifts over time, defining expectations of appropriate parenting practices (Hays 1996; Springer 2010). Through media (e.g., Douglas and Michaels 2007; Springer 2010; Press 2012), educational and employment institutions (e.g., Lareau 2003; Stone 2007; Correll et al. 2007), and cultural socialization (e.g., Berger and Luckman 1966; Rich 1976), these standards are rooted in gender norms, embedded in society, and experienced phenomenologically in everyday life (e.g., Bartky 1990; Collins 1990).

Many scholars suggest that the contemporary standard of good mothering is intensive mothering (e.g., Hays 1996; Bobel 2002; Lareau 2003; Avishai 2007; Miller 2007; Crowley 2014; Reich 2014). The intensive mother and her broad duties lack transferability (Hays 1996; Hays 2007). The belief that the mother-and only the mother-is capable of providing the level of care, resources, and emotional sustenance needed for her child(ren) to grow and thrive is central to the intensive mothering ideology (Hays 1996; Hays 2007). Other caretakers, whether they be fathers, relatives, community members, or paid professionals, are insufficient and threaten to compromise the quality of care provided and, ultimately, the child's future self and achievements.

The privilege afforded by intensive mothers' economic resources, marital status, and whiteness expands options for mothering practices: some eschew vaccinations for their children, valuing their knowledge of their children's well-being more than physicians and public health recommendations (Reich 2014; Bobel 2002). Others cite their innate maternal instinct to explain their natural nurturing abilities (Bobel 2002). Still others employ their professional managerial skills to execute rigorous breastfeeding goals 
while maintaining demanding jobs (Avishai 2007). The financial, emotional, and familial support needed to practice the various interpretations of intensive mothering all require mothers to make their children's cultural, physical, and mental development their top priority (Hays 1996; Reich 2014; Avishai 2007; Miller 2007; Crowley 2014; Lareau 2003; Bobel 2002).

Intensive mothering is modeled on the practices by white, middle-class, married mothers, yet as a standard of good mothering, it extends to other social groups. As socioeconomic status increases, so do the expectations of this intensive practice. For example, a "concerted cultivation" (Lareau 2003) approach to childrearing socializes children to confidently navigate educational, economic, and social institutions. Densely scheduled activities increase children's social capital. Mothers enroll children in a wide range of extracurricular activities (such as music lessons, sports, theatre, chess, etc.); thus, concertedly cultivated children require an intensive mother or someone hired for that role (see Christopher 2012 for a discussion of "extensive mothering"). As mothers' education levels increase, so does the expected amount of time invested in this venture (Arrendale 2000; Lareau 2003; Stone 2007). Parenting with the same fervor required by professional career building, intensive mothers research, evaluate, and pursue mothering as an occupation that rivals — and often exceeds — any full-time profession (e.g., Lareau 2003; Stone 2007).

As socio-economic status decreases, so do the cultural demands on mothers. Poor and working-class families are more likely to regard parenting as an "accomplishment of natural growth" (Lareau 2003) through which children grow organically, without the need for excessive intervention and mediation. These mothers are more likely to 
incorporate a laissez-faire approach to childrearing, resulting in regular free time and an absence of structured activities beyond the mandated school day (Lareau 2003).

Beyond differences in mothering guided by socio-economic status, the intensive mothering ideology assumes various cultural forms. Natural or simple mothering ${ }^{2}$ embodies the elements of intensive mothering (Bobel 2002; Bobel 2007b). These mothers derive their maternal authority from nature — a source they have deemed pure and powerful. Anchored by attachment parenting (extreme physical bonding through limited separation between the mother and child) and simple living (eschewing capitalism and consumerism through an emphasis on self-sufficiency, recycling, and minimalism), these mothers defer to nature to guide them and inform their maternal practices. From this perspective, the act of mothering is instinctual and inherently divined through womanhood.

Extended breastfeeding (EBF) is an intensive mothering practice shared by both simple mothers (Bobel 2002; Bobel 2007b) and upper-middle class professional women (Avishai 2007). While natural mothers accomplish their EBF goals through on-demand feedings and tandem nursing of infants and older children, high-achieving working mothers demonstrate their commitment to this all-consuming maternal practice through rigorous project management. Despite their distinct approaches, both groups aggressively and competitively tackle EBF in a way that demonstrates the societal pressures to conform to the role of the good mother. Less attuned to the inherent forces guiding natural mothers (Bobel 2002; Bobel 2007b), these professional mothers ascribe to

\footnotetext{
${ }^{2}$ While Bobel (2002) describes this maternal practices as "natural mothering," several mothers in this study voiced their preference for the term "simple mothering." I confirmed that these practices aligned, and use the term "simple mothering" out of respect to participants.
} 
intensive mothering with their emphasis on maintaining exhausting demands of nursing that reflect their good mothering practices (Avishai 2007).

Extended breastfeeding is just one way in which intensive mothering manifests in maternal practices. Economic and marital privilege play a significant role in mothers' abilities to achieve demanding intensive mothering goals. Thus, this study explored the extent to which race, class, and family structure intersect and contribute to the various interpretations of intensive mothering practices and standards of good mothering.

\section{Good Mothers versus Bad Mothers}

The construction of the good mother mirrors current gender roles rooted in white, middle-class, heterosexual, married norms (Hays 1996; Douglas and Michaels 2007; Roberts 2007; Springer 2010). While good mothering subtly permeates societal expectations and behavior, deviation from this norm, or "bad" mothering, is blamed for social problems (e.g., Douglas and Michaels 2007; Roberts 2007; Springer 2010; Fouquier 2011). Bad mothers are deemed selfish, neglectful, and unwilling to place their children's needs above their own wants and desires; "bad mothering"- - the manifestation of these characteristics - runs the gamut from not investing time or attention with one's child, to spending more money on oneself than one's child, to alcohol or drug addiction, to verbal, physical, or sexual abuse either at the hands of the mother or someone else. Images, descriptions, and scripts of bad mothering, perpetuated by media representations, influence public opinion, policies and laws, and ultimately influence beliefs about who deserves to mother and who does not (Douglas and Michaels 2007; Roberts 2007; Springer 2010; Fouquier 2011). 
Entire social groups are deemed acceptable or unacceptable mothers, as well. At the height of media's portrayal of crack cocaine babies in the 1990s, for example, government officials promoted efforts to sterilize poor, Black mothers in New York City as a response to their "maternal inadequacies" (Springer 2010:493). Citing the need to protect the unborn children and infants from the harmful effects of maternal drug use, poor, Black women were offered financial compensation for tubal ligations (Springer 2010:493). In-depth content analyses later revealed that the intense focus on pregnant drug users had little to do with protecting children (as the articles purported) and more to do with constructing a racial and economic profile of "bad mothers" (Springer 2010:495). These findings reinforced the argument that acceptable mothers are restricted to raciallyand economically-privileged groups (Collins 1990; Roberts 2007; Springer 2010; Fouquier 2011).

Race, class, and family structure profoundly affect mothers' circumstances, experiences, and outcomes as they navigate these institutions and structural forces. My study's intersectional approach is imperative to understanding the variations within these complex interactions and how they shape mothers' perceptions of good mothering. The majority of the women profiled in the aforementioned studies (Avishai 2007; Hays 1996; Bobel 2002; Lareau 2003; Hays 2007; Bobel 2007b; Stone 2007; Correll et al. 2007; Reich 2014) benefit from racial, economic, and marital privilege, as they are overwhelmingly white, well-educated, middle- to upper-middle class, heterosexual, and have the economic support of a spouse. Those employed outside of the home are highlevel professionals (Avishai 2007) and work in environments with the flexibility and stability (Hays 1996; Hays 2007) required to execute this demanding form of parenting. 
Full-time parenting often requires an employed and financially stable spouse for support (Bobel 2002; Bobel 2007b; Stone 2007). Concerted cultivation, too, requires economic privilege (Lareau 2003; Stone 2007). While women experience structural oppressions through the phenomenology of everyday life (Bartky 1990), an intersectional perspective demonstrates the amplified impact when racism, sexism, and classism are woven together through patriarchy and capitalism (Rothman 1989; Collins 1990; Collins 2007; hooks 2007a; hooks 2007b; Fouquier 2011). Given their race and class privilege, some women do not experience the gendered constraints of family and work until motherhood and employment become incompatible (e.g., Stone 2007). On the other hand, women of color and poor women typically experience class and racial inequalities much earlier in the life course (e.g., Collins 1990; hooks 2007a; Edin and Kefalas 2005; Roberts 2007; Fouquier 2011).

Racial and economic locations profoundly affect how women define and practice good mothering: from middle- and upper-class mothers' concerted cultivation (Hays 1996; Avishai 2007; Stone 2007); to middle-class, white mothers' natural mothering (Bobel 2002); to lower-class, Black mothers' community- and kin-based othermothers (hooks 2007b; Collins 2007; Fouquier 2011). Poor women and women of color also commit to the role of intensive motherhood, with varying practices and outcomes. Some lower-income, Black, white, and Latina mothers frame good mothering as "being there" (Edin and Kefalas 2005). This form of parenting allows marginalized mothers to emphasize the importance of placing their children at the center of their worlds and responding to their social and emotional needs. Being there-both physically and emotionally — constitutes the most significant resource these women can afford their 
children, providing stability and reassurance in a tumultuous environment. Responding to their children's needs ameliorates a lack of consistent financial resources and paternal relationships, and mothers' constant vigilance helps negate the transient nature of relationships in the poor urban core (Edin and Kefalas 2005). Modest living arrangements result in tight proximity for families and allow for constant interaction, and many poor mothers have been socialized as caretakers from a young age (Edin and Kefalas 2005). Severely limited prospects for future roles render motherhood one of the most realistic and obtainable identities marginalized women may have (Collins 1990; Collins 2007; Edin and Kefalas 2005). At the same time, early childbearing reinforces the likelihood of class immobility and finite resources, thus perpetuating multi-generational poverty (Fouquier 2011).

Despite the economic and social disparity between privileged and marginalized mothers, women share experiences shaped by oppressive structures, obstacles to success, and societal pressures to conform to the role of the good mother. In most cases, normative roles, socialization, and typifications (Berger and Luckmann 1966) of the "good mother" reify how intensive mothering is practiced and what a "good mother" should look like. When mothers' race, class, and familial variations challenge these singular ideals, they can either be viewed as deviant practices with punitive social and legal consequences (e.g., Collins 1990; Edin and Kefalas 2005; Roberts 2007; Springer 2010) or active attempts to shift and expand maternal norms (e.g., Bobel 2002; Christopher 2012). Paramount to this distinction is economic and racial privilege (Collins 1990; Bobel 2002; Edin and Kefalas 2005; Avishai 2007; Roberts 2007; Springer 2010; Christopher 2012). Therefore, this study explores perceptions of dominant maternal 
norms; the influence of race, economic class, and family structure on these perceptions; and how participants from diverse backgrounds reconcile these dominant norms with their own maternal practices.

\section{Challenging the Good Mother}

Just as there is not one singular experience of mothering, not all women challenge the good mother the same way. Themes that serve as bedrocks of mothering among women of color illustrate how the experience differs significantly for them (Collins 1990; Collins 2007). The history of slavery and racial segregation created an alternative society for Black women through socially peripheral communities. In these communities, black mothers typically had to work for pay to support their families. Black mothers constructed motherhood differently in response to work expectations and communal childcare, resulting in a unique mothering experience. Thus, by the mid $20^{\text {th }}$ century, while many white women were fighting for the opportunity to enter the workforce as mothers, many Black women were pushing for the right just to have their children and raise their children themselves (Collins 1990; Roberts 2007; Fouquier 2010).

These distinct experiences reflect the matrix of domination in which gender, race, and class intersect, affect the ways people experience reality, and limit (or enhance) social mobility (Collins 1990). For women of color and low-income women, motherhood itself becomes an opportunity to legitimate mothering practices by redefining standards (e.g., Edin and Kefalas 2005; Fouquier 2011). For example, there are differences in the ways white, middle-class women and lower-income women of color frame reproductive freedom (Roberts 2007; Springer 2010; Fouquier 2011). Privileged women typically fight 
for the right to control their reproduction through access to birth control, safe abortion, and postponing procreation, while women of color often fight for the right to bear and raise their children. Bringing a pregnancy to term and embracing the role of mother, therefore, challenges societal expectations thrust upon marginalized women via degrading stereotypes (Collins 2007; Roberts 2007; Springer 2010). These women demonstrate successful mothering by keeping their children in their care.

This embodiment of good mothering by poor mothers extends the power of homeplace (hooks 2007a). By rejecting the chaos in their social and physical environment, poor mothers practice being there for their children in order to alter the negative trajectory on which the children are set. Despite the small window of exclusive time the mothers have (from birth until the children enter school), they work to protect their children from the neighborhood's dangerous influences (Edin and Kefalas 2005). This attempt to instill survival strategies in their children reveals the unique motivation fueling these mothers. These homeplaces (hooks 2007a), therefore, provide love and nurturance that may be salvation.

Class and racial location protects privileged mothers who employ parenting tactics that deviate, at times, from mainstream approaches. Alternative practices, such as extended breast-feeding (Bobel 2002; Avishai 2007), avoiding vaccinations (Bobel 2002; Reich 2014), and not enrolling young children in formal school settings (Bobel 2002) would be less tolerated if practiced by women of color and/or poor mothers. The racial and economic privilege possessed by these mothers allows them to resist conforming to mainstream parenting practices without calling into question the safety of their children. Racially and economically privileged mothers can even relax standards of intensive 
mothering by indulging in a night out with friends or a manicure without being questioned. Without any fear of retribution from state agencies or danger of losing primary custody, privileged women are freer to practice alternative methods of parenting.

Poor mothers and black mothers, however, must be more cautious in their parenting practices. Because other parents may harshly scrutinize them and authority figures have the power to remove their children from their custody, marginalized mothers become hyper-vigilant in their attention to their children's hygiene and appearance to stave off external critiques about their maternal abilities (Edin and Kefalas 2005). These small yet profound acts challenge the racial and economic privilege embedded in good mothering standards and practices.

Natural or simple mothers equate their style of mothering with resistance: They attest that other mothers have been duped into consumerism-based mainstream mothering (Bobel 2002). Yet the natural mothers acknowledge only a raised consciousness, not privilege, that distinguishes them from other mothers. The methods essential for the natural mother's definition of resistance require time and resources that are unattainable for economically marginalized women. The principles of natural mothering — attachment parenting and living simply — are time- and resource-intensive and demand a full-time, athome mother. This devotion to home results in a lack of a secondary income, which is not an option for most families. The white, middle-class, hetero-normative perspective of natural mothering excludes and alienates women of color for whom work is and always has been expected (Collins 1990; Collins 2007; hooks 2007b). This study seeks to extend this research by examining the role of privilege — by race/ethnicity, class, and family structure - in a natural or simple mothering approach. 
If intensive mothering is expected of privileged women, for example, their employment outside of the home could be considered resistance. There is an inherent contradiction in a culture that admonishes working mothers while most mothers are actively engaged in paid work. This condemnation obscures women's experiences as mothers and subjects them to scrutiny and guilt (Arrendale 2000). Not content to operate within such restricted options, some working women redefine the standard of good mothering through extensive mothering (Christopher 2012). These women recognize that they are better equipped to strive for the ideals of mothering when they set aside time for themselves outside of their maternal obligations and cultivate alternative aspects of their identity. The implementation of extensive mothering varies by family structure. For married mothers, it allows women to delegate and subcontract traditionally maternal obligations, such as childcare and domestic chores, to maintain the aspects of their identity from which they most benefit (e.g., work and leisure pursuits). Single mothers, however, employ extensive mothering to construct a new, more forgiving model of the "good mother" with achievable standards. Married or single, these women protect the facets of their identity beyond the singular role of mother, and tackle the obligations of motherhood without fully exhausting themselves (Christopher 2012). Drawing from these studies, my research explores how women talk about good mothering in relation to their paid work.

The desire to challenge maternal norms may not emerge during pregnancy, but this desire can develop through maternal practice (Miller 2007). An under-examined issue in the literature is the role of the "good mother" via birth. Miller's (2007) representation of expecting and new mothers delves into this area through a longitudinal 
qualitative analysis. Yet her homogeneous (all white, all middle-class) sample constrains our understanding to this small population and reinforces the need for more intersectional approaches. Fouquier (2011) adds to this discussion with her all Black sample, yet more research is needed to understand how the birth process informs expectations of mothering for women of color, poor women, and women of other social locations. These and other questions must be addressed to fully appreciate how effectively the construct of the good mother permeates society for all women prior to, throughout, and beyond their reproductive years.

Gendered discourse and good mothering scripts prevail as expecting mothers plan for childbirth and the transition to parenting a newborn (Miller 2007:347). Mothers adhere to cultural standards of intensive mothering during pregnancy, yet when births do not conform to their expectations, they fault themselves (Miller 2007:349). This incongruity creates confusion amongst the mothers who work to compensate for their shortcomings and achieve the good mother role. Feelings of failure contribute to a lack of resistance of this script; the mothers believe they are compromised, not the cultural expectation. As the mothers gain experience with their child(ren), resistance emerges (Miller 2007). Confidence in parenting skills grows and the discourse shifts to reject ideological expectations. With proven successes as mothers, they gain the strength to ignore the dominant script demanding intensive mothering and rewrite their own definitions of good mothering (Miller 2007:354).

Due to the limited portrayal of good mothers of color in media, however, black mothers transitioning to motherhood must refute negative stereotypes and rely instead on communal networks and guidance (e.g., Stack 1976; Martin and Martin 1978; Collins 
1990; Fouquier 2011). The lack of accurate portrayals of everyday mothering requires Black women to select the aspects that seem pertinent and disregard the rest (Fouquier 2011). Fouquier's multigenerational interviews with Black mothers (Fouquier 2011) reveal similar if not identical themes to those found among white mothers (Miller 2007): Both groups expressed being unprepared for the reality of childbirth and mothering and both experienced a disconnect between their expectations and lived experience as they adapted to motherhood (Miller 2007; Fouquier 2011).

These findings suggest that new mothers experience similar challenges across race and class lines, suggesting the potential for a unified effort to expand support for mothers, as exhibited by the peer-support programming by Mothers Helping Mothers (MHM). Drawing from the extant research, this study examines the influence of social locations (i.e., race, class, and family structure) in challenging strict maternal norms. I explore how participants' social locations affect MHM's efforts to unite mothers and create social change. MHM's programming grew out of the founders' experiences with a lack of maternal resources and social isolation after their own pregnancies and birth. This study not only examines how MHM's founders challenged social norms about mothering through their actions to expand social and emotional support to underserved mothers, but also the extent to which their racial, economic, and marital privileges affected their efforts, their successes, and their limitations. It goes on to explore how a racially, economically, and maritally diverse group of mothers outside of MHM's programming talk about challenging maternal norms and their perceptions of maternal support. 


\section{The role of resistance}

The homogeneous view of mothering - as performed by white, middle-class, heterosexual, married women-ignores alternative experiences and family composition by reinforcing the intensive mother as the standard of good mothering. This hegemonic view also places the spousal relationship at the core of family life (Arrendale 2000:1194) rather than the parent-child relationship — which is common in lower-income families (Edin and Kefalas 2005; Edin and Nelson 2013). Acts of resistance to this singular form of mothering — small and large — construct more accurate representations of maternal ideology and practice. How and why women choose to challenge dominant expectations often reveals the rigidity of the roles reinforced by media (Douglas and Michaels 2007), the labor force (Stone 2007), and communities (Edin and Kefalas 2005), and the significant steps mothers may take to refute them.

For example, when state-sponsored parenting classes were offered to lowerincome, immigrant mothers in Britain, facilitators found mothers' parenting practices were in opposition to the dominant middle-class, white maternal norms (Vincent and Warren 1998). With the intention of teaching the women customary ways of mothering in Britain, the curriculum promoted maternal practices aligned with what Lareau (2003) later defined as "concerted cultivation." By teaching mothers about culturally acceptable maternal practices, the classes promoted a specific interpretation of good mothering above others without regard for students' cultural, economic, and familial variations (Vincent and Warren 1998). Instead, the participants' maternal practices conflicted with the resource-intensive maternal practices the instructors encouraged: mothers' practices 
aligned more with the lower-income mothering that Edin and Kefalas (2005) would later identify as "being there."

When the class promoted practices at odds with the mothers' current activities, tensions surfaced. The teacher's frustration with the mothers' unwillingness to embrace intensive mothering practices was compounded by the mothers' inability to conform to the all-consuming ideology while balancing other household duties. Ultimately, the teacher taught the mothers ways to incorporate intensive mothering practices into daily chores routines, thus deeming the socialization of this lower-income, immigrant group a success (Vincent and Warren 1998:189). This case study illuminates the necessity of a compromised approach when privileged facilitators work with marginalized mothers to ensure that the interests of both groups are represented. This strategy was employed by MHM's founders as program participants were provided a platform to shape the peersupport groups' curriculum.

Seemingly small acts of resistance lead to social change. Women have employed various rebellious techniques — collectively and individually — to empower themselves and to challenge the script of good mothers. MHM's founders' efforts to expand social support to mothers of color, poor mothers, and single mothers represent deliberate action to redefine maternal practices. As mothers participate in MHM's peer-based groups to support each other, they also create space for maternal activism. Do these efforts connect to a larger, national agenda for all mothers? Hewett (2006) warns against labeling these actions as such. Just as standards of good mothering shift by social location, so do the voices of resistance. Multiple paths for social change reflect the need for inclusivity and diversity. If a true mothers' movement is underfoot locally, Hewett (2006) recommends 
an intersectional feminist approach to accurately represent the various experiences of the women involved. Therefore, this study asks MHM's participants about their involvement in the peer-support groups. Why did mothers choose to participate in the peer-support groups? Has their participation shaped their maternal practices? In what ways do participants' experiences and practices vary by race, class, and family structure? I examine these themes and evaluate mothers' participation in light of MHM's work to challenge maternal norms and expand social and emotional support for mothers.

\section{Maternal Support}

\section{Maternal Support and Well-Being}

The literature examining the role of social support on maternal and child outcomes backs MHM's program development to expand support to lower-income mothers, single mothers, and mothers of color. Younger mothers, single mothers, and mothers of color exhibit a higher prevalence of depression during pregnancy and postpartum (Rich-Edwards, Kleinman, Abrams, Harlow, McLaughlin, Joffe, and Gillman 2006). This risk of antenatal and postpartum depression is especially of concern for mothers with limited resources and sparse social support. When maternal social support is incorporated in prenatal and postpartum care, however, this elevated risk of maternal depression for young mothers, single mothers, and mothers of color falls to the same levels as older, partnered, and white mothers (Rich-Edwards et al. 2006).

Prenatal social support not only protects mothers against postpartum depression; a lack of prenatal social support for mothers is also associated with elevated adverse outcomes for infants (Feldman, Granat, Parientel Kanety, Kuint, and Gilboa-Schechtman 
2009). Maternal postpartum depression is also linked to behavioral and emotional outcomes as children develop (Elsenbruch et al. 2007). For mothers of color and younger mothers, a perceived lack of social support increases parenting stress, increases rates of maternal depression, and increases the likelihood of infant developmental delays from birth through 18 months of age (Huang, Costeines, Kaufman, and Ayala 2014).

\section{Expanding Maternal Support}

This study's in-depth program evaluation of Mothers Helping Mothers' (MHM) peer-based support group (PSG) programming provided an opportunity to examine how a local group of mothers sought to redefine good mothering by expanding maternal support to under-supported populations. MHM's founders gathered residents' feedback, engaged community leaders, and responded to requests for community-based maternal support by constructing the PSG curriculum based on the maternal support and maternal well-being literature. Furthermore, by incorporating MHM as a nonprofit organization the founders ensured a grassroots, volunteer-based, and community-driven delivery method for its programming.

Beyond expanding maternal support via its programming, MHM works to shift cultural perceptions of maternal practices. Its founders, volunteers, and supporters challenge limited interpretations of good mothering to encompass practices that vary by race, class, and family structure. MHM engaged in social media campaigns, political activism, and public educational opportunities to increase support to redefine mothers' options and increase momentum for social change. Armstrong and Bernstein's (2008) multi-institutional politics approach provides a frame to understanding culturally-focused 
social movements. I employ this frame - discussed below—-to position MHM's work for social change and to argue that its efforts contribute to a larger social movement to expand maternal support.

\section{Theoretical Framework}

The sociological literature provides a multitude of extensive theoretical positions for examining social forces. To construct this study's theoretical lens, I turned to the literatures on feminist theories and social movements. Ultimately, I combined intersectionality and cultural feminist theories, and the multi-institutional politics (MIP) approach to understanding social movements (Armstrong and Bernstein 2008) to frame this study; this lens shaped my research questions, my data collection, my data analyses, and guided my interpretations. Situating my findings within this theoretical framework provides a deeper understanding of how race/ethnicity, class, and family structure influence the institution of motherhood, acts of mothering, and mothers' perceptions of good mothering and maternal support.

\section{Feminist Theories}

Examining social structures, institutions, outcomes, and experiences from a feminist perspective focuses on the relations of power within society to illuminate the influence of social locations (e.g., race, class, gender, etc.) on groups' privilege and marginalization. An intersectional approach extends this perspective: instead of considering each of these social influences individually, however, it explores their cumulative effect as overlapping statuses amplifying privilege, oppression, or both (e.g., 
Crenshaw 1989; Collins 1990; McCall 2005; Ken 2008; Choo and Ferree 2010). Thus, an intersectional approach to understanding how women make sense of mothering and motherhood considers how their narratives and perceptions vary based on their positions of power as defined by race, class, and family structure.

The second-wave of feminism (1960s-1980s) in the U.S. represented both a political ideology and action. Feminism — and its theoretical applications - motivated new research practices, from methodology to analysis, to illuminate gender-based discriminations and inequalities (Mann 2012:3). Placing women and their lived experiences at the center of research yielded a new understanding of institutional imbalances, economic inequities, and political disenfranchisement. Qualitative methods collected narratives, providing a platform for women to share their stories; preserving their words and views through analysis and interpretations revealed the depth of their marginalization. Feminist research exposing social imbalances was often motivated by activism. Feminist researchers "doing" feminist theory sought to validate the oftenoverlooked experiences of living in a gender-stratified society and to embolden women to claim their voices and their power (Mann 2012:8).

Within feminism, beliefs about the movement's goals and paths to achieve them varied. If the intended outcome of the movement was equality for all women, the paths to parity were numerous, encompassing all aspects of society. The movement needed to reshape institutional and social forces, cultural expectations and symbolic representations. Feminist theories provided new ways to consider the complexity of gender inequality and the extent to which it was embedded in society. 
Liberal feminist theory, radical feminist theory, standpoint theory, postmodern feminist, and other interpretations of the origins gender-based oppression emerged, each with its strengths and weaknesses for studying women's shifting status in society. Lorber's (2010) categorization of the current feminist theoretical lenses in three categories demonstrates where these perspectives align and diverge. Originating in the 1970s, gender reform feminisms ${ }^{3}$ (Lorber 2010) sought to reconstruct the structural and systemic forces that subjugated women to gain gender equality in "power, prestige, and economic resources" (10). Developing in the 1980s, gender resistance feminisms ${ }^{4}$ (Lorber 2010) challenged the theoretical underpinnings of the gender reform feminisms. Instead, these theories emphasized the phenomenological oppressions women encountered through interactions in macro (via institutions) and micro (daily exchanges) settings that perpetuated men's dominance (Lorber 2010:11). Only by valorizing women and their attributes (above men's) can women reconstruct society's gendered hierarchy to eliminate gendered oppression (Lorber 2010:12).

Finally, in the 1990s gender rebellion feminisms ${ }^{5}$ responded to gaps in previous feminist theories (Lorber 2010). Shaped by "postmodernist, poststructuralist, and multiculturalist critique," third wave theorists employed "mother-daughter tropes" to draw distinctions between the previously established feminisms and their evolving perspectives (Mann 2012:257). As third wave theories continue to develop, they stress the importance of the multiple interpretations and performances of gender, and the

\footnotetext{
${ }^{3}$ Lorber (2010) categorizes liberal, Marxist, socialist, postcolonial, and Asian feminisms as gender reform feminisms (see Lorber 2010:10, 21-115).

${ }^{4}$ Lorber (2010) categorizes radical, lesbian, psychoanalytical, and standpoint feminisms as gender reform feminisms (see Lorber 2010:11, 117-191).

${ }^{5}$ Lorber (2010) categorizes multiracial/multiethnic, social construction, postmodern, and third wave feminism as gender rebellion feminisms (see Lorber 2010:12, 193-302).
} 
constraints of gendered norms and expectations (Lorber 2010:12). Embracing intersectionality, third wave feminisms are deconstructing sexual and gendered binaries and myopic interpretations of race, class, and other social locations to bring a critical perspective to power and oppression (Lorber 2010:13).

\section{Intersectionality and Motherhood}

Since the 2000s, the third wave literature on mothering has moved away from the "mother-daughter trope:" daughters are shifting away from accounts of their second wave mothers to their own mothering experiences in a "postfeminist" era (e.g., Walker 2008; Kinser 2008). Within the third wave, intersectionality has gained momentum as a theoretical lens and a methodological guide for the exploring the complexities of motherhood and mothering by social locations. This approach strives to validate all women's experiences as mothers, to embrace the myriad practices of mothering, and to acknowledge the inherent privilege(s) and oppression(s) embedded in the institution of motherhood. The result is an intentionally increased emphasis on marginalized mothers' voices and their maternal practices. An intersectional perspective aligns with third wave feminism's approaches, especially when incorporating an expanded understanding of diverse cultures revealed through globalization and increased access to technology and social networking. These social shifts increase feminist opportunities for large-scale reformation and a third-wave imperative for inclusivity in all efforts for equality (Kinser 2008).

Intersectional studies of inequality reflect third wave feminisms' calls for inclusion; yet interpretations of intersectional research vary. Choo and Ferree (2010) 
evaluated and critiqued three theoretical and methodological applications of intersectionality in published studies: group-centered, process-centered, and systemcentered practices (129). They illustrate how group-centered and process-centered studies "underutilize" intersectionality's potential by stopping short of incorporating a systemscentered analysis of inequality (Choo and Ferree 2010:133).

Moving beyond the study of marginalized social groups or relationships of power produces an understanding of inequalities that is greater than the sum of its parts. A limited intersectional approach may add social locations or units of analysis as "ingredients" of a study; even when combined, each element remains distinct. A comprehensive, systems-centered intersectional study transforms these separate ingredients into a new lens or "substance" (Ken 2008). This new theoretical paradigm exposes the systemic imbalances of power in political and economic structures over time, and how the institutionalization of race, class, and gender dynamics within these social structures creates and maintains inequalities among marginalized groups (Ken 2008; Choo and Ferree 2010).

My intersectional study of mothering, motherhood, and maternal support exposes the complex systemic and structural forces that create and perpetuate inequalities. Evaluating the efficacy of MHM's PSG programming from an intersectional perspective reveals how power and oppression can exist simultaneously. As an externally funded, formal organization providing maternal support to lower-income mothers, single mothers, and mother of color, MHM conveys power and authority to its participants; a fledgling non-profit with scarce financial support, it operates at the mercy of its funder, at times beholden to its directives. As white, middle class, married mothers, MHM's founders and 
facilitators occupy privilege; as women, as mothers with biracial children, with partners of color, and families with relatively tenuous resources, they are oppressed. Yet, an intersectional analysis of these positions demonstrates that MHM, its founders, and some of its participants embody elements of racial, economic, and marital privilege and marginalization, often vacillating between these positions of power and oppression (McCall 2005; Choo and Ferree 2010). Thus, the MHM founders were at times blind to how institutionalized inequalities informed the lived experiences of the marginalized mothers they were trying to reach. An intersectional frame considers the complexities in the relations of power that exist between groups, within groups, and how these relations are embedded in multiple institutions. Ultimately, this intersectional approach allowed me to deviate from a limited interpretation of mothering and to incorporate racially, economically, and maritally marginalized women's experiences and perspectives to provide a deeper, more robust understanding of motherhood, mothering, and maternal support.

\section{Cultural Feminism}

While cultural feminism promotes gender-based equality, it does so from its unique perspective. Cultural feminism—also referred to as "feminine feminism," “essential feminism," (Bobel 2002:67) and the "gender-difference knot" (Glenn 1994:22) — celebrates the innate differences between women and men, and mothering is the foremost genetic and cultural manifestation of womanhood and empowerment within this view (e.g., Alcoff 1988; Taylor and Rupp 1993; Bobel 2002; Bobel 2007). Cultural feminism's depoliticized posture and its focus on the distinctive - yet equally valuable- 
aptitudes between men and women that distinguish it from other gender resistance feminisms (Bobel 2002; Lorber 2010).

Bobel (2002) studied women embracing maternal practices that deviated from the mainstream, white, middle-class women's interpretations of intensive mothering (Hays 1996) ideology and rejected liberal feminism's approach to equality via men's and women's similarities (Bobel 2002:71). Instead, natural mothers' practices (simple living and attachment parenting) were bolstered by cultural feminism; they "linked" their maternal ideologies with their interpretation of gender equality (Bobel 2002:71). Beyond "reveling" in the "innate" distinctions between men and women, Bobel's (2002) natural mothers were empowered via their maternal practices (71).

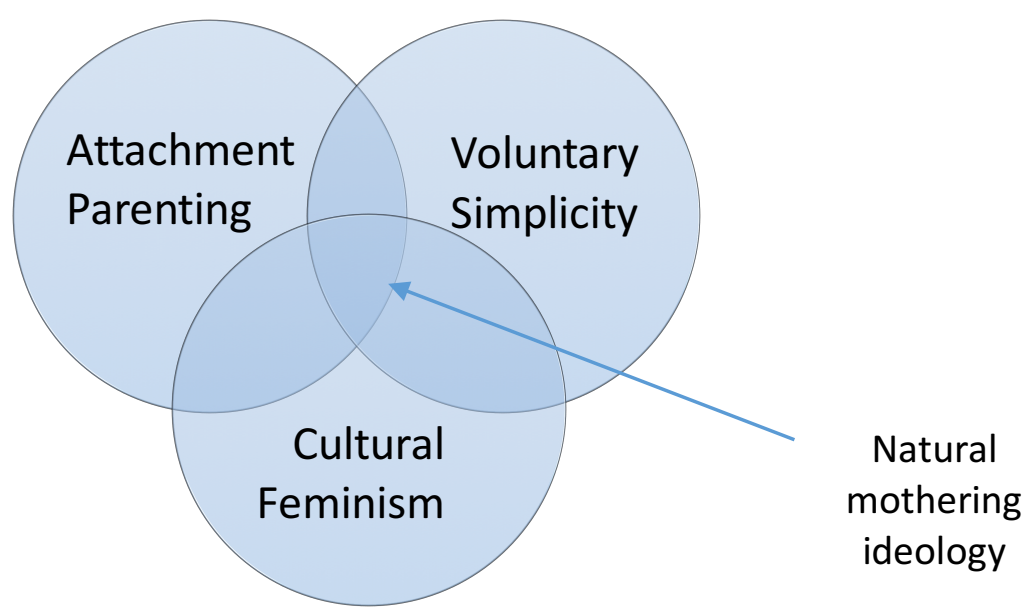

Figure 1: The constitutive elements of natural mothering (Bobel 2002: 49)

At its core, I argue that MHM and its programming —-like the "natural mothers" in Bobel's (2002) study — embody the ethos of cultural feminism with their emphasis on trusting innate maternal instincts, intuiting children's needs, treasuring the mother as the most capable caregiver, and divining empowerment through the acts of motherhood. 
With shared missions of expanding social support for all mothers, however, the organizations, the leaders, and the community participants are engaging in ideological elements that embrace both intersectionality and cultural feminism. This study combines intersectionality and cultural feminism to examine MHM's peer-support group programming. Participant observation, in-depth interviews, and pre- and post-tests provide feedback to better understand how MHM's philosophical underpinnings affect social change efforts; how MHM's leaders incorporate this ethos into framing, identity, and promotion of peer-based support programming; and how variations in race, class, and family structure influenced mothers' participation.

Cultural feminism's emphasis on women's unique (biologically innate) abilities to nurture and mother, however, disregards women who choose to forego mothering, those who are unable to mother, and those who attain motherhood through alternative measures. Applying intersectionality to cultural feminism unearths another glaring oversight. Cultural feminism privileges the woman — her power, her position, her innate attributes; but who is woman? Incorporating women's perspectives fails to acknowledge the myriad social locations of women, thus altering this standpoint. There is no such thing as a singular women's standpoint, or a singular women's experience. Thus, if women have a unique perspective from men, as cultural feminism espouses, then an intersectionality perspective adds that women of color have a unique perspective from white women, poor women have a unique perspective from middle-class women, and single mothers have a unique perspective from married mothers. By applying an intersectional lens to a cultural feminism perspective, this study employs mothers' 
narratives to demonstrate the complexities and inconsistencies in women's perceptions of good mothering and maternal support.

\section{Multi-Institutional Politics Approach to Social Movements}

Understanding Mothers Helping Mothers' (MHM) programming and activism as a social movement to challenge the cultural norms of good mothering and to expand maternal support requires an alternative theoretical approach. Widely accepted frames for examining social movements - political process theory (McAdam 1982) and the contentious politics approach (McAdam, Tarrow, and Tilly 2001)—are limited; they are applicable to understanding state- and economy-centric movements (Bernstein 2008). Social movements that are not state- or economy-centric are difficult to understand using these theoretical lenses (Bernstein 2013:88).

A multi-institutional politics (MIP) frame, however, recognizes that power is often embedded in other institutions and structures beyond the state (Armstrong and Bernstein 2008). MIP incorporates aspects of feminist theories by decentering the state as the sole locus of power in society and acknowledging "marginalized" targets of activism and social change (Bernstein 2013:88). Material and symbolic representations of power exist in various facets of society (Smith 1987; Bartky 1991); MIP theory helps to make sense of movements that target various institutions, and "practices, systems of knowledge, and cultural norms, as well as the state" (Bernstein 2013:88). Social movements targeting shifts in cultural norms or those avoiding disruptive tactics have been dismissed as "expressive" in nature, and often demoted to a less formal status of social action (Armstrong and Bernstein 2008). 
Social movements targeting everyday practices (Bernstein 2013), cultural norms and symbols (Gürbüz and Bernstein 2012), social inequalities, and identities (Bernstein and De La Cruz 2009; Bernstein and Olsen 2009) not aimed at the state can be understood with MIP theory. An MIP frame made sense of collective action in Turkey supporting the wearing of headscarves as a form of passive protesting to normalize Islamic culture (Gürbüz and Bernstein 2012). Examining collective action challenging the practice of asking people of color "What are you?" through an MIP lens revealed the effort's focus on the processing of marginalizing people and devaluing their identities through "categories, codes, and ways of thinking as axes of regulation and domination" (Bernstein and De La Cruz 2009:726).

State-centric social movement theories are too narrow in scope to evaluate MHM's non-state focused efforts to challenge power and oppression; MIP provides the frame to understand and validate them. MIP theory is a lens to analyze MHM's "strategic non-confrontational" (Gürbüz and Bernstein 2012:72) practices through the organization, its programming, and its efforts to expand maternal support. MHM and its peer-support group programming seeks to reshape institutional and extra-institutional practices, and to challenge cultural norms affecting mothering practices and maternal support. Specifically, MHM's founders worked to shift mothering from an isolated endeavor to an inclusive, empathetic network of peers. Through MHM-organized public nurse-ins and en masse baby-wearing, "lactivists" (breastfeeding activists) and attachment parenting advocates incorporated symbolic materials and acts to challenge cultural norms. Institutionally, MHM targeted public and private resources and their allocations, and encouraged the expansion of social, emotional, and financial services for disadvantaged 
mothers at-risk of social isolation, postpartum depression, and toxic stress. The MIP model provided a theoretical framework for evaluating MHM's structure, activities, and outcomes.

I argue that MHM's grassroots strategies, activism, and accomplishments can be best understood as part of a social movement. The MIP lens offers insight into MHM's strategy to challenge maternal norms and to expand resources for under-supported mothers. Furthermore, this study combines intersectionality, cultural feminism, and MIP theories to explore how women perceive good mothering and their views of maternal support. Merging these theories allows me to explore how mothers make sense of cultural norms - how they adhere to accepted practices or challenge restrictive expectations to create social change. Thus, this study's findings (in Chapters IV, V, and VI) contribute to the sociology of mothering literature, and also speak to the social movements and feminist theory literatures. 


\section{CHAPTER III: METHODOLOGY}

To assess MHM's programming and then to understand how mothers talk about good mothering and maternal support, and how these narratives vary by race, class, and family structure, I used a mixed methodological approach. First, between March and December 2014, I conducted a comprehensive program evaluation of MHM's PSG programming to ascertain its influence on postpartum depression, parenting selfconfidence, and sense of community.

Next, I collected narratives via in-depth interviews from racially, economically, and maritally diverse mothers. I digitally recorded these interviews, transcribed them verbatim, coded the transcripts for themes, and analyzed themes using grounded theory (Charmaz 2006). Eighteen of the 41 interview participants were connected to MHM and/or its sister shop, Mama's Village (MV), in some capacity (e.g., program attendee, volunteer, facilitator, staff); the remaining 23 participants had no affiliation with MHM or MV. In the interviews, mothers discussed their perceptions of good mothering, their maternal practices, and the role of maternal support in their acts of mothering. Finally, in September 2015, I conducted a semi-structured focus group interview with MHM's founders to understand how they talked about the organization, its mission, and their interpretations of the PSG programming. This focus group interview was digitally recorded, transcribed verbatim, coded and analyzed along with the participant observation field notes using grounded theory (Charmaz 2006) to construct themes. 
Together with PSG participants' demographic data, these themes help to explain the gap between the mothers MHM envisioned serving and the mothers who attended the PSG programs.

The program evaluation and qualitative methodologies employed in this study respond to four principle research questions. First, did MHM's PSG meet its goals to decrease postpartum depression and increase mothers' parenting self-confidence and sense of community? Why did MHM's PSG program appeal to some groups (white, partnered mothers) but not to others? Third, how do mothers define good mothering across race, class, and family structure; and how do these perceptions influence maternal practices? Fourth, how do mothers view maternal support across race, class, and family structure; and how do they incorporate support into their maternal practices? I used quantitative and qualitative methods to evaluate MHM's PSG programming. I administered topic-based surveys to measure participants' parenting selfconfidence prior to and after each PSG gathering. I then conducted difference of means tests (one-way t-tests) to determine if the change in participants' parenting selfconfidence was statistically significant. I also collected baseline data to assess participants' risk of postpartum depression and sense of community upon their first PSG visit, and comparative measures upon their third and sixth PSG visits. I collected field notes of the PSG meetings from several months of participant observation; these notes were analyzed for thematic patterns and interpreted to provide a comprehensive evaluation of the PSG program and its impact. The remaining methods (in-depth interviews and a focus group interview) used in this study reinforce its feminist theoretical lens by not only answering this study's research questions, but by doing so 
through mothers' own perspectives and in their own voices. Cumulatively, this study's findings provide a detailed exploration of mothers' experiences and practices, and suggest programmatic and policy implications for organizations supporting underresourced mothers.

First, this study focuses on the development and delivery of MHM's maternal support programming (the PSG) and its founders' motivation for creating the organization and mobilizing its resources to serve specific populations. Second, I explore why this form of maternal support resonated with white, partnered mothers, and why this and other forms of peer-based support contradicted black mothers' and single mothers' perceptions of good mothering and maternal practices. Participant observation offered an ideal way to study participants in a naturalistic setting, such as the peer-based support group meetings (Morgan 1997); it provided an appropriate method to discern interaction between MHM and the PSG attendees at these gatherings. In-depth interviewing provided the opportunity for mothers to recount their experiences and perceptions in their own voices (Hesse-Biber and Leavy 2006). Focus group interviewing offered similar opportunities, while also allowing participants to corroborate their experiences, expand upon similarities and differences in their perceptions, and feed off each other's responses (Morgan 1997; Hesse-Biber and Leavy 2006). As an inductive method of data analysis, grounded theory (Charmaz 2006) guided this study throughout. 


\section{Sampling}

\section{Program Evaluation}

Sampling practices varied between the program evaluation and the in-depth interviews. I did not construct a sample of PSG participants; instead, I administered preand post-test surveys and baseline measurements to all attendees of MHM's PSG programming. While participation was voluntary, $98 \%$ of attendees competed these initial visit forms (one participant left a community baby shower program early, taking her packet of forms with her). Thus, the "sample" of PSG participants I collected was not a sample at all; quantitative findings from this program evaluation are representative of PSG programming's population $(\mathrm{N}=80)$. See Table 1, page 54 for PSG program participant demographics.

\section{In-depth Interviews}

The in-depth interview participant sample required a different, more strategic approach. I began by interviewing three participants of the MHM programs, asking each to share details of the study, parameters for participation, and my contact information with other mothers. This generated the next round of interview participants, and each relayed study details and contact information to their own contacts. I continued snowball sampling until I collected seventeen in-depth interviews.

I assessed the demographics of these seventeen participants, noting the need to diversify my sample by race, class, and family structure. Doing so allowed me to compare and contrast emerging themes from interviews, and to avoid a heterogeneous (mostly white, middle class, and married) representation (Weiss 1994; Charmaz 2006). 
Moving forward, I combined convenience, purposive, and snowball sampling techniques.

I first approached three black mothers from my daughter's public elementary school while we gathered for a student talent show, a technique recommended for groups that may be difficult to penetrate (Weiss 1994; Charmaz 2006). Two mothers agreed to interviews, and both referred other black mothers to participate in the study, as well. The majority of referrals and participants from contact and subsequent snowball sample were married and partnered black mothers and were middle- and upper-middle class.

Next, I employed a convenience sampling approach (Charmaz 2006); I sent emails about the study to past participants of MHM's PSG programming ${ }^{6}$. I combined this technique with purposive sampling techniques, however, by intentionally targeting single, black mothers, and lower-income, black mothers to add depth to my intersectional analysis. Two mothers responded to this technique and became participants. One of these participants provided several contacts for additional participants, yielding a chain of participants and referrals comprised of five participants. Ultimately, this purposive, then snowball sampling technique resulted in several lower-income and single, black participants for this study, generating diversity across racial, economic, and marital groups.

My final purposive sampling technique was to attract white participants who were single and lower-income mothers. I asked an existing participant for potential referrals within these demographics; she relayed details of the study to members of a private Facebook community for single mothers. Because she was a well-respected member of this online support community, and due to her positive experience in the study, several

\footnotetext{
${ }^{6}$ Mothers who participated in the PSG programming from the residential treatment facility (Urban Site 2) were no longer living there when I began collecting narratives. Without contact information, I was unable to interview mothers from this site.
} 
members of that group contacted me to participate. I collected interviews with seven white, single mothers from that contact. While income levels fluctuated among these participants, nearly half of the mothers were lower- or lower-middle income. After employing these various techniques, I was confident that the sample of mothers providing in-depth interviews for this study was demographically and theoretically diverse enough (Charmaz 2006) to conduct my intersectional analysis of mothers' perceptions of good mothering and their experiences with maternal support. See Table 2, page 56 for in-depth interview participant demographics.

\section{Access, Consent, and Confidentiality}

\section{Program Evaluation}

I had full access to MHM's programming (meetings and curriculum), its partners, and its participants throughout the evaluation; I was present at nearly every gathering between May and December of 2014. I began each PSG program meeting by introducing myself as an independent attendee (not a MHM employee), describing the program evaluation, reviewing the forms in front of each participant, and emphasizing participants' voluntary involvement in the process. In addition to the demographic and baseline forms, I gave participants take-home information about the study, consent, and my personal contact information for questions or withdrawing consent should they change their minds. Despite this, no one expressed concerns nor withdrew from the study; all completed baseline and subsequent forms. The University of Louisville Institutional Review Board (IRB) reviewed and approved this program evaluation. I replaced participants' names with alphanumeric codes to track attendance, and baseline 
and follow-up surveys. I removed identifying characteristics from the participant observation of the PSG programming.

\section{In-depth Interviews}

Per the mothering literature, race/ethnicity, economic class, and family structure affect women's mothering experiences. To this end, this study's sample included an oversampling of non-white mothers, lower-income mothers, and single mothers. As reflected in Bobel's (2007a) activism research, Mothers Helping Mothers (MHM) participants may have distinct motivations for their involvement. This study's sample, therefore, also included MHM's founders and facilitators, and a few MHM program participants and advocates.

With origins in the natural (or simple) parenting movement, MHM advocated for mothers to tap into the wisdom and skills they innately possess, echoing the tenets of cultural feminism. However, MHM's founders deviated from the natural mothers in Bobel's (2002) study by acknowledging their own racial, economic, and marital privilege. They employed community outreach to connect with residents and to learn from the racially, economically, and maritally diverse mothers they intended to serve. MHM conducted focus groups with black mothers, single mothers, and mothers from economically underserved neighborhoods to glean what the mothers themselves regarded as their most pressing needs. Thus, mothers' voices were instrumental in MHM's creation of the peer-based support (PSG) programming curriculum and in its efforts to expand maternal support. Despite these efforts, once the PSG programming was launched the majority of participants were white, partnered mothers. 
Gaining access to and establishing rapport with participants required intentional action. Prior to the official start of this study, I developed a relationship with Maria, the lead founder and executive director of MHM over two years. I expressed my desire to learn from her and from the mothers with whom she has built strong relationships through online and in-person communities. The groups' rapid growth was a testament to the support and resources Maria offers to mothers, and the trust and confidence they have placed in her. Within this community, however, most members were white, middle-class mothers, thus potentially over-representing a more privileged demographic.

To be a success, it was imperative that I included experiences from racially, economically, and maritally diverse mothers in this study. Because of my standpoint and perspective as a white, middle-class mother, a lack of cultural and socioeconomic diversity could have resulted in a myopic view and understanding of mothering experiences and perceptions of maternal support (e.g., Harding 1991; Harding 1987; Sprague 2005; Reinharz and Davidman 1992; Hesse-Biber and Leavy 2006).

In addition to constructing a diverse sample, I established trust with each in-depth interviewee. Throughout the PSG programming, for example, I established rapport with attendees, including economically and racially marginalized mothers. Many expressed their comfort sharing experiences with the group of attendees and me. Those who provided in-depth interviews were willing to provide subsequent referrals. Those referrals led to interviewees who attributed their willingness to participate to their friends' involvement with the study and validation of the project (Denzin 2010; Sprague 2005; Hesse-Biber et al. 2006; Reinharz and Davidman 1992; Denzin and Lincoln 1994). In every interview, I emphasized that the mother was the expert and I was the student. I 
explained my role in the process: to learn from each participant, and to convey these findings authentically to increase understanding of mothering experiences and maternal support. I reiterated my gratitude for each placing her trust and confidence in my ability to relay her story.

I conducted all interviews face-to-face at locations of the participant's choosing. Many selected coffee shops and restaurants, some chose their place of employment. A few invited me to their homes. Both the focus group with MHM staff and two in-depth interviews took place in my home. One interview occurred in the participant's car, one at her church, and one at the local public library. Interviews ranged from one to three hours. All interviews except one were completed in one meeting; the exception required two meetings due to time constraints. To preserve confidentiality, I assigned every mother an alphanumeric code, then a pseudonym; family members' names were replaced with generic identifiers (e.g., "her daughter," "my ex-husband") during the transcription process.

\section{Participant Demographics}

\section{Program Evaluation}

MHM's PSG program served 80 participants during this program evaluation: 59 participants in its three urban sites and 21 in its rural site, with an average of three to seven attendees at each meeting. MHM designed and implemented its peer-based support group (PSG) programming to reach mothers at-risk for social isolation and postpartum depression within resource-poor communities. Specifically, MHM hoped to serve mothers of color, lower-income mothers, and single mothers. The PSG programming 
succeeded in serving low-income women, with $40.7 \%$ of urban site mothers and $42.9 \%$ of rural site mothers living in households with less than $\$ 10,000$ annual income. The majority of the participants qualified for and received Medicaid (67.9\% urban sites, $68.4 \%$ rural site). Thus, MHM's PSG programming, including its resource referrals was a solid strategy for reaching this lower-income population. However, MHM was less successful in attracting mothers of color and single mothers (see Table 1, page 54 for participant demographics).

The typical participant at one of the three urban sites was 27 years old, married (45.6\%) or in a relationship (31.6\%). She was white/non-Hispanic (71.2\%) and had an annual income less than $\$ 10,000(40.7 \%)$. The typical participant at the rural site was 25 years old, married (42.9\%) or in a relationship (33.3\%). She was white/non-Hispanic (95.2\%) and had an annual income less than $\$ 10,000$ (42.9\%). Urban Site 1 succeeded in attracting the most racially diverse participants (39.2\% non-white), while Urban Site 3 and Rural Site's participants were exclusively white. Urban Site 3 also stood out as the PSG location with the highest average income ( $75 \%$ of mothers' households earned $\$ 30,000$ or more), suggesting that Urban Site 3 mothers may have more access to resources and/or support systems than the other participants in PSG locations.

All data collection occurred at the program meeting sites: a neighborhood community center (Urban Site 1); a residential treatment facility for addicted mothers (Urban Site 2); a public library meeting room (Urban Site 3); and a county human services conference room (Rural Site). I collected demographic information, a baseline parenting self-confidence score, and a baseline postpartum depression risk score at participants' first visits. At participants' third and sixth visits, I collected additional 
parenting self-confidence scores and postpartum depression risks scores, and a sense of community score based on their experience with the PSG. All participants also completed a topic-specific parenting self-confidence survey at the beginning and end of each PSG meeting.

Table 1: Mothers Helping Mothers' PSG Participant Demographics by Location $(\mathbf{N}=\mathbf{8 0})$

\begin{tabular}{|l|c|c|c|c|}
\hline & $\begin{array}{c}\text { Urban } \\
\text { Site 1 }\end{array}$ & $\begin{array}{c}\text { Urban } \\
\text { Site 2 }\end{array}$ & $\begin{array}{c}\text { Urban } \\
\text { Site 3 }\end{array}$ & $\begin{array}{c}\text { Rural } \\
\text { Site }\end{array}$ \\
\hline Average age & 26 years & 27 years & 28 years & 25 years \\
\hline First-time mothers & $46.4 \%$ & $20.0 \%$ & $75.0 \%$ & $57.1 \%$ \\
\hline Average number of children & 3.7 & 3.0 & 3.0 & 2.3 \\
\hline Relationship status & & & & \\
\hline Married & $32.1 \%$ & $10.0 \%$ & $75.0 \%$ & $42.9 \%$ \\
\hline In a relationship & $46.4 \%$ & $30.0 \%$ & $0.0 \%$ & $33.3 \%$ \\
\hline Single/other & $21.4 \%$ & $60.0 \%$ & $25.0 \%$ & $23.8 \%$ \\
\hline Race/ethnicity & & & & \\
\hline Hispanic/Latina & $7.1 \%$ & $0.0 \%$ & $12.5 \%$ & $4.8 \%$ \\
\hline Black/African American & $32.1 \%$ & $20.0 \%$ & $0.0 \%$ & $0.0 \%$ \\
\hline White/non-Hispanic & $64.3 \%$ & $80.0 \%$ & $100.0 \%$ & $95.2 \%$ \\
\hline Asian/other & $0.0 \%$ & $0.0 \%$ & $0.0 \%$ & $0.0 \%$ \\
\hline Annual income & & & & \\
\hline Less than \$10,000 & $39.2 \%$ & $100.0 \%$ & $25.0 \%$ & $42.9 \%$ \\
\hline \$10,000-19,999 & $17.8 \%$ & $0.0 \%$ & $0.0 \%$ & $28.6 \%$ \\
\hline \$20,000-29,999 & $21.4 \%$ & $0.0 \%$ & $0.0 \%$ & $9.5 \%$ \\
\hline \$30,000 or more & $14.3 \%$ & $0.0 \%$ & $75.0 \%$ & $19.0 \%$ \\
\hline Education & & & & \\
\hline Less than HS diploma & $17.8 \%$ & $40.0 \%$ & $0.0 \%$ & $9.5 \%$ \\
\hline High school diploma/GED & $28.6 \%$ & $20.0 \%$ & $12.5 \%$ & $23.8 \%$ \\
\hline Some postsecondary & $32.1 \%$ & $40.0 \%$ & $50.0 \%$ & $47.6 \%$ \\
\hline College degree or more & $21.4 \%$ & $0.0 \%$ & $37.5 \%$ & $19.0 \%$ \\
\hline
\end{tabular}

\section{In-depth Interviews}

The 41 respondents of in-depth interviews were demographically diverse (see Table 2, page 56). Ages ranged from 24 to 47 years old, with a mean age of 35 years. The average age in which participants entered motherhood was 26 years old; the youngest was 15 years old, the oldest was 37 years old. Participants had an average of two

\footnotetext{
${ }^{7}$ Participants selecting more than one race/ethnicity resulted in totals other than $100 \%$ at some sites.

${ }^{8}$ Missing responses contributed to totals of less than $100 \%$.
} 
children; one was expecting her first child, another had full custody of her niece, and two participants had six children each. Eight participants were raising step-children in addition to their own children; six were parenting nieces or nephews. Twenty-one participants identified as non-white mothers including 19 identifying as black, one identifying as Latina and one identifying as Asian American. The remaining 20 participants identified as white.

Twenty-three participants were partnered: sixteen were in their first marriage, six were remarried, and one was in a relationship. The remaining 18 were either divorced (11) or never married (seven). All participants identified as heterosexual. Twenty-three participants were living with a partner; 37 were living with their children. Eight mothers were living with extended family on a long-term basis, as well; three were temporarily living with friends or family. Six participants were lower-income with household income less than $\$ 30,000$ annually. Seventeen were lower-middle-income ( $\$ 30,000$ to $\$ 59,999$ per year); 11 participants were upper-middle-income ( $\$ 60,000$ to $\$ 99,999$ per year). The remaining seven were upper-income with an annual household income more than $\$ 100,000$. Thus, this sample is relatively equally split between lower-income (23) and higher-income (18) mothers. Thirty-one participants work outside the home either fulltime (24) or part-time (seven). Of the ten participants not working outside the home, only three were looking for work. Eighteen mothers were affiliated with MHM, either as a participant in the PSG program, a facilitator, a volunteer, or community advocate. 
Table 2: In-depth Interview Participant Demographics $(n=41)$

\begin{tabular}{|c|c|c|c|}
\hline & Percentage & Number & Range \\
\hline Average current age & 35.3 years & 35.3 years & $24-47$ years \\
\hline Average age entered motherhood & 26.6 years & 26.6 years & $15-37$ years \\
\hline Mothers Helping Mothers participant & $43.9 \%$ & 18 & \\
\hline \multicolumn{4}{|l|}{ Current Living Situation } \\
\hline Reside with own children & $90.2 \%$ & 37 & \\
\hline Reside with spouse/partner & $56.1 \%$ & 23 & \\
\hline Reside with extended family (permanent) & $13.3 \%$ & 8 & \\
\hline Staying with friends/family (temporary) & $7.3 \%$ & 3 & \\
\hline Average no. children in household (own) & 2.0 & 2.0 & $0-6$ children \\
\hline Average no. children in household (all) & 2.3 & 2.3 & $0-6$ children \\
\hline Raising step-children & $19.5 \%$ & 8 & \\
\hline Raising niece/nephew/other & $14.6 \%$ & 6 & \\
\hline \multicolumn{4}{|l|}{ Relationship status } \\
\hline Partnered & $56.1 \%$ & 23 & \\
\hline Married (first marriage) & $39.0 \%$ & 16 & \\
\hline Remarried & $14.6 \%$ & 6 & \\
\hline In a relationship & $2.4 \%$ & 1 & \\
\hline Not partnered & $43.9 \%$ & 18 & \\
\hline Single (never married) & $26.8 \%$ & 11 & \\
\hline Divorced & $17.1 \%$ & 7 & \\
\hline \multicolumn{4}{|l|}{ Race/ethnicity } \\
\hline Non-white & $53.7 \%$ & 21 & \\
\hline White/non-Hispanic & $48.8 \%$ & 20 & \\
\hline \multicolumn{4}{|l|}{ Non-white participants: } \\
\hline Black/African-American & $46.3 \%$ & 19 & \\
\hline Hispanic/Latina & $4.9 \%$ & 2 & \\
\hline Biracial & $4.9 \%$ & 2 & \\
\hline Asian & $2.4 \%$ & 1 & \\
\hline \multicolumn{4}{|l|}{ Annual income } \\
\hline Less than $\$ 30,000 /$ Lower-income & $14.6 \%$ & 6 & \\
\hline$\$ 30,000-59,999 /$ Lower-middle income & $41.5 \%$ & 17 & \\
\hline$\$ 60,000-99,999 /$ Upper-middle income & $26.8 \%$ & 11 & \\
\hline$\$ 100,000$ or more/Upper-income & $17.1 \%$ & 7 & \\
\hline \multicolumn{4}{|l|}{ Residence } \\
\hline Own apartment/home & $61.0 \%$ & 25 & \\
\hline Rent apartment/home & $31.7 \%$ & 13 & \\
\hline Other & $7.3 \%$ & 3 & \\
\hline \multicolumn{4}{|l|}{ Education $^{9}$} \\
\hline High school diploma/GED & $9.8 \%$ & 4 & \\
\hline Some postsecondary school & $36.6 \%$ & 15 & \\
\hline College degree or higher & $56.1 \%$ & 23 & \\
\hline Bachelor's degree only (BA or BS) & $29.3 \%$ & 12 & \\
\hline Graduate or Professional degree & $26.8 \%$ & 11 & \\
\hline Employment & & & \\
\hline
\end{tabular}

\footnotetext{
${ }^{9}$ Participants who earned professional training or certificates beyond high school diploma/GED selected both options; totals in this category do not equal $100 \%$.
} 


\begin{tabular}{|c|c|c|c|}
\hline Working outside the home & $75.6 \%$ & 31 & \\
\hline Part-time (1-30 hrs. per week) & $17.1 \%$ & 7 & \\
\hline Full-time (31+ hrs. per week) & $58.5 \%$ & 24 & \\
\hline Not working outside the home & $24.4 \%$ & 10 & \\
\hline Looking for work & $7.3 \%$ & 3 & \\
\hline Not looking for work & $17.1 \%$ & 7 & \\
\hline
\end{tabular}

\section{Data Collection}

Program Evaluation

Between February and December 2014, I collaborated with Mothers Helping Mothers (MHM) to design and implement a program evaluation of its peer-based support group (PSG). I collected data between April and December at four PSG sites. I authored reports on behalf of MHM to the external funding agency. MHM established the parameters of the program evaluation. The organization deemed its PSG a success if it attracted a diverse group of attendees; increased participants' self-confidence in parenting skills; decreased participants' risk of postpartum depression; and increased its participants' sense of community. To ascertain if these objectives were met, I also collected participant demographic data and participant observation field notes. Baseline and comparative measures and topic-based pre- and post-test surveys were designed based on the following evaluative instruments (see Appendix I):

1) Parenting Self-Efficacy (PSE) Subscale of Gibaud-Wallston's Parenting Sense of Competence Scale to measure parenting self-confidence. The general PSE was administered as a pre- and post-test survey to all participants at baseline, third, and sixth visits; the topic-specific PSE was administered to all participants monthly;

2) Edinburgh Postpartum Depression Scale (EPDS) to measure risk of postpartum depression. The EPDS was administered at participants' baseline, third, and sixth visits;

3) Sense of Community Index (SCI) to measure participant's feeling of community in group and peer support. The SCI was administered at participants' third and sixth visits. 
All three instruments were externally validated and assigned Chronbach's alpha scores - a reliability index score, ranging from a score of 0.00 (low reliability) to 1.00 (high reliability). The PSE and its skills and knowledge subscale has an alpha score of 0.83 (Copeland and Harbaugh 2004). The EPDS has an alpha score of 0.77 (Jadresic, Araya, and Jara 1995). The SCI, specifically adapted for citizen participation as it mimics membership in a group, has an alpha of 0.78 (Long and Perkins 2003). Based on external evaluations and alpha scores, these instruments possess a high level of external validity.

I used a mixed-methods approach for data collection (Bledsoe and Graham 2005). This included participant observation during the PSG programming and the use of surveys and forms to evaluate the program's influence on attendees' parenting selfconfidence. The evaluative instruments produced quantifiable results for difference of means tests and analysis; participant observation generated qualitative field notes and insight into the atmosphere, culture, and interactions during the PSG meetings. I conducted participant observations for every topic-based meeting except one. I coded and analyzed my field notes using a grounded theory approach (Charmaz 2006). Each attendee, survey, and form was assigned an alphanumeric code to maintain participant confidentiality. I had sole access to the attendees' names for tracking purposes.

As an external evaluator, I observed, recorded, and analyzed attendee demographics, pre- and post-test scores, and program-based interactions. Cumulatively, I provided constructive feedback for MHM and addressed the PSG programming's successes and short-comings. With these findings, MHM would be able to:

1) Control and strengthen staff activities;

2) Strengthen program design;

3) Maintain a record of the program's progress;

4) Maintain a record of the program's costs; and 
5) Report the program's progress to the program's financial sponsor, policy board, community members, and other investors (Stufflebeam 2001:6).

Thus, this comprehensive program evaluation not only fulfilled a condition of funding from the granting agency underwriting the PSG programming, it also provided recommendations for MHM (and similar nonprofit agencies) to achieve its mission to support mothers with limited resources and mothers of color.

In-depth Interviews

After completing the program evaluation of MHM's PSG programming, I launched the second phase of this study. Between March and September 2015, I conducted 41 in-depth interviews with local mothers. I used in-depth, semi-structured interviews to collect mothers' narratives about the standards of "good mothering," who and what influenced their own maternal experiences, and their views of maternal support. Given the sample's diversity, these narratives demonstrated how maternal practices, perceptions, and standards varied across race, class, and family structure.

As I prepared the interview guide, I referred to the literature on qualitative methodology (specifically, Charmaz 2006). I approached this study qualitatively to learn about participants' experiences, and their interpretations thereof. I devised broad, openended questions to avoid limiting responses (Charmaz 2006:26). Because participants reflected on mothering — an act that was simultaneously past and present—perceptions of their maternal practices and maternal standards were essential to construct (and often reconstruct) accounts of their maternal experiences (Charmaz 2006:27). Thus, qualitative methodology—specifically semi-structured, in-depth interviews—was essential to collecting these narratives. 
I constructed open-ended questions to learn about the maternal standards, practices, and perceptions shaping local mothers' experiences (see Appendix II). I asked respondents about the standard of "good mothering." Specific questions included: What is good mothering? How is good mothering performed? What does good mothering represent? How do mothers recognize good mothering? Conversely, I asked mothers similar questions about "bad mothering." I also asked questions about maternal support if respondents did not address the topic in their narratives of good and bad mothering. Specifically, I asked if respondents had maternal support, what maternal support looked like, who provided maternal support, and if maternal support influenced their own mothering practices and standards.

I asked the 18 respondents with a connection to MHM supplemental questions (see Appendix III) to establish their involvement with the organization. I asked about participation in MHM's programming, respondents' motivation for participation, their perceived value of MHM and/or the PSG programming, and if they perceived that MHM influenced their own maternal standards, practices, and views about maternal support.

I asked all respondents similar questions. I encouraged mothers to discuss issues that were important to them, even if they deviated from the original questions. As a result, respondents prioritized their own maternal influences, often moving beyond the initial categories I established. As patterns emerged in participants' responses, I adapted questions to incorporate these topics. For example, I originally asked respondents to describe what influenced their views of good mothering. I was unaware that the way I framed this question reflected my own perception that mothers were influenced by media, advertising, and other societal messages. Instead, I learned to ask who or what influenced 
views of good mothering. Doing so allowed respondents - especially mothers of colorto discuss the effect of their own upbringing and its influence on their maternal practices. Many black mothers' narratives revealed the ways in which their own grandmothers, mothers, aunts, and othermothers (Collins 1990; hooks 2007a) contributed to their current practices of communal mothering. The original construction of these questions-and my own racialized view of mothering - limited the space for black mothers to talk about important cultural influences on their own perceptions of good mothering.

Participants were extremely willing to talk about their maternal experiences and perceptions, often at great length. Being a mother myself established a basic connection with respondents. Assuring participants that I was neither purporting to be an expert in mothering, nor was I suggesting that I was a "good" mother established a more comfortable tone for the interviews. My genuine interest in learning from other mothers, and acknowledging that each mother was an expert in her own experience, lent credibility to my desire to learn, putting participants at ease. I related to the challenges of mothering and was sympathetic to the daily struggles. Sharing the ambivalence of the maternal experience (Rich 1976) with participants helped me to establish rapport. If necessary, I used prompts (e.g., "Tell me more." "Why do you think that is?" "How so?") to elicit more details from participants. Overall, I believe interviewees were extremely forthcoming about their maternal practices, challenges, and perceptions.

\section{Focus Group Interview}

On a weekday afternoon in September 2015, I hosted a semi-structured focus group interview at my home with three of the four women who created and implemented 
MHM as an organization and the peer-based support group (PSG) programming. ${ }^{10}$ Collectively, the women developed MHM's mission and its programs, formed its Board of Directors and its organizational and operational structure, and sought external sources of sustainable funding while remaining intimately involved with other forms of local activism on behalf of mothers. I asked the women about their motivations for founding MHM, their personal and organizational goals, the obstacles they encountered, and their own perceptions of maternal activism. The focus group interview questions (see Appendix III) were guided by the theoretical literature.

Over the course of three hours, the participants recounted their experiences and perceptions of MHM's activities, successes, struggles, and limitations. Most times, they corroborated each other's stories; variations demonstrated the diverse responsibilities and the years of strategic planning invested to launch the organization formally. We sat around my dining room table; I provided water and tea, fresh fruit, crackers and cheese. One breastfeeding mother brought her newborn infant along; the participants' older children were still in school for the day. With their written consent, I recorded the focus group interview and transcribed it verbatim for analysis.

Conducting a focus group interview with MHM's founders allowed me to glean the collective and individual experiences designing and overseeing the organization from concept to fruition (Weiss 1994). The participants' passion for social change was discernable, as evidenced by their facial expressions, their enthusiastic agreement about issues, and their verbal tone during the focus group (Morgan 1997). The potential weaknesses of focus group interviewing — ranging from conformity in responses to

\footnotetext{
${ }^{10}$ The fourth founder was unable to attend the focus group; I provided her with written questions, but she did not respond.
} 
polarization among participants (Morgan 1997) — were outweighed by the strengths in this setting. These nonverbal cues communicated supplementary details about the purpose and focus of MHM, while the interaction that emerged between participants in regards to specific issues reinforced the benefits of the focus group methodology (Morgan 1997).

\section{Methodological Strengths and Weaknesses}

Strengths

Cumulatively, this study's various methodological techniques (pre- and post-tests of survey data, participant observation, in-depth interviews, and focus group interview) provided abundant data, context, and depth to understanding perceptions of good mothering and maternal support. While the program evaluation of MHM's PSG programming included quantitative instruments, pre- and post-test surveys, and difference of means tests, this study's methodological focus was its qualitative data collection. I employed qualitative methodologies to better understand women's lived experiences and perceptions of good mothering, their views of maternal support, and variations across race, class, and family structure; this study's theoretical framesintersectionality, multi-institutional politics approach, and cultural feminism—-further validate this approach. Qualitative methods provided the tools for me to learn from mothers, to respond to their narratives, to represent mothers as experts of their lived experiences, and to evaluate my own position in the research process.

I was able to adapt these tools and reflect upon patterns and themes in participants' narratives, refining the data collection process, as needed (Charmaz 
2006:15). The data collection process empowered participants who are often marginalized (e.g., all mothers, particularly lower-income women, women of color, and single mothers); it allowed me to represent women's experiences and expertise, and provide a vehicle for mothers to control how they shared their stories (Charmaz 2006). Additionally, qualitative research demanded constant reflexivity on my part; it required me to review the positions of power between myself and participants, and to revisit sensitizing concepts that emerged throughout the data collection process (Blumer 1969; Charmaz 2006).

\section{Weaknesses}

This study's data collection represented nearly three years of relationship building with the founders of MHM. This necessary step provided entrée to MHM's organizational structure, its financial workings, and its founders' personal motivations for investing time and energy to bring this concept to fruition. As a result, my professional relationships developed into friendships; MHM vouched for me and promoted the study to the MHM community. This benefitted me in several ways: I established rapport with mothers associated with MHM almost instantly as they were eager and willing to participate in the study, divulging candid narratives about their maternal (and marital) struggles and challenges. I attended internal meetings with the MHM Board of Directors and with other community programs to establish partnerships with MHM; and I had direct access to the funding agency and its top-tier managers administering the financial support for the PSG programming. 
As Huisman (2008) encountered in her own qualitative research, feminist researchers often attempt to reconcile the unequal positions of power we encounter through the data collection process. I felt responsible (and was willing) to provide reciprocal labor for the organization in exchange for its contacts, connections, and validation of my study. I provided reports to the funding agency, I participated (and occasionally, filled in) in other Mama's Village (MV) and MHM gatherings in the community. To establish rapport with other mothers - especially those without any connections to MHM-I changed diapers, helped with feedings, and lent a hand whenever I could to allow mothers to provide narratives without interruption. A few mothers called the in-depth interview process "therapeutic;" some sent me friend requests on Facebook afterwards. Boundaries I intended to maintain as a researcher were blurred as some participants became acquaintances.

Over the course of this study, this long-term association with MHM and my respect and reverence for MHM's founders' dedication and commitment to the PSG program and community-based maternal activism made it difficult at times to provide constructive criticism to the organization. Similar to Huisman's (2008) struggles, I felt the tensions between my roles as researcher, empathetic mother, and friendly peer. I worried about hurting the founders' feelings and invalidating their tremendous work and commitment to the community. I was concerned that maintaining my "friendly façade" with participants could be confusing, leaving them feeling manipulated as I extracted data from the next participant (Stacey 1988:387).

Revisiting works by other feminist, qualitative researchers (e.g., Huisman 2008; Stacey 1988; Kirsch 1999; Irwin 2006) provided context for my challenges and 
intentional steps to ensure the study's validity. Acknowledging that the strengths of feminist research (e.g., its collaborative relationship between researcher and participant, the intimacy of in-depth interviewing) can unintentionally produce the very ethical dilemmas (e.g., power dynamics, inauthenticity) researchers seek to deconstruct reveals the paradox of feminist, qualitative work (Huisman 2008:387; Kirsch 1999; Irwin 2006). I combined multiple qualitative methods (participant observation, focus group interviewing, in-depth interviewing) to triangulate my data collection. The practice of memoing throughout the in-depth interview collection process revealed patterns and themes in mothers' narratives; I revised my interview guide to compare new patterns and triangulate the themes I constructed.

I invited Maria (the founder of MV and MHM) to my program evaluation defense with my $\mathrm{PhD}$ committee. I struggled to critique MHM's programming; I worried that pointing out shortcomings might call into question the hours of work Maria and MHM's staff and volunteers invested in supporting mothers. Maria and my committee members encouraged me to share my critical feedback: doing so would ultimately benefit MHM and its programming, while remaining silent would not. This process, and the support of my committee members, helped me to resolve the tensions I encountered throughout this study's data collection process, and added validity to the narratives and observations, as well.

\section{Data Analysis}

In addition to this study's defined theoretical framework-employing a cultural feminist theoretical lens to analyze MHM's operational and programmatic structure and a 
Multi-Institutional Politics (MIP) approach to situate MHM's collective efforts within a broader movement for social change (see Chapter II) — intersectionality and grounded theory guided this study. As previously discussed, these methodological approaches shaped the study's design and its data collection; this section outlines how they informed its data analysis.

\section{Grounded Theory}

A grounded theory analysis of the data provided flexibility to interpret women's perceptions of good mothering and views of maternal support. While coding and categorizing narratives, for example, I noticed that mothers revealed internalized beliefs about acceptable forms of maternal support shaped by institutional forces (e.g., media, work force, family). I responded to this emerging pattern by diversifying my sample of participants (e.g., working mothers, stay-at-home-mothers, single mothers, divorced mothers, etc.) and concurrently comparing participants' responses. This process deepened my understanding of the relationship between women's standards and practices of good mothering and their perceptions of maternal support (Charmaz 2006:20-21).

I repeated this line-by-line process, first assigning broad categories (e.g., "mother," "mothering," "motherhood," "support"), then refining the categories into focused codes and sub-codes (e.g., "bad mother," "image," "own needs," and "child's needs"). Patterns in mothers' narratives suggested stronger themes. I replaced "bad mother," for example, with "self-care" and "self-sacrifice," then constructed themes within these two sub-codes. I continued coding and sorting codes into comprehensive themes until my findings yielded no new variations (Charmaz 2006:96). 
It is important to note whose approach to grounded theory informed my study. Charmaz's (2006) interpretation of constructing grounded theory is compatible with an intersectional approach to qualitative methodology. She acknowledges research bias and subjectivity, the importance of reflexivity throughout the research process, and the flexibility to adapt the research trajectory to data-driven findings. Grounded theory provided the analytic guidelines and tools to construct robust theoretical findings from my extensive and diverse collection of qualitative data.

\section{Intersectionality}

Choo and Ferree's (2010:132) group-centered approach ${ }^{11}$ and its emphasis on inclusion of qualitatively diverse identities, perspectives, and experiences guided my data analysis in this study. This process focuses on the relationship of power to groups-the dimensions of privilege and oppression - and its influence on constructing distinctive perspectives. Expanding maternal experiences, for example, to include representations of missing voices (e.g., mothers of color, lower income mothers, single mothers, etc.) deepens our understanding of mothering standards, maternal practices, and views of maternal support. This group-centered practice and analysis (Choo and Ferree 2010) destabilizes the normative maternal perspectives based on white, middle class, married mothers and reveals the intricacies of social forces with regards to race, class, and family structure.

I framed the participants as the experts of their own experiences, perceptions, and narratives. I structured this study to amplify their voices by using their own words and

\footnotetext{
${ }^{11}$ Process-centered and system-centered are the other two intersectional approaches outlined by the scholars (Choo and Ferree 2010).
} 
language to reveal the phenomenology of oppression through their lived experiences (Bartky 1990; Blumer 1969; Denzin 1994; Kleinman 2007; Denzin 2010). As the researcher, however, I ultimately controlled whose voices were included and my interpretation of their narratives. I referred to Collins' (1990) discussion of "either/or" and "both/and" to guide me through the contradictions in power and ownership. By recognizing participants as both empowered/disempowered and expert/subject, I reconciled my responsibility to represent their narratives as best I could. Analyzing data via intersectionality and grounded theory allowed me to explore the relationships of power embedded in maternal norms and practices, and gendered and racial oppression and empowerment (hooks 1984; Collins 1990; Bartky 1991; hooks 2007a; Choo and Ferree 2010).

\section{Researcher Subjectivity}

I presented issues concerning my relationship with the founders of MHM as a potential weakness of this study. Researcher subjectivity poses potential concerns, as well. Even though I operated as an external evaluator to assess MHM's PSG programming, my presence was apparent to attendees. Despite my repeated assurances to participants that I was not affiliated with MHM, my presence as an older, white, married, middle-income mother was apparent. I sat with participants during the PSG meetings, but only contributed to group discussions if asked a direct question. While this occurred infrequently, over the eight months of data collection, I received questions about parenting an older child ${ }^{12}$; raising an only child; premature labor, delivery and spending

\footnotetext{
${ }^{12}$ My daughter was eight years old for most of the evaluation; she turned nine near the end of my data collection.
} 
time in the neonatal intensive care unit (NICU) following a premature birth; natural childbirth; and breastfeeding challenges. I responded as a mother, not as a parenting expert or authority on the subject. The majority of the time, I was a silent observer. I avoided taking notes during the meetings, instead recording field notes afterwards to maintain participants' confidentiality and comfort sharing.

Social research in practice is potentially muddled and complex. Weaving feminist theory into methods spurs epistemic debates. While (most) sociologists accept the limitations of positivism and the quest for neutral objectivity, support for the alternatives is varied. Constructivists argue that the feminist perspective leads to new ways of knowing (Tuana 1996; Guba and Lincoln 1994), while interpretivists (Rouse 1996; Schwandt 1994) credit it with new ways of analyzing existing epistemologies. What they do agree on is the recognition of researcher subjectivity and the value of this standpoint in the qualitative process (Smith 1990; Smith 1987; Harding 1987; Harding 1991; Hartsock 1998; Reinharz and Davidman 1992; Kleinman 2007; Denzin 2010; HesseBiber et al. 2006; Sprague 2005; Charmaz 2006; Denzin and Lincoln 1994; Guba and Lincoln 1994). The positionality and social locations of the researcher inform assumptions, interactions, and interpretations of the research questions, data, and processes.

My standpoint, therefore, as a white, middle-class, heterosexual, married, educated mother of one daughter influenced my data collection, interpretation, analysis, and theme-based construction of findings. As a feminist researcher, it was my priority to strive for neutrality throughout the interviewing process. I reflexively checked my own privileges and social biases as I interpreted participants' narratives and presented their 
perspectives. Despite these acts, I struggled to maintain neutrality at times. One mother, for example, offered me wine during our morning interview at her apartment. I declined. During my time with her and her infant daughter, she consumed two to three glasses of wine, while voicing her frustration with CPS's ongoing investigation of her maternal practices. It was difficult to react in a detached manner; instead, I was empathetic to her situation. She was a single mother, living in poverty, lacking any maternal support, facing the threat of losing custody of (another) child, and sharing her story with a stranger. If wine helped her to negotiate that morning's circumstances, I was in no position to pass judgement. Throughout this study, my responses and assumptions reflected my subjectivity and informed every aspect of this study.

These ethical considerations surfaced despite my best efforts to ameliorate them. The construct of my sample, data collection, and analysis are likely skewed accordingly. However, I was successful in constructing a sample with racial, economic, and familial variation on race, economic class, and family structure. My attention to my own subjectivity and biases guided my research and analysis; by placing mothers' stories at the center of this study, I believe their experiences and voices obscured my own.

\section{Generalizability of Findings}

While this study's qualitative data were not collected from a representative sample and therefore not broadly generalizable, I contend that its findings are relevant and transferable. By continually comparing themes in participants' narratives and diversifying the participant sample and data collection techniques to triangulate my findings, I corroborated thematic patterns in the data (Weiss 1994). I sought counter- 
narratives to validate emerging patterns and to provide context to the racial, economic, and marital variations in mothers' experiences (Weiss 1994). My results, therefore, convey thematic and theoretical consistency that may be applicable to similar groups of mothers beyond the scope of this study.

\section{Conclusion}

Combining a feminist approach and qualitative methodology in research can generate powerful, tangible outcomes, whether it be new epistemologies (Harding 1991; Reinharz and Davidman 1992; Hesse-Biber et al. 2006), social action (Kleinman 2007; Denzin 1994; Denzin 2010; Mills 1959), or both (Sprague 2005). The construction of comprehensive knowledge via plural experiences and ways of knowing deepens the understanding of groups' interactions with institutions and structures of power and control. Feminist research reveals how policies and structures favor and empower some while marginalizing and disempowering others, and is necessary for reshaping these systems and eradicating inequalities via social change. This study contributes the voices

of a diverse group of mothers to the cultural conversation of good mothering and maternal practices.

Despite this study's limitations, it yielded important findings about mothering, maternal support, and maternal activism. This study provided a better understanding of how women challenge social norms, expand support, and shape collective action. This study revealed how women talk about mothering, how they view their practices, and how support may or may not align with their views. By examining these themes in context with MHM's grassroots efforts, this study demonstrated how mothers' experiences vary 
by race, class, and family structure and how an organization attempted to create supportive space for all mothers. 


\section{CHAPTER IV: \\ MOTHERS HELPING MOTHERS ${ }^{13}$ AND PEER-BASED SUPPORT}

Accessing maternal support in various forms (e.g., hands-on parenting support, resource-based support, financial support, emotional and social support) is beneficial for mothers. Financial support and transaction-based support expands parenting resources and eases economic strain; mothers receiving social and emotional support experience a decreased likelihood of postpartum depression, anxiety, toxic stress, and child abuse (e.g., Balaji, Claussen, Smith, Visser, Morales, and Perou 2007). Thus, social and emotional support can alleviate maternal tensions; social connections can expand mothers' networks and offer options for additional resources and assistance with competing parental demands. New research suggests that maternal support not only assists new mothers with their transition into motherhood, but throughout their children's developmental stages (Luther and Ciciolla 2016). Despite these potential benefits, not all mothers incorporate social and emotional support systems into their spheres of maternal support.

Mothers' parenting practices and usage of support systems are shaped by race, class, and family structure (e.g., Stack 1974; Dow 2016a; Dow 2016b). In addition to these social forces, geographic obstacles impede access to maternal support. Government services and organizational programs are often concentrated in resource-sufficient

\footnotetext{
${ }^{13}$ Pseudonyms were assigned to private organizations, staff members, participants, locations, and MHM programs. Public and government organizations' names (e.g., La Leche League, WIC, SNAP, HANDS) were used.
} 
neighborhoods where mothers are more likely to have adequate means and support systems; mothers residing in resource-deficient neighborhoods encumbered by insufficient transportation systems are left with few—if any-accessible resources. Given the empirical benefits of maternal support, and the inconsistency in which support is provided — especially for mothers lacking other forms of support (e.g., familial, resourcebased, financial)—would increasing provisions for maternal support and removing obstacles to accessing this support assist mothers most at-risk of social isolation and parental stress? I designed this evaluation to answer this question.

Three local mothers founded a nonprofit organization (Mothers Helping Mothers, or MHM) and devised programming (Peer-based Support Groups, or PSG) in 2014 to extend social and emotional maternal support to underserved neighborhoods. I employed quantitative and qualitative measures to evaluate the PSG program. Pre- and post-tests, difference of means tests, and extensive participant observation yielded mixed outcomes.

This chapter presents the quantitative and qualitative findings from the formal evaluation. A subsequent focus group with three of the four founders and analyses of the PSG's outcomes and practices used to guide the program from its initial concept through its implementation reveal the complexity of racial and economic biases and privilege embedded in social support. First, I draw from focus group interviews with MHM's founders to explore the development of the organization, its programming, and its ultimate goals. The mothers' narratives also provided insight into their own maternal ideologies and how these shaped the PSG programming and their collective efforts to expand maternal support. Next, I show how MHM's PSG program was successful in decreasing participants' risk of postpartum depression and social isolation, while 
increasing their sense of community. Finally, findings from extensive participant observations demonstrate how the PSG curriculum replicated cultural norms about mothering that resonated with participants similar to MHM's staff, but deterred the black mothers and single mothers they hoped to reach. I provide recommendations for MHM to increase its program's cultural competency. These findings also provide a rationale for in-depth interviews with a racially, economically, and maritally diverse group of mothers to understand - in their own words - their perceptions of "good mothering" and familial support (Chapter V) and non-familial, mother-centric support (Chapter VI), to better understand their views of peer-based, mother-centric support.

\section{Mothers Helping Mothers}

The Organization's Origins

Maternal advocates Maria, Lauren, and Tracey recognized the need for community-based social and emotional support for mothers at-risk of toxic stress in these neighborhoods. As they considered how to address this need, Maria's business-Mama's Village (MV) - provided an effective model. MV is a small, yet popular destination for white, middle- to upper-middle income, urban mothers. Maria, a 31-year-old, white, remarried, lower-middle income mother of two school-aged sons from a previous marriage, founded MV six years ago. The cozy, bright destination for mothers more resembles a community center than a commercial business: mommy and me yoga classes, sing-along music time, and toddler art groups are scheduled in between childbirth preparation classes and La Leche League meetings. While limited items (e.g., baby wearing wraps, amber teething necklaces, wooden baby rattles, organic diaper cream, 
etc.) are available for purchase in a small corner of the former house, most women arrive with one, two, three, or more small children and infants in tow and head directly to the open rooms beyond this retail section.

There, in what feels like a friend's living room, while children (most are preschool age and younger) explore, play with toys, and interact with each other, mothers sit in comfortable chairs, on the couch, or on the floor and talk. They discuss children's developmental stages, breastfeeding issues, a lack of sleep, picky eaters, concerning rashes, and frustrations at home. They celebrate children's milestones, share tips and strategies for coping with defiant behavior, and potty training successes. On the surface, MV appears to be a destination for child(ren): a plethora of child-centric activities keep them entertained for hours, leaving them contented and exhausted. But Maria and the MV mothers know that this is only a secondary benefit. For most attendees, the maternal community provides camaraderie with other mothers who may also experience the emotional ambivalence of motherhood. The MV group is a venue for maternal self-care: mothers listen to other mothers, empathize with each other, and reassure and comfort each other. This is how peer-based, mother-centric support is defined by Maria and MV's growing community of mothers who interact in person and through MV's online portal.

MV is not the only maternal resource in this urban neighborhood. Income-based, free, and fee-for-service maternal support programs (e.g., prenatal and postnatal health care, pregnancy and postpartum wellness, SNAP, WIC, La Leche League, mommy and me yoga, music, library story time, etc.) are available and relatively accessible via public transportation (even though most of the neighborhood's residents own personal vehicles). To learn more about the transition from MV's model of serving mothers to the creation of 
the nonprofit Mothers Helping Mothers (MHM), I hosted three of MHM's founding members at my home. For nearly three hours on an afternoon in September 2015, I facilitated a semi-structured focus group to hear their thoughts about launching MHM, their intentions with the peer-based support groups, and how they made sense of their first foray into nonprofit programming.

Prior to the creation of MHM and despite watching her own peer-based maternal programming thrive, Maria wrestled with MV's inability to serve mothers in less affluent neighborhoods where maternal resources are sparse or nonexistent. Residents in other parts of the city could also benefit from peer-based support and maternal services, yet they face physical obstacles, social barriers, or both. Unreliable and inadequate public transportation, inflexible work schedules, and even ignorance about these programs for mothers and young children rendered them nonexistent. If mothers were unaware of or unable to access MV or other maternal resources, their existence was irrelevant. This realization pushed Maria to reconsider her model for serving mothers:

I'd been at [Mama's Village] for a couple of years and learning about what it meant to support families and realizing there was not a lot of access...there were all these great classes in town and groups in town...but...if you weren't... white, middle-class, you know, [of a] certain education level, family-type with a car, you just weren't going to come in [to use these services].

When Maria unexpectedly became a single mother herself and struggled financially to support her toddler and infant, the issue of inaccessibility to communitybased support intensified: "Becoming a single parent at the time helped me realize...all these parenting ideas are great in theory, but they're not always possible... and I knew that the work I wanted to do was to make that stuff more accessible." In fact, learning to 
navigate institutional and community-based supports provided Maria's early vision for MHM and its potential capacity for serving at-risk mothers:

My first idea was very small...it was creating directories of resources to give out to people...like an actual, tangible directory...Because I felt like that was the biggest [need]. There's a lot of great resources in this city, but no way to access them, and I felt [MHM] could just be this platform...like a conduit.

In early 2012 while incubating this concept, Maria met Lauren. Lauren, a white, 28-year-old birth doula and former nonprofit executive, had recently relocated to town. Pregnant, she, her husband, and her toddler-aged son moved in with her parents. Lauren and Maria shared a passion for increasing maternal support; their parallel personal experiences-living in financially grim circumstances and learning to navigate bureaucracy to access social resources - provided first-hand insight into the obstacles facing lower-income and single mothers. First, Lauren proposed a volunteer doula program to expand access to birth support for low-resource mothers. "Because [my family and I] were in such dire straits in our own situation...I had a real empathy and sudden realization and understanding of [birth support] not being accessible to people. I'm a doula and it's not even accessible to me."

Soon after, Tracey, a 34-year-old white married mother and her young family moved to the area, also residing with her parents. A few years prior to their move, both she and her husband were employed and financially stable. They welcomed their first daughter while on private insurance and tried for a second child soon after. Tracey stayed home with their infant daughter while her husband continued working. During her second pregnancy, however, her husband lost his job and the couple scrambled to accommodate their new financial situation and impending birth: 
I had a baby, and [my husband] had been laid off and we're on Medicaid and food stamps, and our doula donated her services...And I had doubleincome 3 or 4 years before that. I've been on two sides of the coin...it's easy to say 'cultural competency'...it's fine for people to serve who they want to serve, but...there was a personal touch to why...we all felt a connection...we want women to feel supported during this life-shift [becoming a mother] because we wanted support and we needed support, too.

While Tracey and Lauren researched models for a community-based volunteer doula program, Maria continued to network with area service providers. She gauged the need for maternal services in certain neighborhoods; the gap that MHM could fill in supporting at-risk mothers became evident. She met a physician from a nonprofit health clinic based in an extremely impoverished, predominantly Black neighborhood. After learning about Maria's vision for extending peer-based support to mothers in underresourced neighborhoods, the doctor committed to helping MHM become a reality: "We met at the farmers' market one day and [she] was like, 'I have patients who really need this stuff!' and I was like, 'Good! That would be great.' And...we stayed in touch.” The physician secured funding through her national professional association to contract with Maria and MHM to expand peer-based support and access to community-based resources to the health clinic's patients. Maria, Lauren, Tracey, and the doctor's interpretation of maternal support via a resource referral platform aligned; they shared a common vision to connect racially and economically diverse neighborhoods in the city to an existing network of support and resources.

As Lauren spearheaded the search for organizational models and format for a volunteer doula program, MHM and its efforts to support marginalized mothers received more validation. That fall, MHM launched an online crowd-funding campaign to begin the first community-based program; the financial goal was reached in just two months. 
Tracey oversaw the campaign: "We had amazing people. We hit our goal...it was pretty energizing." Maria echoed this excitement: "It was! We had received funding from...an 'official' grant...and then individuals in the community and that felt like, 'Ah! Okay!'”

Even before receiving formal nonprofit status, the organization's momentum continued to build; MHM's strategies shifted away from connecting mothers to existing programs to developing its own curriculum and providing the support itself. Lauren remembers: "Some of that evolved simultaneously...so some of it was influenced by how the funding [process] worked...by the time we did the first [health clinic] grant and really had...feedback [from participants] ...we were already starting to perceive what some program needs were in that community." Regardless of its delivery, MHM shared its vision for providing mother-centric, peer-based support to the public, and the public responded with resounding encouragement.

\section{Peer-based Support Group Programming}

MHM's programming — the Peer-based Support Group (PSG) — and its curriculum were developed to offer parenting skills, information, and resources to new mothers within a group setting. Topics were chosen by the previously gathered community feedback, and each PSG meeting rotated topics monthly. These topics ranged from pregnancy self-care to birth options, from car seats and baby-wearing to nursing and solid foods. Lauren served as the primary facilitator for most meetings; Maria filled in when needed during the course of the evaluation. Lauren's extensive training in breastfeeding support, childbirth options, and postpartum care meant she could respond to participants' questions. She made referrals to specific programs, services, and/or care 
providers throughout the community based on individual needs. Other times, she suggested books, websites, or articles as references for mothers.

The PSG's setting served as an essential component of its programming, as well. The sites chosen were resource-poor neighborhoods with low average incomes and high rates of racial and ethnic diversity. MHM partnered with established and familiar organizations and service providers within these communities_-including a community center, a health and human service provider, and a library — to make participation more accessible for local residents. Intentionally, the PSG's face-to-face format would foster connections between participants, while its informal structure allowed for participants to guide discussion to relevant topics. Even though Lauren served as the facilitator, the atmosphere was purposely relaxed. MHM encouraged other attendees to offer suggestions or feedback on topics to avoid establishing Lauren as the group's "expert." Participants made comments about the discussions and topics; the topical schedule would be tailored to respond to each location's needs.

The two-hour gathering began with a topic-based discussion, guided by Lauren. She incorporated games and trivia at times to generate participation; other times participants received candy for their feedback. As camaraderie increased, the PSG's format adapted to the natural flow of conversation and attendees' questions and concerns. Through its parenting skills-based curriculum, participants would forge connections with each other and create a peer-based network for social and emotional support. MHM's role would fade into the background, allowing attendees to steer the discussions and the level of MHM's contribution. 


\section{Launching the Program}

MHM obtained formal nonprofit status, secured additional financial resources, and finalized its PSG curriculum for mothers of color, poor mothers, and single mothers in resource-deficient neighborhoods. If MHM and its PSG was to be a success, framing the curriculum and selecting the location would be critical. The PSG's purpose and its intentions were promoted carefully. The staff crafted fliers and brochures using culturally sensitive language, emphasizing the group's neutral views on mothering practices. All mothers - regardless of racial, ethnic, or cultural background, financial position, or family structure-were welcome to attend the PSG. Lauren strongly believed that MHM was positioned to serve these marginalized communities well:

[C]ulturally speaking, I didn't think [any other potential partners] had the cultural competence or the desire to serve [impoverished communities] and they weren't in a place where they were wanting to tackle that. MHM ... from the very beginning had this sense of wanting to be an outreach source for people who couldn't access those kinds of more affluent services that other people were able to access. It was more intentional in that way.

Additionally, given their own personal experiences with financial and social obstacles, Maria, Tracey, and Lauren felt they provided the community outreach and programming with a level of authenticity and empathy missing from other organizations:

"We were motivated for all personal reasons," Lauren explained, "because ... we may have experienced those hardships...certainly nothing to the extent that many people do in different parts of the community, but that gave us... a little snapshot of this world." Maria agreed with Lauren and expanded upon her position:

It felt like a responsibility, being one of these people who's...had very little resources, but I've always had a safety net and now there's a responsibility to say, 'I can access all this stuff. I know how to speak the 
language to access this stuff.' Even if I don't know how to do something, I can learn how and who to ask that can bring that.

Tracey recognized that despite the women's personal experiences, negotiating the landscape remained tenuous: "I think we've really all been learning as we go on this. So there's a little bit of deliberate action [in MHM's strategy and goals] and there's personal experience and there's also, like, figuring it out as we go, too." Tracey also remained sensitive to the fact that MHM was serving mothers in extreme poverty who regularly faced judgment and criticism for their mothering practices:

I'll be the first to admit that in the beginning, I'm sure there was a little bit of savior complex, of like, 'I'm going to go into these communities and offer these [services]' you know, and it's not [like that]. It's way more complex than that when you get in there and you realize what the barriers are and something they're really practical ones and sometimes they're cultural ones, and all of those take a long time and some creative strategies to help people deal with them. And I realize that we can't fix those things. We can't fix it, but we can help become a bridge for people.

Tracey's sensitivity to the vulnerable position many mothers find themselves in as they struggle to parent with minimal resources is representative of MHM's acknowledgement of their position to provide assistance to racially and economically subjugated populations. Their programming was aimed at ameliorating the lack of social and emotional maternal support, but they recognized that the underlying issues and the effects of extreme social inequalities were significantly more complex than peer-based maternal support could ever address. Part of the intentional steps the founders took in recognizing their own privileged positions in offering such a program to marginalized groups meant accepting their own limitations: the program's contribution would not resolve the effects of social forces on their participants, but it could connect them to 
services, support, and resources that may allay the impact of these forces-however slightly—on their maternal practices.

Despite apparent similarities between participants' and their own personal experiences, MHM's leaders remained mindful of their racial and economic privilege and that participants could encounter significant economic and social obstacles. Maria explained how this process informed MHM's strategic mission and refined its focus on increasing maternal support:

We can be part of a conversation about improving those things [limited access to resources] and we can be the ones to say, 'Hey, this isn't okay.' Because people who are that overwhelmed [the women MHM serves] shouldn't have to say [this]. That burden shouldn't be put on them. It's our responsibility to say, 'Those people are really struggling and suffering.'

Maria and her colleagues actively considered how race, class, and family structure constructed various maternal experiences. Their in-depth discussions probed issues about privilege, co-optation, and cautionary tales of "well-intentioned" materialistic programs that imposed White cultural standards on marginalized populations. Ultimately, they determined that it was not imperative that MHM's participants approached and experienced mothering in ways similar to them. It would be necessary, however, that they align with MHM's vision of external support: a peer-based, mother-centric vehicle for self-care.

To glean from the residents in the program's targeted neighborhoods, Maria, Lauren, and Tracey conducted focus groups and interviews with community leaders and volunteers. Feedback confirmed the need for social services to support mothers, infants, and young children and an overall dearth of social and emotional support for women in the area. Based on participants' comments, MHM devised the PSG model and mode for 
delivery. They chose the inaugural PSG locale for its familiarity as a frequented community center and its proximity to public transportation. They assured mothers that their repeated requests for "support" and "resources" in their community would be heeded through peer-based support proposed by the PSG.

In concept, mothers of color, white mothers, poor mothers, middle-class mothers, single mothers, married mothers, all mothers would unite under a shared mantle of maternal support, regardless of social locations. The PSG would offer a backdrop where mothers mutually guided each other through the social and emotional obstacles of motherhood. Communally, women referred each other to community-based services, listened compassionately, commiserated and offered parenting and self-care advice. This vision steered the PSG gatherings and activities: everything was intended to foster social cohesion amongst the participants.

In reality, this did not transpire as MHM intended. While black mothers would occasionally attend the PSG hosted at Urban Site 1, they seldom became regular participants. The mothers who attended most consistently were on average White and partnered, yet it was rare for participants to return to more than three PSG gatherings. Faced with a new mix of mothers at each meeting, social cohesion and collegiality were difficult to foster. The PSG at Urban Site 2 was the most racially and maritally diverse, but due to its function as a court-ordered substance abuse treatment facility, the program's rigid structure and residents' regular turnover made for inconsistent PSG attendance.

MHM encouraged mother-centric, peer-based, social and emotional support between strangers in socially disorganized neighborhoods. Perhaps MHM's founders 
naively presumed that women's collective status of "mother" would allay incongruities between participants' maternal experiences and needs. Despite exhaustive efforts to understand and acknowledge racial and economic privilege-laden maternal ideologies and practices, the PSG model did not appeal to a diverse audience of mothers based on race, class, and family structure. However, as I show below in outcomes from the evaluative instruments, while the PSG model fell short in reaching women from different social locations than those of the MHM founders (e.g., white, partnered), it was successful in increasing parenting self-confidence, a sense of community, and decreasing the risk of postpartum depression for its participants.

\section{Evaluation Findings}

Difference of means tests from participants' pre- and post-test surveys demonstrated that MHM's programming was effective in addressing its programmatic objectives. Participant observation and extensive field notes provided context to the implementation of the PSG programming and participants' interactions.

Pre- and Post-Tests

Between May and December 2014, I collected pre- and post-test surveys from every participant to measure their self-reported parenting self-confidence (at every meeting), sense of community (at participants' third and sixth meetings), and risk of postpartum depression (at participants' first, third, and sixth meetings). Altogether, I conducted surveys at 20 separate meetings between the four locations: Urban Site 1 (five meetings); Urban Site 2 (five meetings); Urban Site 3 (four meetings); and Rural Site (six 
meetings). Throughout the evaluation period, the PSG program served 80 unique participants. ${ }^{14}$ I collected the baseline and demographic data (see Table 1, page 54) from all participants during their first visit ${ }^{15}$. A limited number of participants attended the necessary number of PSG meetings to collect mid-point (third visit) and end-point (sixth visit) data (sense of community index and risk of postpartum depression measures). Due to the small number of participants who qualified for the third- and sixth-visit surveys, measures of PSG's impact on sense of community and risk of postpartum depression over time lacked statistical significance.

At every meeting, all participants received a customized pre- and post-test to assess their parenting self-confidence regarding that meeting's topic. For example, if "Breastfeeding" was the topic for that week's PSG, the pre- and post-test questionnaire asked mothers to assess their confidence of their own knowledge about breastfeeding and serving as a resource for other mothers regarding breastfeeding (see Table 3, below, for pre-test and post-test means for each of the topics covered by MHM's PSG programming; see Appendix I for surveys). The weekly topic-based pre- and post-tests revealed increases in parenting self-confidence across all topics and all locations. Three topics produced a significant difference between pre-test and post-test means: New Parenting Trends (99\% confidence); Pregnancy Self-Care and Wellness (90\% confidence); and Newborn Care (90\% confidence). The differences in the remaining pretest and post-test means were not statistically significant.

\footnotetext{
${ }^{14}$ Urban Sites 1, 2, and 3 together, $N=59$; Rural Site, $N=21$. Average attendees per meeting $=3$ to 7 .

${ }^{15}$ The overall response rate for all instruments administered was $97 \%$.
} 
Table 3: Pre- and Post-test Mean Difference in Parenting Skills Self-Confidence by Parenting Topic

\begin{tabular}{|c|c|c|c|c|c|c|}
\hline $\begin{array}{c}\text { Topic of } \\
\text { parenting } \\
\text { self-confidence } \\
\text { pre-test/post-test }^{+}\end{array}$ & $\begin{array}{l}\text { Responses; } \\
\text { (degrees of } \\
\text { freedom) }\end{array}$ & $\begin{array}{c}\text { Pre-test } \\
\text { means } \\
(0-5) ; \\
\text { (stand. } \\
\text { dev.) }\end{array}$ & $\begin{array}{c}\text { Post-test } \\
\text { means } \\
(0-5) ; \\
\text { (stand. } \\
\text { dev.) } \\
\end{array}$ & $\begin{array}{l}\text { t statistic; } \\
\text { (t critical) }\end{array}$ & $\begin{array}{l}\text { Change } \\
\text { between } \\
\text { pre- and } \\
\text { post-test }\end{array}$ & $\begin{array}{l}\text { Sites of survey } \\
\text { administered }\end{array}$ \\
\hline Birth Options & $6(10)$ & $\begin{array}{c}3.98 \\
(0.64)\end{array}$ & $\begin{array}{c}4.57 \\
(0.57)\end{array}$ & $\begin{array}{c}-1.71 \\
(1.81)\end{array}$ & .59 & $\begin{array}{l}\text { Urban Site 1; } \\
\text { Rural Site }\end{array}$ \\
\hline $\begin{array}{l}\text { Pregnancy Self- } \\
\text { Care and Wellness }\end{array}$ & $6(10)$ & $\begin{array}{l}4.21 \\
(0.55)\end{array}$ & $\begin{array}{c}4.71 \\
(0.27)\end{array}$ & $\begin{array}{r}-2.00 \\
(1.89)\end{array}$ & $.50 *$ & $\begin{array}{l}\text { Urban Site 1; } \\
\text { Rural Site }\end{array}$ \\
\hline $\begin{array}{l}\text { Navigating } \\
\text { Motherhood }\end{array}$ & $14(22)$ & $\begin{array}{c}3.93 \\
(0.81)\end{array}$ & $\begin{array}{c}4.01 \\
(0.77)\end{array}$ & $\begin{array}{r}-0.25 \\
(1.72)\end{array}$ & .08 & $\begin{array}{l}\text { Urban Site 2; } \\
\text { Urban Site 3; } \\
\text { Rural Site }\end{array}$ \\
\hline $\begin{array}{l}\text { Planning } \\
\text { Postpartum } \\
\text { Support }\end{array}$ & $9(16)$ & $\begin{array}{l}2.95 \\
(1.02)\end{array}$ & $\begin{array}{c}3.71 \\
(1.03)\end{array}$ & $\begin{array}{l}-1.58 \\
(1.75)\end{array}$ & .76 & $\begin{array}{l}\text { Urban Site 2; } \\
\text { Rural Site }\end{array}$ \\
\hline $\begin{array}{l}\text { Labor Comfort } \\
\text { Measures }\end{array}$ & $7(9)$ & $\begin{array}{c}3.67 \\
(0.97)\end{array}$ & $\begin{array}{l}4.09 \\
(0.85)\end{array}$ & $\begin{array}{l}-0.78 \\
(1.83)\end{array}$ & .42 & $\begin{array}{l}\text { Urban Site 1; } \\
\text { Rural Site }\end{array}$ \\
\hline Newborn Care & $27(52)$ & $\begin{array}{c}3.91 \\
(0.76)\end{array}$ & $\begin{array}{c}4.26 \\
(0.73)\end{array}$ & $\begin{array}{l}-1.69 \\
(1.67)\end{array}$ & $.35^{*}$ & $\begin{array}{l}\text { Urban Site 1; } \\
\text { Urban Site 2; } \\
\text { Urban Site } 3 \\
\end{array}$ \\
\hline $\begin{array}{l}\text { New Parenting } \\
\text { Trends }\end{array}$ & $29(56)$ & $\begin{array}{c}3.89 \\
(0.71)\end{array}$ & $\begin{array}{l}4.45 \\
(0.66)\end{array}$ & $\begin{array}{r}-3.12 \\
(1.67)\end{array}$ & $.56^{* * *}$ & $\begin{array}{l}\text { Urban Site 1; } \\
\text { Urban Site 2; } \\
\text { Urban Site 3; } \\
\text { Rural Site }\end{array}$ \\
\hline Breastfeeding & $4(6)$ & $\begin{array}{c}3.75 \\
(0.66)\end{array}$ & $\begin{array}{c}4.11 \\
(0.61)\end{array}$ & $\begin{array}{r}-0.79 \\
(1.94)\end{array}$ & .36 & Urban Site 3 \\
\hline
\end{tabular}

Aggregated difference of means tests were performed on pre-test and post-test measures by site, as well (see Table 4 below). The differences in pre-test and post-test means at Urban Site 1 (95\% confidence); Urban Site 3 (90\% confidence); and Rural Site (99\% confidence) were statistically significant. In sum, the direction of these tests suggest that the PSG program has the potential to increase parenting self-confidence, and to ameliorate the effects of social isolation and risk of postpartum depression, yet this evaluation lacks the statistical power needed to determine these findings conclusively. 
Table 4: Peer-based Support Group Findings by Site

\begin{tabular}{|c|c|c|c|c|c|}
\hline & \multicolumn{4}{|c|}{ Urban Locations } & \multirow{2}{*}{$\begin{array}{l}\text { Rural } \\
\text { Rural } \\
\text { Site }\end{array}$} \\
\hline & $\begin{array}{l}\text { All urban } \\
\text { locations }\end{array}$ & $\begin{array}{l}\text { Urban } \\
\text { Site } 1\end{array}$ & $\begin{array}{l}\text { Urban } \\
\text { Site } 2\end{array}$ & $\begin{array}{l}\text { Urban } \\
\text { Site } 3\end{array}$ & \\
\hline \multicolumn{6}{|c|}{ Parenting Self-Confidence Pre-/Post-tests (aggregate of topic-based surveys) } \\
\hline Responses; (degrees of freedom) & $76(144)^{16}$ & $28(52)$ & $19(35)$ & $13(23)$ & $41(73)$ \\
\hline Pre-test mean $(0$ to 5$)$ & 3.65 & 4.00 & 3.40 & 3.90 & 3.88 \\
\hline Post-test mean $(0$ to 5$)$ & 4.09 & 4.49 & 3.58 & 4.25 & 4.45 \\
\hline t-statistic; (t critical) & $\begin{array}{l}-3.50 \\
(1.66)\end{array}$ & $\begin{array}{l}-2.69 \\
(1.67)\end{array}$ & $\begin{array}{l}-0.63 \\
(1.69)\end{array}$ & $\begin{array}{l}-1.79 \\
(1.71)\end{array}$ & $\begin{array}{l}-3.33 \\
(1.67)\end{array}$ \\
\hline Change between pre-/post-tests & $.44 * * *$ & $.49 * *$ & .18 & $.35^{*}$ & $.57 * * *$ \\
\hline \multirow{2}{*}{\multicolumn{6}{|c|}{$*=p<.10 ; * *=p<.05 ; * * *=p<.01$}} \\
\hline & & & & & \\
\hline $\begin{array}{l}\text { SCI average at first check-in; (sample } \\
\text { size) }\end{array}$ & (7) & $\begin{array}{l}95.85 \% \\
\quad(2)\end{array}$ & $\begin{array}{l}91.67 \% \\
\quad(5)\end{array}$ & --- & $\begin{array}{l}97.62 \% \\
\quad(7)\end{array}$ \\
\hline $\begin{array}{l}\text { SCI average at second check-in; } \\
\text { (sample size) }\end{array}$ & (1) & --- & $\begin{array}{l}91.67 \% \\
(1)\end{array}$ & --- & $\begin{array}{c}100.0 \% ; \\
(1)\end{array}$ \\
\hline $\begin{array}{l}\% \text { change from first to second check- } \\
\text { in; (sample size) }\end{array}$ & --- & --- & $\begin{array}{l}\text { No } \\
\text { change; } \\
\text { (1) }\end{array}$ & --- & $\begin{array}{l}+16.67 \% \\
\quad(1)\end{array}$ \\
\hline \multicolumn{6}{|c|}{ Edinburgh Postpartum Depression Averages } \\
\hline $\begin{array}{l}\text { At-risk scores (13 or greater) at } \\
\text { baseline; (sample size). }\end{array}$ & --- & $\begin{array}{c}7.14 \% \\
(28)\end{array}$ & $\begin{array}{c}40.0 \% \\
(10)\end{array}$ & $\begin{array}{c}0.00 \% \\
(8)\end{array}$ & $\begin{array}{c}4.76 \% \\
(21)\end{array}$ \\
\hline $\begin{array}{l}\text { At-risk scores ( } 13 \text { or greater) at first } \\
\text { check-in; (sample size). }\end{array}$ & --- & $\begin{array}{c}0.00 \% \\
(2)\end{array}$ & $\begin{array}{c}0.00 \% \\
(1)\end{array}$ & --- & $\begin{array}{c}16.67 \% \\
(1)\end{array}$ \\
\hline $\begin{array}{l}\text { At-risk scores (13 or greater) at second } \\
\text { check-in; (sample size). }\end{array}$ & --- & --- & --- & --- & $\begin{array}{l}0.00 \% \\
(2)\end{array}$ \\
\hline $\begin{array}{l}\text { Average percent change from baseline } \\
\text { to first check-in. }\end{array}$ & --- & $\begin{array}{c}+76.19 \% \\
(2)\end{array}$ & $\begin{array}{c}+100.0 \% \\
(1)\end{array}$ & --- & $\begin{array}{l}-27.75 \% \\
(1)\end{array}$ \\
\hline $\begin{array}{l}\text { Average percent change from first to } \\
\text { final check-in. }\end{array}$ & --- & --- & --- & --- & $0.00 \%$ \\
\hline $\begin{array}{l}\text { Average percent change from baseline } \\
\text { to final check-in. }\end{array}$ & --- & --- & --- & --- & $-12.5 \%$ \\
\hline
\end{tabular}

\section{Parenting Skills Self-Confidence}

As I conducted this survey at every PSG meeting for all participants, the topicspecific parenting self-confidence pre- and post-tests provided the most data collected (102 surveys returned over all four sites). Table 3 (page 89) provides an aggregate of percent change between pre- and post-test means by site; Table 4 (page 90) provides the

\footnotetext{
${ }^{16}$ Includes 16 responses from the community baby shower, a one-time program for at-risk mothers in addition to regular PSG programming at Urban Sites 1, 2, and 3.
} 
percent change between pre- and post-test means by topic. All pre- and post-test means revealed increases in parenting self-confidence. I conducted difference of means tests (ttests) on these averages to determine statistical significance of these variations. The most significant changes from pre- to post-test confidence occurred at Urban Site 1 and Rural Site, the two sites with the greatest amount of pre-program planning, collaborative efforts, and consistent programming (May through December and June through November, respectively). These two locations also regularly hosted groups with an average monthly attendance of four to five participants.

The demographics for these two sites were economically similar, but differed in regards to racial diversity ${ }^{17}$. During the initial planning phase with Urban Site 1, MHM worked with racially diverse communities; together, they planned program design, curriculum and topics, and forged solid community connections. For the Rural Site, MHM partnered with existing groups and well-trusted providers serving the targeted populations to create quicker entrée to these communities and to bolster trust and authenticity amongst participants. For example, the Rural Site's county-based health and human services program coordinators from parenting programs (HANDS and WIC) attended every PSG meeting at the rural location. MHM launched the remaining sites (Urban Site 2 and Urban Site 3) without the benefit of pre-planning and established relationships. Programming at Urban Site 2 faced additional obstacles beyond the scope of the PSG's curriculum: Expectant and new mothers were overcoming addiction, separated from their families, and housed in a residential treatment facility. Many faced criminal charges, lost custody of other children to foster care, and lacked basic needs

\footnotetext{
${ }^{17}$ See Table 1, page 54 for participant demographics and Appendix III for a discussion of participant demographics by site.
} 
(housing, income, etc.) beyond the resource referrals and mothering support provided by MHM.

Urban Site 3 was the last program implemented (September) and lacked the time needed to build participant momentum. This population was also the least racially diverse (all white), the most economically stable, and the most educated of the urban PSG sites. Given the success of the PSG programming to Rural Site's all-white population, it is likely that the PSG programming and resource referral was less crucial for Urban Site 3's more affluent and better educated mothers. In fact, it is likely that these mothers had existing parenting resources at their disposal. Thus, the lack of significant increases in parental skills self-confidence suggested that a revised approach and curriculum for more affluent and educated mothers could benefit MHM in the future. Given more time, MHM may have learned the specific support needs of this more privileged group and shifted the curriculum accordingly. Additionally, MHM could establish relationships with local immigrant populations to further its goal of increasing diversity in its PSG program. Connecting with the nearby community center and organizations serving refugee and immigrant mothers in Urban Site 3's ethnically diverse neighborhood could generate an important collaborative relationship.

\section{Sense of Community}

Across all three urban locations and the rural location, every participant reported strong scores on the Sense of Community index $(\mathrm{SCI})^{18}$. Each site with SCI data (Urban Site 1, Urban Site 2, and Rural Site) provided distinctive reasons for less than perfect

\footnotetext{
${ }^{18}$ A limited number of participants qualified for this survey; I cannot generalize the findings with confidence.
} 
indexes, thus reflecting the diverse needs of each group. An attendee from Urban Site 1 reported a lack of influence ('I don't care what my fellow group members think about me"). Rural Site attendees also described a lack of influence ("If there is a problem in this group, the people who participate cannot get it solved") and reinforcement of needs ("The people in this group do not share the same values"). Participants at Urban Site 2 (the residential facility) cited the most diverse challenges to their sense of community in the group: reinforcement of needs ("The people in this group do not share the same values"); influence ("I have no influence over what this group is like"); and membership ("Very few group members know me" and "People in the group generally don't get along with each other"). Despite these comments, Urban Site's SCI score (91.67\%) reflects a strong, supportive sense of community.

MHM's intention was to create a safe, compassionate environment for mothers to share concerns and to offer and receive social and emotional support. Overall, the SCI scores reflect a successful group dynamic at the three locations measured, even though some participants reported feeling a lack of influence or other issues. The sense of community amongst participants was strongest at Rural Site, perhaps reflecting the racial and economic homogeneity of the group. Subsequent data collection at the racially and economically homogeneous Urban Site 3 site may strengthen or refute this claim.

\section{Risk of Postpartum Depression}

The PSG programming's effect on participants' risk of postpartum depression as measured by Edinburgh Postpartum Depression Scale (EPDS) scores was inconclusive. While baseline EPDS scores were recorded for all participants, a limited number of participants met the attendance criteria (three monthly meetings and six monthly 
meetings) to complete the subsequent surveys. Thus, due to the small sample sizes, the EPDS did not provide significant outcomes. Despite lacking statistical significance, attendees' scores may offer anecdotal feedback about their maternal well-being and their participation with MHM's PSG program. The lack of overall improvement between baseline and subsequent scores at Urban Site 1 and Urban Site 2 reflects 1) the inconsistent attendance for Urban Site 1 (which resulted in a small number of participants taking the EPDS survey), and 2) residents of Urban Site 2 (who completed the greatest number of surveys) faced multiple challenges in addition to maternal struggles (e.g., addiction recovery, custody issues, adjusting to newborns in a group housing environment, etc.). I expected Urban Site 2's participants to be both the most at-risk for postpartum depression (PPD) and facing the greatest number of challenges that may contribute to an increasing prevalence of PPD.

Most helpful, however, may be the initial measure of participants at-risk for PPD collected at the baseline. The percentage of participants by site at risk for PPD as measured by their first visit scores on the EPDS ranged from $0.0 \%$ (Urban Site 3 ) to $40.0 \%$ (Urban Site 2). Nationally, an estimated 10-20\% of new mothers experience PPD (Mental Health America). Comparatively, the populations at three sites-Urban Site 1 (7.14\%), Urban Site $3(0.00 \%)$, and Rural Site (4.76\%)—reported PPD at-risk scores lower than this national average; cumulatively, only $12.5 \%$ of all urban sites' participants measured at-risk of PPD.

As previously mentioned, Urban Site 2's higher than average at-risk population $(40.0 \%)$ is likely indicative of its participants' combined obstacles, including racial, economic, marital, educational disadvantages amplified by homelessness, addiction, and 
physical and mental health challenges. Removing Urban Site 2's participants from the overall measure decreased the percentage of new mothers at-risk of PPD in this study (scores of 13 or higher on the EPDS) to $6.0 \%$, substantially lower than the national average. More consistent attendance would have generated more 3rd- and 6th-visit EPDS measures for mothers across all locations. Additional evidence is needed to determine the relationship between participation in MHM's PSG program and the risk of PPD.

Survey findings indicate that some programmatic elements accomplished the desired outcomes; others were inconclusive due to the limited number of participants. Attendees' demographic data demonstrated that MHM and the PSG did not recruit and retain the racially and maritally diverse populations it envisioned: participants were overwhelmingly white and partnered. The PSG was successful in engaging lower-income mothers ${ }^{19}$. Findings from participant observation provide insight into MHM's disconnect with its targeted populations; the remaining findings discussed herein are based upon these observations.

\section{Participant Observation Findings}

While the pre- and post-test surveys provided measurable outcomes for this study, the bulk of the evaluation's findings and recommendations for MHM and its PSG programming came from participant observation at the three urban sites and the one rural site. From these observations, I recorded field notes and analyzed them using grounded theory (Charmaz 2000). Together with the evaluative instruments, these data were sufficient to generate findings and recommendations for MHM and its PSG. Overall, the

\footnotetext{
${ }^{19}$ Refer to Chapter III for a comprehensive demographic table of PSG participants.
} 
findings attest to the PSG program's potential for serving racially homogeneous populations, and reveal its challenges in serving racially diverse participants.

Between May and December 2014, I conducted 54 hours of participant observation at MHM's regular PSG meetings between Urban Site 1; Urban Site 2; Urban Site 3; and Rural Site. These findings center on two interdependent themes. First, a "simple" mothering ${ }^{20}$ ideology permeated the course curriculum, while the populations targeted by the PSG program represented diverse maternal ideologies. Many practitioners of this maternal ideology (informed by cultural feminism) benefit from economic and marital privilege (Bobel 2002). To that end, MHM's staff's economic and marital privilege - vis-a-vis its practice and promotion of "simple" mothering — remained embedded in its program's material and delivery. Second, I argue that the meaning of "support" is subjective. MHM's promotion of peer-based, mother-centric support was likely shaped by its staff's "simple" mothering ideology; this interpretation of support was incompatible with MHM's targeted populations' interpretations of support.

These findings are intended to extend the discussion of how to better facilitate peer-based maternal support among diverse groups of mothers. The time and insight invested by Maria, Lauren, and Tracey and the many community and financial supporters have been a testament to the tremendous need for more maternal services developed and administered at the grassroots, community level. Prior to launching this program, MHM's staff members coordinated outreach efforts for other maternal programming using a grassroots model for community building. Its leaders also knew through previous work and participant feedback that peer-based maternal support was in demand; the PSG

\footnotetext{
${ }^{20}$ This is referred to as "natural" mothering in Bobel's (2002) work. While there may be nuanced distinctions between "simple" and "natural" mothering in ideology and practice, the terms are used interchangeably in my study.
} 
program would introduce this model of support, implement it, and follow a process to generate peer-based maternal support networks. The organizers found that rapid expansion of the PSG to additional and unplanned sites (specifically Urban Site 2 and Urban Site 3) strained their finite resources and decreased their efficacy in constructing peer support to new and diverse communities. The struggle to attract and retain a core group of participants at all three urban locations plagued the PSG through the evaluation time period. The overwhelming exception was the rural location's PSG. Rural Site's human services providers' willingness to collaborate with MHM salvaged its expansion efforts and yielded a consistent group of PSG attendees (young, low-income, partnered mothers either pregnant or new mothers with newborn- to toddler-aged children). Through Rural Site's regular gatherings and constant promotion by local practitioners, mothers constructed the mutual support system lauded by MHM and its PSG, and forged peer-based relationships that have lasted long beyond the program's end.

\section{Maternal Ideology}

MHM's founders trust that women innately possess the wisdom and skills needed to mother. PSG programming encouraged women to connect to this "naturally divined knowledge" to parent their child(ren) instinctually. This ethos and its organic approach to parenting contradicts mainstream, commercial culture by eschewing consumerism, capitalism, and technology (e.g., Bobel 2002; Bobel 2007). Aspects of this ideology are rooted in cultural feminist literature and, though not consciously, this perspective guides MHM's PSG model and curriculum by framing women as natural caretakers and empowering women through their maternal roles. The PSG's meetings are intentionally 
group-directed and egalitarian and focused on empowering participants by utilizing attendee feedback to shape the group's culture. Despite this communal approach, the PSG's attendance, engagement, and efficacy varied by location.

Three PSG gathering topics - baby-wearing, cloth diapering, and delaying solid foods - illustrate the mothering ideology shaping MHM's cultural milieu. First, an activity steeped in MHM's staff philosophical bias was also one of its most successful activities for the predominantly white locations (Urban Site 1 and Rural Site): MHM's staff introduced participants to baby-wearing. Baby-wearing - a tenet of attachment mothering — dovetails with simple mothering. Many mothers responded enthusiastically, calling the demonstration "an amazing experience" and praising the new-found ability to be hands-free and to keep their babies close to them. Mothers could now meet their baby's needs and care for themselves.

In addition to instruction, MHM provided free baby-carriers (wraps) for participants. This generous gift (retailing for $\$ 40$ or more) thrilled many mothers. Those attendees for whom baby-wearing did not resonate accepted the gifted wraps, as well, and planned to resell the wraps online for cash. Overall, MHM cited the baby-wearing gathering as one if its most successful in meeting its goal of helping mothers gain confidence in their parenting skills, an essential element of this program. More importantly, MHM saw PSG participants discover that they could be good mothers despite the day-to-day challenges and unrelenting stresses of motherhood. Mothers' engagement revealed the safety they felt in the PSG to be vulnerable and secure in their mothering abilities. 
Next, MHM staff provided PSG attendees with cost-saving information about cloth diapering. A box of disposable diapers—retailing for \$25—was displayed next to the same size box filled with $\$ 25$-worth of cloth diapers. For the same financial investment, mothers could procure a permanent supply of cloth diapers and avoid replenishing their diaper supply regularly. Framing cloth diapering as an economic benefit was laudable and avoided the potentially elitist attitude embedded in an environmental benefit. What MHM's staff failed to include in its demonstration was the additional labor and costs of laundering cloth diapers and the lack of access to homebased laundering facilities. For mothers already strapped for time and relying on coinbased laundry, the additional price and inconvenience of regular - if not dailylaundering with cloth diapers rendered the option unattainable. In the end, MHM recognized its participants' unrelenting demand for disposable diapers (a necessity not covered by "food stamps" or WIC); they ended each PSG gathering by giving away packets disposable diapers.

Finally, the PSG practices for infant and toddler feeding were strongly influenced by simple mothering creed, as well. The gatherings discussing these topics promoted breast-feeding and delaying solid foods for older babies. The mantra, "Food before one (year of age) is just for fun!" reminded mothers that the breast is truly best for children, well into toddlerhood. While this ethos may be scientifically accurate, it ignored incomebased obstacles to breast-feeding (e.g., Avishai 2007) and postponing solid foods for toddlers. Beyond physical challenges some mothers face when nursing, inflexible work environments and schedules prohibit breaks for pumping and storing breast milk, an essential function to maintain supply while unable to nurse. Infant formula, a costly 
alternative to breast-feeding, is more expensive than basic solid foods (e.g., cheese, eggs, fruit) for older babies and toddlers. MHM's failure to recognize the financial implications and economic privilege of delaying solid foods may have alienated mothers lacking resources to adhere to this advice.

At Urban Site 2, mothers faced an additional and seemingly insurmountable obstacle to breast-feeding. The facility's residents were court-ordered to participate in programming about substance abuse and addiction. The managing organization followed a regimented curriculum and schedule to fulfill this mandate, while mothers adhered to strict attendance guidelines with limited flexibility for maternal obligations and needs. Residents were excused from attending meetings for birth and hospital stays, for example, but other absences jeopardized mothers' completion of the program. After delivery, mothers were prohibited from bringing their babies to classes; the structured schedule did not include long enough breaks to nurse or pump breast milk during its limited breaks.

MHM made repeated requests to the program director to extend break times during the day to support nursing mothers. The PSG program — something that the facility's director and staff outwardly supported — and MHM's involvement with Urban Site 2 and its residents appeared on the surface to be a collaborative partnership. Culturally, however, the facility's leadership's discomfort with breastfeeding translated into minimal support for its nursing residents. Conflicting messaging from the facility's staff ("Breastfeeding is good for your baby! Here's some free formula for when you're ready to quit nursing.") directly opposed the programming and encouragement MHM offered to its PSG participants. The tension between MHM's pro-breastfeeding rhetoric, 
staff's (and participants') cultural norms, programmatic messaging and practices, and an overall lack of institutional support resulted in an environment that was unsupportive to nursing mothers.

MHM and the PSG incorporated specific language throughout the programming to encourage and support mothers. Messages emphasized the mothers' collective and innate knowledge and skills of mothering, urging women to trust themselves to intuitively handle the most daunting parenting challenges. "You've got this!" is the sympathetic and reassuring mantra inspiring all mothers to tap into their natural ability to tackle structural forces hindering their attempts to balance competing demands. Yet this seemingly innocuous, if not endearing cheer masks conflicting messages and may be doing more harm than good for some participants. First, the language used positions mothers as experts. It suggests that they already possess the resources and comprehension needed to be "good" mothers, thus negating the purpose of the PSG's topic-based classes. Instead, the classes situate the organization's leaders as the authorities of this intrinsic ability tasked with the responsibility of "teaching" others how to access already existing traits.

This may imply that this instinctive approach to "good" mothering only works for the mothers who grasp it, excluding mothers for whom this does not translate. Promoting a maternal ideology aligned with white, economically privileged mothers is likely to alienate mothers of color and lower-income mothers. MHM's messaging and approach to "good" mothering risks not translating to the very mothers they sought to include. Other simple mothering practices, such as exclusively breastfeeding and attachment parenting, can be very difficult to maintain in the face of rigid and unpredictable work schedules, 
unpaid time off, and a lack of options for pumping breast milk (e.g., Avishai 2007). Thus, the "You've got this!" mantra may actually alienate mothers who try to succeed in these practices but face cultural, social, and structural impediments.

MHM's powerful pro-mothering ideology and language risk misinterpretation as denying institutional and structural culpability. This framing places the onus on mothers to establish support and resources for each other, instead of institutions (e.g., the workforce, education, health care, etc.) taking responsibility to provide these services or to amend policies in response to mothers' needs. When combined with messages that mothers have always harbored all of the information and expertise needed to be good mothers, the message becomes: If you are failing as a mother, you have no one but yourself to blame.

To address this potential issue, organizations like MHM might expand the messaging to incorporate options for those who may be struggling: "You've got this! And if you don't feel like you do, come talk to us so we can support each other," may leave the door open for apprehensive mothers. Sharing personal stories of mothering struggles might position the facilitators as peers-relatable mothers, not experts who might judge mothers who may be hesitant to ask for help. Again, this would reposition MHM as a neutral source of support and resources and remove the potentially presumptive messaging that mothering is innate and intuitive - a concept with which some mothers may struggle. 


\section{Cultural Competency}

Organizations working to achieve cultural competency incorporate two distinct practices. First, cultural competency requires recognizing differences (e.g., racial/ethnic, economic, marital, sexual, linguistic) between oneself as a practitioner or researcher and the group or groups being served through outreach or collaboration (e.g., Williams and Graham 2016). Second, culturally competent organizations implement these services specifically to address power imbalances between parties; thus, organizations avoid replicating inequalities based on differences (e.g., Hatchett and Duran 2002). In social work, public health, and community building, cultural competency has been shown to empower marginalized populations, strengthen collaborative efforts, and to affect positive community change (Hatchett and Duran 2002; Williams and Graham 2016). In social science research, cultural competency creates the potential for cooperative interdisciplinary research (Reich and Reich 2006). A lack of cultural competency can reinforce cultural and social barriers, reproduce ethnocentric views, and result in “othering" of subjugated populations (Williams and Graham 2016; Hatchett and Duran 2002).

MHM's staff worked diligently to create a culturally competent organization by acknowledging its own racial, economic, and marital privileges. By incorporating voices from other groups and critiquing their own practices, programming, and curriculum, they strived to remove cultural biases based on these privileges. In doing so, MHM hoped its PSG would resonate with black mothers and single mothers, and complement the white, partnered mothers being served through MV and its programs. The fact that MHM's staff openly wrestled with their own social locations and positions of power is evidence of 
their strong commitment to cultural competency. In the end, however, elements of privilege and bias remained embedded in the PSG programming.

Despite MHM's inability to connect with participants of color at the level it desired, the PSG participants were still more likely to be living in poverty, to be women of color, and to be unmarried parents than the state's population, at large. They had limited social service resources, including health care, education, childcare, employments, and less tangible resources like community support and cultural capital. MHM did attract attendees at an increased risk for social isolation, post-partum depression, and limited maternal support.

Participants' race/ethnicity was the most notable variation between the PSG's three urban sites and one rural site and MHM's targeted demographic. The program was developed to reach mothers of color, and especially single mothers and mothers with few financial resources. The PSG was designed for candid dialogue, relationship building, and emotional sharing in a relaxed, non-confrontational environment. MHM's strongest attendance and participation, however, was with the Rural Site and its all-white, lowincome, partnered mothers. These white mothers demonstrated comfort with the open, communal setting quickly. Participants' willingness to share deeply emotional details was often surprising, but a testament to the safety and trust built within the peer-group. In one activity, mothers were given cards resembling baggage tags. On one tag they wrote things or ideas to "pack in their suitcase"-items to take with them on their parenting journey; on the other tag, they wrote ideas and experiences to release and leave behind. Mothers openly shared details about their joys and struggles, illustrating courage to share intimate details of their lives with women who had been strangers not long before. To make this 
exercise a success, mothers had to feel safe, heard, and supported to do this-a demonstration of MHM's leaders' ability to create such an atmosphere.

Another gathering at the Rural Site evolved into a discussion about obstacles to maternal support. Several participants disclosed that one or more parents or other close family members were emotionally or physically absent, weakening mothers' sources of support. As they talked, the women learned that several of them had loved ones in prison and/or were struggling with drug addiction. Participants spoke freely about the challenges these scenarios presented and processed the loss of loved ones when familial support was so needed. The mothers acknowledged that the PSG provided a new source of support to strengthen their fragile networks.

The white, lower-income participants at Urban Site 1 also tapped into their newly constructed peer-based support, yet not as consistently as the Rural Site's participants. In one gathering, attendees recounted traumatic births, especially those that resulted in unplanned caesarean sections and disrespectful treatment by medical professionals. Mothers used the PSG setting to heal from these difficult experiences and to learn ways of avoiding similar experiences in the future. The smaller, predominately black participants at Urban Site 2 also held intimate connections with each other; these established relationships were primarily due to the residential format of their treatment facility. Building from this familiarity, MHM continued to foster and encourage authentic conversations and supportive responses between peers.

Revisiting the problematic construction of "good mothering" is necessary to address MHM's issues of cultural competency within its PSG programming and execution. The mothering literature (see Chapter II) cites variations in practices and 
perceptions of mothering by mothers' social locations. Mothers' narratives add complexity and depth regarding these variations in Chapter V, demonstrating how standards of "good mothering" differ significantly based on race, income, family structure, and other factors. Practicing cultural competency requires MHM to assess these differences — and how they can reproduce power and inequality—at every level of the PSG programming. Scale (e.g., one-on-one interaction, group dynamics, etc.), delivery (e.g., positioning MHM as the "authority" vs. participants positioned as experts of their own experiences), and content (e.g., cloth diapering, extended breastfeeding) must be regularly examined and re-examined—by MHM's staff, its attendees, external community members - to avoid shifting the PSG programming from a tool of empowerment to one of subjugation. Instead, MHM's transmission of the principles of simple or natural mothering through its PSG curriculum reinforced a cultural divide between MHM and its participants.

Translating mothering practices in the curriculum across race, income, and relationship status created challenges for MHM. These cultural divides hindered MHM's ability to initially attract women of color to the meetings and to connect with them in a way that encouraged them to return. Despite efforts to the contrary, MHM's leaders' greatest trial was detaching their privilege from their promoted mothering practices; framing cloth diapering as a cost-saving measure, for example, was one notable example of this. Forgetting that many mothers in poverty depend on public, coin-operated laundry facilities and other inconvenient methods of tending to soiled diapers reinstated the disconnect between them and their intended community. Reframing parenting themes, acknowledging cultural practices, and adapting the PSG material to reflect MHM's 
sensitivity to these differences in defining "good" mothering would remove some hurdles to connecting with participants.

Because mothering practices vary across populations, it is dangerous to represent mothering with a single perspective. The literature demonstrates the importance of expanding the definition of "good mothering" to reflect the myriad perspectives and experiences within the institution of motherhood. While this intersectionality perspective initially complicates the understanding of "good mothering" by including multiple axes of inequality, this inclusive perspective ultimately strengthens the communities served by shifting from a singular white, middle-class, married focus to encompass all mothers. Validating and welcoming all mothers amplifies voices and builds a more powerful collective, providing greater support and access to needed resources.

To this end, applying similar programming, information, and resources to every site was not universally accepted. The mothers at Urban Site 2, for example, were the most resistant to the messages supporting and encouraging less familiar maternal practices. MHM's approach—couching the use of cloth diapers as an economically sensitive approach to a very real obstacle facing poor mothers - was met with snickers by some, and apathy by others. Breast-feeding also posed additional challenges for this population of single mothers. As a residential facility, Urban Site 2 required the mothers lived in small, dorm-like apartments with their newborns; they were on their own to respond to their newborn's every need. When nursing posed challenges, as it often does, the isolation of solo parenting exacerbated already emotionally raw and frustrated mothers. The rigidity of the recovery programming, as well, compounded the likelihood that breastfeeding was difficult to sustain. Required attendance — without babies — by all 
residents at structured, daylong meetings and programming, meant no breaks for nursing or pumping, even when infants were less than a few weeks old. This lack of support by the residential programming staff sent conflicting messages to MHM's pro-nursing encouragement.

To assuage this cultural incompatibility, MHM could present topic-based classes with several avenues for implementation, weighing the pros and cons of each option, and asking participants to provide their experiences with various methods. For example, on the topic of transporting infants they would discuss widely known methods (e.g., strollers, car seats) and lesser-known options (e.g., slings, wraps). For each option, prices range and usages vary. Incorporating feedback at different price points (e.g., a $\$ 600$ stroller compared to a $\$ 50$ model) removes the top-down decision-making that purports the value of certain options over others for certain populations. Additionally, this approach encourages peer-to-peer sharing, and repositions MHM as a neutral venue for mothering resources and facilitator for peer support.

MHM's staff recognized that mothers sought information to feel supported, and not for the sake of having more details. Mothers with one or more children (the average for participants who were not first time mothers was three children) demonstrated this in their skepticism toward the advice format prevalent in other parenting and birth workshops. Instead, they wanted validation for and reinforcement of their parenting skills and practices, and resources to supplement them. For these mothers, the intimate, experiential learning opportunities offered by the PSG allowed them to share experiences and perspectives, and to discuss alternative practices, allowing mothers to consider new ideas safely. 
The PSG program model—a mix of instructor-led classes and peer-based support-appears to decrease social isolation and maternal stress for its participants. But a formulaic approach to helping mothers will not work. Instead, tailoring the curriculum and programming to site-specific needs led to a more organic, peer-based format that encouraged participants to lead and discuss concerns and conveyed the message of support for all mothers, not only those aligned with MHM's mothering ethos. Overall, the PSG groups maintained balance between being informative and overly didactic or paternalistic.

\section{Discussion}

This evaluation served two purposes. First, I provided a comprehensive assessment of Mothers Helping Mothers' Peer-based Support Group as a mechanism for increasing mothers' self-confidence in parenting skills and sense of community and decreasing mothers' risk of postpartum depression. Second, I offered an intersectional examination of MHM's efforts to expand maternal support to resource-deficient neighborhoods and racially- and economically-underserved populations. This report extends the sociological literatures on motherhood by showing how maternal ideology (i.e., simple mothering) overshadowed deliberate steps to assuage racial, economic, and marital privilege.

MHM's PSG program provided real benefits for its participants, especially for those who mirrored MHM's staff members (white and partnered mothers). Parenting selfconfidence increased for all participants. The PSG's regular attendees reported a strong sense of community within the program. The majority of its participants were lower- 
income, and MHM referred many mothers to community resources offering additional support. MHM's inability to form peer-based support systems within racially marginalized communities, however, suggests a cultural disconnect between the MHM's and its participants' mothering ideologies. Bobel's (2002) research on natural/simple mothering highlighted mothers' economic and marital privilege as essential elements of their maternal practices. Unlike the simple mothers in Bobel's study (2002), MHM's founders possessed an acute awareness about their own economic and racial privileges. Even though MHM's founders worked to acknowledge their individually privileged positions, simple mothering — as an ideology and practice-requires racial, economic, and marital privilege. Ultimately, MHM's staff's own maternal ideology—one that was inherently biased toward economically, racially, and maritally privileged womenimpeded its ability to connect with racially and maritally diverse participants.

These findings and their implications can benefit other mothering groups, especially those for whom cultural feminism informs maternal ideology. Within closed maternal support communities, mothers' acknowledgement of their own privileged locations and the ways these positions guide their maternal practices strengthen individual and collective cultural competency regarding maternal experiences. For maternal support groups working to connect with racially, economically, and maritally diverse mothers (like MHM), this practice is imperative to fostering connections with new communities and validating various maternal practices, ideologies, and ways of support. Taking these steps not only acknowledges the ways in which social hierarchies are reproduced through social interaction and maternal practices, it can ameliorate cultural feminist-informed mothering's alienating effects on black mothers and lower- 
income mothers. Since this evaluation, MHM has learned the importance of working collaboratively with mothers from diverse backgrounds, actively listening to participants and incorporating feedback into a compromised approach. Recognizing one's individual influence in reinforcing or dismantling these power-based structures is one way to recognize cultural feminist-informed mothering; collectively, cultural feminism can be reformed, becoming a more inclusive maternal ideology and welcoming practice.

\section{Challenging the Institution of Motherhood:}

Framing and maternal ideology

Race, class, and family structure—as relations of power within society—can and do alter mothers' individual and collective experiences significantly. Defining a collective starting point for macro-level change, outlining a shared strategy, and agreeing upon a mutual goal all become problematic. MHM's leaders shared similar experiencespoverty, single motherhood, postpartum isolation and depression - with many of the participants they sought to engage, lending authenticity and empathy to the struggles facing many mothers. As white, married, middle-class women, MHM's founders' privilege and power masked the transferability of their personal experiences, impeding connections to the very women they sought to engage. If MHM's staff were perceived to be irrelevant to single mothers, lower-income mothers, and black mothers, the PSG programming's deliberate emphasis on inclusivity failed.

MHM's macro-level goal to expand support for "all mothers"- of all races, classes, and family structures - was incompatible with its micro-level programming's "simple mothering" curriculum that required economic and marital privilege to accomplish. Ignoring this incongruity may have fractured MHM's potential support. By 
attempting to speak to "all mothers," MHM may have unintentionally assumed the position of speaking for "all mothers." Thus, the organization encountered similar challenges as white, middle-class groups in the women's movement of the 1960s and 1970s: the presumptions that a shared status (woman) would trump women's other statuses (e.g., Black, poor, lesbian, single) and forge a cohesive bond. Applying a systems-focused intersectional approach (Choo and Ferree 2010) helps to understand these obstacles: the power embedded in institutional and structural forces shapes groups' experiences and perceptions. Racial, economic, and marital statuses construct various forms of privilege and oppression that create potential barriers for social cohesion, even between mothers. These forces interfere with the formation of a collective mothering identity and pose challenges for efforts to expand maternal support to all mothers.

How MHM framed its micro-level goal (to empower individual mothers) and its macro-level goal (to broaden the societal standard of good mothering and expand maternal support), might have been incompatible, as well. Promoting the tenets of simple mothering in the PSG programming was intended to empower individual mothers and to encourage individual participants to tap into their innate, intuitive maternal consciousness. Thus, MHM's micro-level messaging revered the instinctual aspects of individual mothers. The macro-level messaging recast good mothering as a communal activity (not a socially isolated one) by expanding peer-based maternal support, also suggesting a shared perspective of mothering among its participants. While it may not have been imperative for participants to share identical experiences and approaches to the act of mothering (micro-level), challenging the institution of motherhood (macro-level) required MHM and its participants to work collectively to align strategies and goals. 
These efforts to alter the institutional forces shaping motherhood are illuminated by a systems-centric approach to intersectionality (Choo and Ferree 2010). Working to address the structural forces in which power is embedded — and the disparate ways these forces affect groups of various statuses of privilege and marginalization—offers a vehicle for collective action.

Future research is necessary to understand if and how MHM's work—along with other grassroots efforts - constitutes a social movement to reshape maternal standards culturally. Where does power reside within the institution of motherhood? How do these groups define the culture that is being challenged? I propose using the multi-institutional politics (MIP) approach (Armstrong and Bernstein 2008) to examine MHM (and other organizations) to examine groups' efforts as social movement organizations (SMO) and vehicles for cultural changes in mothering and maternal support. Doing so would provide context for MHM's approach to extending maternal support to less-resourced populations as action for social change. Through the acts of offering support in communities often lacking resources (MHM) and of procuring this support (MHM's participants), the existing structures and institutions of power are exposed. Despite work to remove these obstacles to support, however, MHM's challenges demonstrate the depth to which structural and institutional power are embedded and influencing groups of marginalized statuses (Choo and Ferree 2010). The MIP approach helps to explain how MHM's efforts - as a social movement organization (SMO) — to target other institutions of power (e.g., family, education, community, gender) can be understood as a social movement (Armstrong and Bernstein 2008); as a result, the SMO literature, specifically the framing literature (e.g., Snow, Rochford, Worden, and Benford 1986; Snow and Benford 1988; 
Snow and Benford 1992; Johnston 1995) provides context and resources to increase MHM's efficacy in expanding maternal support.

The remainder of this study incorporates findings from in-depth interviews with mothers to learn how women talk about good mothering and maternal support, and why MHM fell short in engaging mothers of color and single mothers in their peer-based support. Mothers' narratives reveal interpretations that vary significantly by race, income, and family structure, and reinforce why MHM's extensive planning and efforts did not succeed in serving the women they intended to help. Chapter V explores how mothers define and talk about good mothering. Their narratives demonstrate the various interpretations and maternal practices, emphasizing self-sacrifice and self-care. Then, Chapter VI considers mothers' various perceptions of maternal support and how support aligns with their maternal practices and perceptions of good mothering. Mothers' narratives provide deeper insight into why some mothers employ maternal support, why some mothers avoid it, and how they make sense of these differences. Considering these narratives comprehensively, along with the findings from this program evaluation, I offer another way to understand MHM's limitations in attracting mothers of color as participants in the PSG programming: mothers — especially mothers of color-hold distinct interpretations of maternal support. 


\section{CHAPTER V: WHAT IS GOOD MOTHERING?}

To better understand why Mothers Helping Mothers' (MHM) peer-based support group (PSG) programming failed to attract a significant number of participants of color and single mothers, I conducted 41 in-depth interviews with a racially, economically, and maritally diverse group of mothers. I explored how women talk about good mothering, how these views shape their maternal practices and use of maternal support (see Chapter VI), and why they may be incompatible with the maternal support offered by MHM's programming (see Table 1—Participant Demographics, page 54.)

In this chapter, I focus on good mothering. I explore how mothers construct scripts of good mothering, and how these narratives vary by race, class, and family structure. ${ }^{21}$ These interpretations provide additional insight into why MHM's PSG programming resonated less with black mothers and single mothers: black mothers, lower-income mothers, and single mothers in this study aligned good mothering practices with self-sacrifice; white mothers, more affluent mothers, and partnered mothers in this study were more likely to balance self-sacrifice with self-care. If MHM's PSG programming is perceived as a means of self-care, it lacks relevance with mothers who equate good mothering with self-sacrifice.

\footnotetext{
${ }^{21}$ Because family structure is so strongly reflected in economic class - single mothers were more likely to be less economically secure than their married peers - these two social locations were intertwined and difficult to tease out clearly for analysis.
} 


\section{Perceptions of Good Mothering}

Interpretations of intensive mothering ideology (Hays 1996) inform maternal practices and are influenced by race, class, and family structure. Each maternal practice (e.g., concerted cultivation; simple mothering; being there) informs its own standard of good mothering. Regardless of maternal practice, however, the standards of good mothering are pervasive in our society (Hays 1996). In fact, every woman in my study recited what was expected of her as a mother, her mothering abilities, and her maternal practices, whether she adhered to these external standards or not. ${ }^{22}$ How mothers made sense of social standards of good mothering was laden with discussions of self-sacrifice and self-care. For many, declarations of self-sacrifice were reflexive; those who equated good mothering with self-sacrifice did so emphatically. Mothers' dialogues about selfcare, however, were less concrete and vacillated between something they "knew" they "should" do, but might not.

Every participant discussed self-sacrifice as an essential component of good mothering; distinctions followed two primary patterns: good mothers sacrifice themselves; or good mothers also practice self-care to accomplish good mothering. While some mothers made provisions to exercise both self-sacrifice and self-care, most mothers talked about self-care and self-sacrifice as mutually exclusive elements of good mothering. Mothers' narratives of self-care and self-sacrifice, and their adherence to one or both practices varied by income, marital status (especially between single and partnered mothers), and employment status.

\footnotetext{
${ }^{22}$ It is possible, too, that this inescapable rhetoric may have influenced participants' responses. If one believes that the good mother deems self-care and maternal support to be indications of maternal shortcomings, her personal account may downplay her use of non-familial resources in order to maintain an outward appearance of good mothering.
} 


\section{Affluent, Partnered, Black mothers:}

Concerted cultivation

Libby (a 38-year-old, black, upper-income, married mother of two daughters) used maternal rhetoric that mirrored the women in Lareau's (2003) study of mothers practicing concerted cultivation. Good mothering was an intensive, all-consuming venture, focused on investing resources and time to identify and nurture children's unique talents: "I strongly support [my daughters] to be what they want to be and the dreams that they have for themselves." To achieve this, she encouraged her daughters to explore any and all extracurricular activities that interest them. To Libby, her daughters were destined to be successful, and her mothering suggested this: "I want [my daughters] to be exposed to a number of things because you don't know what they might be good at if you don't expose them to that. 'Let's do this, let's do that, let's see what it is that you can excel at because I want you to excel."” Her children's cultural capital linked them to social networks and lucrative connections to advance their educational and employment goals.

The concerted cultivation approach to mothering also resonated with Lisa, a 45year-old, married, upper-class, black mother with two daughters. She associated concerted cultivation to her good mothering objectives: "I'm aspiring to be the mom who is available, who encourages exploration, who mentors [her daughters] through their journey.... [to be] comfortable to beat their own drum and lov[e] the music that they create.... I very much try and allow them to be who they are." At the same time, Lisa coached her daughters to consider the practical implications of their interests and passions:

I do my best to try and find what their personality is, and really grow that...Even having conversations like, "[My oldest is] into art," so in longterm what does that look like? Let's talk about what careers that parlays 
into. "I want to be an artist." I go, “...In the meantime, how are you going to earn money? Do you want to be an art teacher? Do you want to run an art gallery? Do you want to curate a museum? What kind of job with income does that look like to you?"

Lisa's maternal responsibilities included cheerleader and career advisor: she wanted her daughters to know they can be anything, and she will coach them to achieve their aspirations. Her class privilege granted her the resources to introduce her children to various interests, and the network to connect them to opportunities; her marital privilege afforded her the time to devote to these undertakings.

Brenda, a 44-year-old, married, upper-income, black mother with a nine-year-old daughter, practiced concerted cultivation like the other affluent black mothers. Unlike the other affluent black mothers in this study, however, she worked full-time as a high-level project manager at a corporation in addition to maintaining a frenetic schedule to keep up with her daughter's extensive array of extracurricular activities. Brenda's view of good mothering was intrinsically tied to this practice: "I don't think we're raising children; I feel like [good mothers] help raise the adults that they will be. That gives them the building blocks to become the person that they want to be." Brenda's interactions with her daughter were opportunities for cultivation, as well. She taught her to construct persuasive arguments and to negotiate, skills that she believed would advance her daughter's social development: "I want [my daughter] to be independent and strong and feel as though she can speak her mind and say her piece." She knew that these various activities would increase her daughter's "future options" and provide her with prospects that she never had growing up in poverty. Brenda also knew that these "opportunities" could be converted into financial and familial stability for her daughter and protect her from the same challenges Brenda faced growing up poor. 
As black mothers with significant financial resources and familial stability, concerted cultivation (Lareau 2003) appealed to Libby, Lisa, and Brenda as an achievable and desirable intensive mothering (Hays 1996) practice. They willingly accepted the allconsuming nature of this devoted practice and personal sacrifices they made for the tangible returns on their time- and resource-based investments: like the higher-income black mothers in Lareau's (2003) study, they strategically incorporated resources, programming, and social networks to increase their children's cultural capital, positioning them for academic and professional success.

Lower-Middle Class, Partnered, Stay-at-Home Mothers:

Being there and simple mothering

Yvonne (a 28-year-old, partnered, lower-middle-income, black mother raising six children) has amended standards of good mothering to reflect her economic status. Instead of enrolling her children into private sports clubs and social organizations, Yvonne identified attentiveness as a priority for good mothering: “I really can't explain it. You just do what you have to do. Whenever [her infant daughter] calls, you just run. That's what I do...you have to go." In addition to meeting her children's basic needs, she catered her expectations to their individual abilities: "I have to make sure they stay healthy. Make sure they stay busy. Make sure their grades are good....Everybody has their own [expectations], and they understand it." Because of limited financial and social resources, Yvonne's maternal practice was more aligned with "being there," the practice associated with the lower-income mothers in Edin and Kefalas' study (2005).

Unlike Libby, Lisa, and Brenda, Yvonne was less confident talking to her kids about college. Two of the six children expressed an interest in college and careers. 
Yvonne talked to them about what they need to attend college, but when urged to share details about this conversation, she returned to her area of expertise—-being a mom. In fact, much of her validation of her children's professional interests was based upon their physical and emotional attributes (e.g., being nurturing, being small) and not their academic abilities: "The two 12-year-olds [talk about wanting to go to college]. ... [My stepson] wants to be an engineer. My daughter, she wants to be a mom, but she [also] wants to be a nurse. She wants to deliver babies. She loves babies... She loves kids." I asked Yvonne what she told her children about becoming an engineer or a nurse and if college was part of those discussions. "Yes. My youngest son, he wants to be a [horse] jockey...the way it's looking, he could be ... He's really, really low on the growth chart.” Again, I asked Yvonne about how she prepared and encouraged her two children who were interested in careers that require a college education: "I tell them all the time, especially [my daughter]: being a mom is hard work. She's like, 'I know, I know it's a lot of responsibility.' She's very, very mature for her age." Even though she recognized that her children would need additional education and training to attain these professional goals, Yvonne was less confident addressing the cultural and financial resources that would benefit them in the same way that Libby, Lisa, and Brenda did.

For Maya, (a 24-year-old, married, lower-middle-income, Latina mother with a one-year-old daughter) good mothering was less focused on tangible measures of children's success and more of an "intuitive" characteristic embodied by women. Just as intensive, however, she accessed this innate ability through a "spiritual connection" between mother and child, and nurtured it by remaining "present" in that relationship: "I just think we're able to do this [mothering], you know? It's just the way it's supposed to 
be. We have the power to, so why not try, at least? ...[it's] like a oneness." When I asked Maya how she evaluated mothering as "good," she revisited the connection she and her daughter shared:

I guess when I'm offering what she needs is when I feel like I'm being a good mother. I guess I just feel her. I just know. I just feel it. You know? She doesn't talk, so I don't know if she's getting what she needs, but I know she's not crying and I know she's okay and I know when she's just frustrated, and that's okay.

Maya credited her "innate maternal intuition" to sense her pre-verbal daughter's needs and desires, creating an intimate relationship unique to mothers and their children. To Hailey, a 31-year-old, white, middle-income, married, stay-at-home-mother expecting her third child, good mothering was also less outcome oriented, but just as consuming. Hailey stressed her selfless devotion as an essential element of her mothering; but whereas Libby and Lisa's concerted cultivation practices benefitted from having both parents involved, Hailey's parental practices were solely her own responsibility:

I think it's really good to love your kids.... I think a really good quality is to be not obsessed, but 'with' your kids. ... Kids need to have that person that ... won't kill them when it gets rough. I think there's a reason for moms. ...I think loving your kid, being less selfish can be learned... That's my definite difference post-[her first son's] birth is you just keep losing a bit of the selfishness. You just have to do this to be a good mom. It's such a key quality.

Hailey, Yvonne, and Maya reflected tenets of good mothering practices rooted in both being there (Edin and Kefalas 2005) and simple mothering (Bobel 2002). Hailey was intimately involved with MV, its programming, its advocacy, and its online community on a daily basis. Classes and community events at MV's physical location anchored her schedule. She often volunteered to staff the small retail operation when coverage was needed; she promoted the programming and resources offered by MHM via social media. 
Maya, on the other hand, was not familiar with MV, MHM, or the programming offered by the organizations. Yet, both mothers' narratives reflected tenets of simple mothering: they talked openly about their "intuitive knowledge" of parenting and their "intimate connections" with their children, and recognized that they - as mothers - were the only parent equipped to nurture this connection. Without the financial resources and cultural capital to practice concerted cultivation, their cultural feminism-informed expression of intensive mothering met their standards of good mothering.

Despite racial and class-based variations, partnered mothers embraced the tenets of intensive mothering ideology (Hays 1996). Regardless of race, affluent mothers (e.g., Libby, Lisa, and Brenda) incorporated concerted cultivation (Lareau 2003) strategies that required financial and time-based investments to manage their children's extensive activities and to develop their social networks. Some middle-income mothers in this study adhered to the cultural feminist attributes of simple mothering (Bobel 2002), benefitting from their modest economic and marital privilege to execute this "intuitive" form of intensive mothering. While more fully embraced by lower-income SAHMs in this study, elements of being there (Edin and Kefalas 2005)—especially mothers' intensive emotional and physical availability_were evident in both middle-income SAHMs' and lower-income SAHMs' maternal practices. For partnered mothers, the financial resources (whether abundant or limited) and familial stability provided by a coparent helped them to achieve their interpretations and standards of good mothering. 


\section{Good Mothering and Public Surveillance}

Normative standards of good mothering and maternal practices are shaped by white, middle-class, married mothers' interpretations of intensive mothering ideology (Hays 1996). Media representations of these practices (Michaels and Douglass 2007) promote and perpetuate this myopic interpretation into a hegemonic, instantly recognizable maternal standard; even slight deviations from this standard are recognizable and critiqued. Mothers of color, lower-income mothers, and single mothers aware of this surveillance have modified their maternal practices in different ways to compensate for their less-privileged status(es). Mothers in this study demonstrated how they adapted their own maternal standards and practices to accommodate their inability to attain society's expectations of good mothering.

Single, Lower-Income Mothers and Public Scrutiny:

Modifying standards, debunking stereotypes, and maintaining appearances

Bearing most, if not all, of the parenting responsibilities, many single mothers reinterpreted standards of good mothering to account for their lack of financial resources and time; they modified their practices in the short-term in hopes of longer-term benefits for themselves and their children. Jodi (a 29-year-old, single, lower-income, black mother of two children) expressed the immediate needs of good mothering, and how she adapted these standards when she returned to work after being a stay at-home mother:

I went from the mom that always made the arts and crafts stuff for them to take to school, and I still try, but holy shit... mommy guilt is real! ... 'Oh, mommy failed, we're going through a McDonald's drive thru tonight.' It's really not a mommy fail... They ate! They're being fed, but you still have it in your head, 'I'm not being a good mom because we're doing drive thru tonight.' You should have your meals prepped. I have tried... [to be] the 1950's stay-at-home mom...the whole Suzy homemaker thing...to be a wife and a mom and have dinner waiting at home on the table. 
Although Jodi grappled to reconcile her internalized standards of good mothering with her own maternal abilities, she recognized it as an ongoing process: "I definitely don't have it all figured out and I'm still working on it, but I realize different things here and there...I don't know what being a perfect mom is... [but] my mom did it, [so I feel like] I should be able to do this."

Cara (a 33-year-old, white, single, lower-income mother of a four-year-old son), now a divorced mother on a limited income and a full-time student, altered her own approach to good mothering by focusing on "the essentials." She conceded that her own maternal experiences made her more empathetic to the struggles her own mother faced when she was young: "My own mother... was not a great mom and she'll admit to it now. She was very emotionally distant, [but] she kept us fed and kept us clean and clothed." Sandi, a 32-year-old, single, white, lower-income mother ${ }^{23}$, echoed other single mothers in this study as she modified a "perfect ideal" of mothering to her more realistic, daily practice: "You have this perfect ideal of how things were going to be or what you were going to do. ... 'I will always do that.' No, you won't. You won't do a damn thing you said you were gonna do. You'll probably do things that you said you'd never do every day." Sandi equated her decision to return to school full-time and to pursue a law degree to good mothering, not (only) for the earning potential it may provide, but for the example it set for her daughter:

...[To] be a role model...that is huge.... My mom's a nurse; dad's a surgeon. They always stressed the importance of education.... I think that's important and I wanted [my daughter] to see me doing something I

\footnotetext{
${ }^{23}$ Sandi identified herself as a lower-income mother; she regularly referred to extensive support (housing, childcare, private school tuition, etc.) provided by her upper-middle income parents. I acknowledge that her experience may differ from other single, lower-income mothers in this study.
} 
enjoy, too. ... I wanted to be a big role model for her. And [to] do

something I wanted to do... I think that is being a good role model.

She elaborated further about her views of good mothering; she emphasized nurturing all aspects of her daughter: "Someone that wants their best and works to fill their child's needs...You need to provide a safe environment, physically, emotionally, psychologically."

Miranda, like Jodi, Cara, and Sandi, also found herself adjusting her standards of good mothering after divorcing her children's father and becoming a single mother.

Now ... [it's] caring about my kids and being involved in their lives and making sure they know that. It used to be, 'A good mom does $\mathrm{x}, \mathrm{y}$, and z,' and I think I thought that way until I was a single mom and I couldn't do $\mathrm{x}, \mathrm{y}$, and $\mathrm{z}$. I was still doing a really good job. I didn't wanna beat myself up over it anymore. And seeing all these other moms going thru that and beating themselves up over the choices they made.... and it's not even a choice oftentimes. So now it's just...be involved, and to me that's good mothering.

Single and lower-income mothers in this study undoubtedly lacked the financial and cultural resources to practice the tenets of concerted cultivation (Lareau 2003) embraced by more affluent mothers, yet they did not ascribe to the laissez-faire "accomplishment of natural growth" that Lareau found amongst lower-income families in her study (2003). Instead, lower-income mothers in this study talked about a modified, more hands-on approach to mothering that prepares their children to negotiate in middle-class environments. I conceptualized this practice as "nurtured growth" to reflect their adapted standards of good mothering by combining the physical and emotional accessibility of being there (Edin and Kefalas 2005) with budget-friendly modification of intensive mothering ideology (Hays 1996). Mothers like Cara and Sandi strategically accumulated familial and institutional resources to supplement their sparse income. Returning home to 
live with family provided Sandi and her daughter with housing, childcare, and regular interaction with immediate family members while she pursued a college degree. Cara turned to family (her parents, her former in-laws) to provide supplemental childcare and interaction for her son, and to allow her to practice forms of self-care (e.g., yoga, classes). Both discussed their desire to be less dependent on family members, but were unwilling to compromise the care and financial benefits offered by familial support. Thus, they remain emotionally and physically present for their children and continued with their goals of higher education. Because of their modified standards of good mothering and nurtured growth practices, these intensive acts and forms of self-care were attainable. Mothers practicing nurtured growth believed that these short-term sacrifices will translate into benefits (e.g., financial stability, familial support for their children) in the future.

\section{Debunking perceptions of single mothers}

Sandi hoped to debunk the stereotype of single mothers as disengaged and careless that she believed society holds by amending her standards of good mothering:

There's this stereotype of single mom at the club with the kids at home. ... I think maybe if I was a lot younger, it'd be different. But...I want to do what's right by [my daughter] and what's good for me, too. ... I don't want people to be like, 'Oh, [Sandi's] a bad mom. Look at her.' That plays into it.

In addition to perceptions about lower-income mothers and single mothers, black mothers face additional controlling images (e.g., welfare queens, mammies, matriarchs, and jezebels) that challenge their maternal abilities (Collins 1990:77; Roberts 2007; Springer 2010). These controlling images objectify black mothers, labeling black women as 
"others" justifies their racial oppression and ensures their diminished power and peripheral status in society (Collins 1990:78).

Valerie, like other single, lower-income, black mothers in this study, recognized the controlling image of the "welfare queen" (Collins 1990; Roberts 2007): single black mothers who would rather collect government support instead of work and procreate to increase the amount of their public assistance. As a single, lower-income, black mother on public assistance, Valerie, a 41-year-old mother of six, was aware that she shared the characteristics of this stereotype. She found that single mothers are judged unfairly and that assumptions are routinely made about their goals and productivity.

Valerie worked to counteract this controlling image through her maternal practices:

I think people have the wrong perception of single motherhood. They think, "Oh, well, they don't want to work and they don't want to do this. They just want to sit at home and get assistance." That's not true...you know that you have to provide for someone else. Your survival instinct kicks in and you're like, "What am I going to do? I got to pay bills, I got to take care of my kids, make sure they eat, make sure they have clothes, and things that they need."

Even without a universal consensus of good mothering practices, and despite the varying and sometimes unattainable standards facing them, single mothers in this study felt that they were good mothers, even if they stumbled along their paths. Sandi acknowledged her shortcomings, but credited herself with persevering: “[I'm] completely flawed, but yeah, I count myself as a good mom. Most days. Some days. I'm trying, though. I'm trying." The experience of becoming a single mother made Cara sensitive to the criticisms mothers face striving to achieve this standard: "We're all just doing the best we can. It's easy to pass judgment and I had a real dose of that, like an awakening after the divorce. I was so emotionally shaken. It changed everything." 
Miranda's economically privileged position provided her with additional resources many single mothers lack. Still, as a single mother, Miranda adapted her previous standards, practices, and expectations to make them more attainable. Miranda believed that mothering was unique to each woman and her circumstances: "I [now] have the idea that every mom is doing the best she can based on what she's got. ...Her experiences and what she's got to work with... She's her child's best expert and best advocate." By "letting go" of her view that good mothering was a singular standard achieved through specific acts, Miranda recognized the structural forces influencing other mothers.

Single mothers and lower-income mothers in this study modified their own practices to reflect more manageable standards of good mothering as they acknowledged the impracticality of society's definition of good mothering. This societal standard remains, however, and is enforced through public judgement, criticisms, and scrutiny. Mothers in this study talked about making accommodations for public presentations of their mothering through image maintenance. Ensuring that their children's appearance was acceptable offered mothers protection from visible inspections of societal standards.

\section{Image maintenance: Lower-income mothers}

Some mothers discussed children's appearances as an additional aspect of good mothering, similar to the rhetoric present in Edin and Kefalas' (2005) study of poor, single mothers. Talia (a 33-year-old, single, lower-middle income, black mother of one with a second child on the way) acknowledged that image maintenance is an aspect of good mothering; she explained what her son's appearance says about her mothering: 
... [I] I'm dressed up and [my son] look[s] like don't nobody care about him, then that's what it seems like. That's the image that it portrays is... She must not care about her son. ... I try to get him [to] understand, "When you go out in this world, look like somebody care about you. Look like somebody loves you, because I do." ... Not that I care what other people think, but... they'll swear up and down you homeless if you look homeless. I don't want nobody asking my kid, "Do you have a home? Does your mom care about you?" ... It's probably just an external portrayal of care, not necessarily keeping up with the Joneses.

Angeline, a 26-year-old, partnered (although estranged), lower-income, AsianAmerican mother, had custody of two of her three children. She was acutely aware of the pressure to maintain an acceptable image for herself as a mother and for her children. Angeline's life has included Child Protective Services (CPS) for as long as she can remember, first as a foster child and then as a mother. She was cognizant of public scrutiny of her maternal practices and lost custody of her oldest child. She equated being judged as a mother to having (CPS) called by members of the public to intervene on behalf of her children. When we talked, Angeline was not working and was scared to leave her home for fear of being deemed an unfit mother. In addition to her children's physical appearances, she explained that CPS was called for other reasons that she deemed unfair: “[Once, CPS was called] because I don't have enough food for my kids...another because I drink [alcohol] on the weekends."

Edin and Kefalas's (2005) study showed that mothers maintained their child(ren)'s image to deflect additional critiques tied to their maternal ability. Their findings highlighted how lower-income mothers - regardless of race —were acutely aware of this added layer of public scrutiny regarding their mothering practices. Because of this, lower-income mothers sensed an obligation to ensure that their children always be presentable in public to avoid calling their parenting into question. 


\section{Image maintenance: Affluent black mothers}

Mothers' narratives in my study, however, diverged from the class-based rhetoric in Edin and Kefalas's study (2005). Rather, I found black mothers who subscribed to image maintenance as part of good mothering across all income levels. Miranda - the upper-middle income, divorced, black mother-also tied her children's appearances to good mothering: "Good moms make sure their kids have certain kinds of, not fancy clothes, but good moms don't let their kids go out filthy." Nina, a 44-year-old, married, upper-middle-income, black mother to three daughters between the ages of 12 and 21 , recently retired from the military. She rejected the idea that she is held to a stricter standard of mothering because of her race; yet, despite her class-based privilege, appearance and image maintenance remained a large part of good mothering for Nina:

A good mother is one [that] is neat, because if I dress nice, my daughters dress nice. You will never catch [me] when my hair's not done.... You see moms out there and they're like Kim Kardashian and then, like, look at the kid and you're like, "What in the world? Why isn't their hair combed? Why is she all, what's wrong with her?" ...Some moms maybe cannot afford to dress their kids nice, but when you're looking nice? There's an issue, because if you can afford it, you should be trying to get your child dressed better than you.

Thus, in this sample of mothers, race was more predictive of image maintenance narratives than class.

\section{Image maintenance and racial privilege}

Unlike Edin and Kefalas's findings (2005) in which lower-income mothers across race emphasized their children's appearances, the emphasis on maternal abilities vis-à-vis children's appearance was largely absent for poor, single, white mothers in this study. While white mothers - especially single and lower-income - felt pressured to conform to 
societal standards of good mothering and knew that their children's appearances may be closely inspected, they were much less likely to internalize public judgment as a reflection of their own mothering abilities. For example, Suzanne acknowledged the societal standards of good mothering, but rejected them. She described what is expected of good mothers: "[She] makes breakfast in the morning, gets [the kids] to school...the perfectly involved parent. I'm not delusional to think that I'm a failure because I don't meet those [standards]." Her racial privilege was reflected in this dismissive attitude of public scrutiny and her maternal abilities.

Even if racial privilege protects white mothers from being publicly judged as harshly as black mothers, all mothers are susceptible to an endless loop of internal criticism compounded by societal standards of good mothering and public inspection. A few minutes after she rejected the connection between appearances and the realities of mothering, Suzanne expressed concern about her one-year-old niece. She wondered if her niece would "be okay" even though she could not afford "cute diapers and all that stuff." This and other outward expressions of her mothering weighed on her mind:

You see what society puts on you to be this perfect parent and when you don't live up to it, you can struggle.... not being able to buy the cute boutique dresses... hopefully that doesn't mess her up...It's kind of hard to balance being by myself and giving her everything that I want to.

Taking steps to separate these two standards — children's appearances and good mothering - demonstrates how intertwined they can be. Cara tried to defend other mothers who are judged by their children's appearances. When she and her mother saw a mother at a restaurant with her disheveled children, for example, Cara chastised her mother for critiquing the woman's appearance: 
...My mom was like, "I can't believe she left the house like that," totally passing judgment on this woman. I said, "Mom, she could be going through what I'm going through." ... It would be so easy for someone to pass judgment... It may not look like they have their shit together, but they're doing the best they can. That kid's eating. They have clothes on, and they're eating. And they're breathing.

Maya was also aware of how easy it can be to jump to conclusions about other women's mothering. She hesitated to generalize characteristics about her own maternal practices for fear of sounding judgmental of other mothers: "I feel like I may know when I'm being a good mother; I can't tell for everybody else, though...I just can't speak for other mothers. I just can't, because I don't know what they're going through or what their child puts them through, you know?"

Empathy for other mothers' practices and struggles was more common among lower-income mothers and single mothers in this study who have been forced to modify their own practices and standards of good mothering due to financial constraints. Other mothers reconciled the notions of good mothering they held prior to becoming parents with the realities of intensive mothering. Their good mothering standards evolved over time, often becoming less rigid. Hailey admitted to judging mothers prior to becoming a mother herself, especially for their less conventional parenting choices. Some of these practices were ones that she ended up incorporating into her own maternal practices:

I paid attention to people I babysat for. I was like, "Wow, I'm never doing that." I often made a mental note: "[I] will not do this!' Or, "I totally will do that." ... I had friends that had a 5-year-old that slept in their bed and I was like, "What are you doing? What were they thinking?" ... Now, it's like no, [our son is] not leaving our bed.... I do most things the opposite of what I thought I'd do. 
Managing exacting standards of intensive mothering becomes unsustainable for SAHMs

lacking financial and/or parenting assistance. When something must give, it is most often in the form of relaxing good mothering standards.

Modifying Maternal Standards and Practices:

Lower- and lower-middle income mothers

Like Hailey, Zoe (a 29-year-old, white, married, lower-middle income mother of four children) — who was also actively involved with MV, its programming, its advocacy, and its online community and an active volunteer for MHM — practiced simple mothering (Bobel 2002). The ideology of this consuming maternal practice appealed to Zoe, but it proved to be too much as she attempted to manage postpartum depression, her family's limited resources, and her partner's demanding work schedule. Zoe described the ambivalence she felt as she struggled to meet the rigid standards of simple mothering: "I felt like I had to cloth diaper, which was exhausting. Even though I loved it, it was also exhausting. I had to breastfeed him, I had to wear him all the time, I had to practice gentle parenting.....it got to where I was so horribly overwhelmed, and I just cried and cried." Zoe decided to modify her maternal practices to make simple mothering work within her limitations:

I told [my husband], "Something has to go right now. I can't keep doing all this, I'm not made for this." ... So the first thing to go was the cloth diapers. I was like, "We're done, sorry planet." ... Then a few months later ... I was like, "I need to be done nursing." ... I was just like, "I can't do this." We had already finished co-sleeping...I was like, "You're done in the bed. Mama can't sleep at all." So I put him in his crib, but he still woke up like five times a night [to nurse] and I just couldn't. So I started as giving him a bottle at night to make him sleep. 
By adapting her maternal practice to her abilities, Zoe maintained the elements of simple mothering ideology that were manageable to her. She continued to struggle to reconcile her modified approach with the "proper" practices of simple mothering: "I did feel, even in my home, somehow people were gonna find out [that I adapted my practices] and I was gonna be judged [for] it." As an active participant in MV's in-person and online communities, Zoe encountered abundant examples of successful simple mothering, while mothers who were struggling with these intensive acts seemed elusive. This exacerbated Zoe's feelings of guilt and inadequacy as she wrestled with ways to modify her simple mothering practices.

Single mothers, lower-income mothers, and black mothers in this study were forgiving of their own (and others') inabilities to achieve their unattainable standard of good mothering. They recognized the limits of their resources and capacities and modified their maternal standards and practices based on their income and marital status. Regardless of the leniency embedded in their amended standards, these mothers and every other mother in this study acknowledged that good mothering calls for selfsacrifice. The extent to which mothers made these sacrifices and how they compensated for this depleting practice were influenced by their race, class, and family structure, and rooted in their interpretations of good mothering.

\section{Good Mothers and Self-Sacrifice}

When mothers articulated the parameters of good mothering, they referenced selfsacrifice. In fact, self-sacrifice—attending to children's needs before one's own needswas used by every mother in this study to describe good mothering. Mothers' responses 
were immediate, like a reflex. Self-sacrifice can be all-consuming and infiltrate various aspects of mothering. It often extends beyond the basic necessities of childcare (such as food, shelter, "keeping them alive," and "not killing them") to include the less tangible acts of fostering children's emotional and physical development, and nurturing their cultural development, physical appearance, and social capital. Mothers talked about sacrificing aspects of their own behaviors, their futures, and even themselves for their children. Mothers were most likely to discuss sacrifices in their work life, social life, and personal maintenance, restructuring priorities to make sacrifices for their children.

\section{Self-Sacrifice: Work life}

Three-quarters (31) of the mothers in this study were employed outside the home; most (24) worked full-time (30 or more hours per week), while seven worked part-time (fewer than 30 hours per week). Of the ten mothers not working outside the home, only three were casually looking for part-time employment; most (seven) were intentionally not employed. Mothers acknowledged altering work schedules, changing jobs, or scrapping career aspirations altogether for mothering, an option afforded to higherincome mothers.

Lisa, for example, wrestled with relinquishing her career to care for her children. Prior to having children, she had a demanding and active nursing career. She felt the desire to return to work to fulfill the aspects of herself associated with her professional achievements and talents, but she "can't make it work" for her family: "I was feeling that something was off-balance...I was like, 'I think it's time for me to go back to work.' It just didn't work for the operations of the household, so I had to find a different way to 
feed that need." Instead, she threw herself into more maternal duties: "I'm learning to make school functions, like PTA and those kinds of things, to feed that need for leadership and organization and planning and social. I've learned to work those things in, to meet those needs." Miranda also stopped working to focus on the principles of intensive mothering when her oldest child was born: “...Whatever it takes to push my children to be the best they can be, I'll do it.... I even left my job after I had my son and was a stay-at-home mom."

The incompatibilities between intensive mothering and the labor force are well documented (e.g., Hays 1996; Hays 2007; Stone 2007; Williams 2010). Employers expect fully-devoted employees, accessible all days, at all times. The lack of consistent family-friendly policies (e.g., family leave, flexible scheduling, part-time options) forces mothers to reconcile the all-consuming demands of mothering with the all-consuming expectations of employers. Gender inequalities at work, such as lower pay, more stringent performance-based outcomes, and less flexibility (Correll et al. 2007; Stone 2007; Williams 2010) push some mothers out of the workforce.

In the end, some mothers with economic and marital resources-like Libby, Lisa, and Miranda — left the work force to become intensive mothers cultivating their children's social and cultural development (Lareau 2003). Yet, these mothers viewed this act as an individual decision, not a byproduct of structural constraints in the workforce. In doing so, they reclaimed control over their personal trajectories and echoed the highachieving professional mothers profiled in Stone's (2007) study who cited their departure from established careers as personal "choice." For working mothers without this 
economic and marital privilege, the rigidity of the work place forced them to reconsider their practices of intensive mothering, adjusting their expectations accordingly.

\section{Self-Sacrifice: Social life}

Mothers in this study identified other sacrifices: socializing, dating, friendships, and maintaining a social life. Relationships and outings that were regular aspects of mothers' lives prior to children were shelved. Sometimes, this was a result of greatly reduced time or energy; other times, it was due to a lack of spending money to afford nights out at a bar or movies. Usually, it was a combination of all three. But more so than logistics, the shift in mothers' social lives was often attributed to a change in mindset: good mothers do not go out. This view was even more stringent for mothers in this study determined to debunk the stereotype of single mothers as absent and irresponsible parents.

As a young, intelligent, single woman, the topic of dating came up in Sandi's life, but she has decided to not pursue it: "Yeah. I'm busy. To me, right now, there are just more important things beyond...just [my daughter], and then school. I've got a lot going on. ... I don't have the energy. I don't have the time." Cara echoed this refrain as she, too, balanced single parenting, school, and work, but also cited a lack of "emotional bandwidth" to invest in new relationships: "I can't be [dating], I don't have time to text him or [to] care about someone else's feelings, if that makes sense. Sounds harsh, but you have a finite amount of energy and time and right now I'm barely able to stay afloat. Just staying afloat here." 
Social relationships did not always disappear entirely. Similar to the modification of good mothering's stringent standards, single mothers talked about adapting their practices. Sandi altered how she socialized by combining her friends and her good mothering practices:

We had a ... party and we invited my mom friends and their kids. We were up on the porch and having fun and they were playing on the swing set. That's always fun. I do that kind of stuff. That incorporates both social and children, but not a date or romantic...My mommy friends and that kind of thing.

Sandi's form of socializing allowed her to maintain friendships and continue to debunk the stereotype of the single mother as one whose social life takes precedence over her maternal responsibilities.

Sandi talked about urging other single mothers to seek a balance between socializing and mothering: "If someone wants to go out and spend all this time with their friends or at a bar, these things they want to do... at the expense of their child...I can understand the occasional, but [mothering is] your responsibility." Lisa also emphasized balancing a night out with friends and being neglectful of maternal duties: "You need to have girls' night out; [but] 4 nights a week, and your kid's at home? We need to think about what it is we're doing. My suggestion is, we can do that, but just not now." In fact, nearly three-quarters of the mothers in this study agreed with the sentiment that good mothering and an active social life were incompatible practices.

Although less prevalent, some mothers in this study discussed sacrificing their happiness for their children by remaining in relationships longer than desired. Jodi explained that after their marriage was over emotionally, she and her children's father continued to live together for the benefit of their children and their budgets: "I think [my 
husband] and I knew our relationship was over for a while, but... [the kids] deserved a better life...[We] just put our big girl panties on and dealt." Cara and her former husband had this arrangement, as well. At first, she thought having her son's father continue to live with them would ease the transition as their relationship dissolved and promote coparenting. Her son's father soon made it clear that parenting was something he would do "only when it was convenient for him." After he began bringing dates home, however, it was time for him to leave and Cara was on her own. She accepted this as the natural order of parenting: "For a mom, I think we can handle [parenting] better. Women just tend to be more self-sacrificing," echoing many mothers' sentiments in the MV community.

\section{Self-Sacrifice: Concerted cultivation}

Lisa's approach to socializing reflected her standard of good mothering through the concerted cultivation (Lareau 2003) of her daughters. New to the city, she approached the construction of a social network methodically and intentionally. She searched for homes in areas conducive to a specific school, one in which her daughters would have plentiful opportunities to engage in activities and extracurricular offerings. Lisa recognized the importance of establishing social networks for her children's benefits, not her own: "In thinking it through, like, I'm bringing my child, who has never been outside of Florida really, to this faraway place at a time that's really critical. Social connections are the pinnacle of their world...they can have their own little network and build it." Lisa's friends back home warned her against sacrificing herself in her new locale, acknowledging that the potential existed to immerse herself in her children's social 
development. She brushed aside this advice, citing the importance of sacrificing her own interests for her children's connections:

Some of my friends just kept saying to me, "Make sure when you get there, you make your own set of friends and figure it out. Don't let it be all about the kids." At some point, it's got to be about the kids. From that, how can I juggle this out?... it was for the connection of the kids.

By prioritizing her children's connections over her own, Lisa reflected her self-sacrificing standards of good mothering and her commitment to concerted cultivation: she was willing to forego her own social network at the expense of establishing her children's.

Brenda adhered to the same tenets of concerted cultivation as Lisa, while she worked full-time as a high-level project manager at a corporation. As a result, she maintained a frenetic schedule to keep up with her daughter's extensive array of extracurricular activities. Any down-time Brenda found was devoted to coaching her daughter: informal interactions offered opportunities for cultivation, as well. She taught her daughter to construct persuasive arguments and to negotiate, skills that she believed would advance her daughter's social development: "I want [my daughter] to be independent and strong and feel as though she can speak her mind and say her piece." More affluent black mothers in this study talked about self-sacrificing time and resources to achieve their practice of concerted cultivation (Lareau 2003). To this end, their selfsacrifice was an expected element of this intensive maternal practice.

\section{Self-Sacrifice: Personal maintenance}

Every mother attested to the disorienting influence that the first few months of parenting can have on maintaining personal hygiene. Suzanne reminisced about her 
unanticipated transition to parenting her newborn niece while also caring for her recently bed-ridden mother:

I fought it [being responsible for her niece and her mother] for a really long time. I was very depressed ...At one point when my mom had gotten out of the hospital ... I was having to get her a bath and then get the baby a bath and I'm, like, a two-baths-a-day kind of girl and just not even get to take a bath myself. I cried a lot, a whole lot.

But mothers in this study also discussed a decline in personal maintenance that extended beyond the initial newborn period. For more than two-thirds of the mothers, relegating their own care (including physical appearances, such as hair, clothes, and make up, and physical maintenance, such as exercise and eating well) to the least important position on their to-do lists became the norm in their maternal practices.

Some of the mothers recognized that underlying this tension between good mothering and self-sacrifice was the all-consuming and unrelenting mental weight of managing schedules and obligations, maintaining households, and even general concerns about children's well-being that extended beyond the strains of day-to-day parenting. Cara pointed out that mothers' shifts in priorities begin even before the first child arrives: "You take care of yourself while you're pregnant, and then the minute they come, you forget all about yourself. So, you're really just initially taking care of them; it just looks like you're taking care of yourself."

\section{Self-Sacrifice: Shifting priorities}

Elise, a 41-year-old, white, married, upper-income mother, has two children. Her struggles stemmed from the lack of a reprieve from mothering. Elise illustrated the distance between the mundane practice of mothering and the inescapable emotional 
pressure: "I love my kids; I would take a bullet for my kids any day. But I'm not really fond of motherhood. It's chronic. You get no break. I can't get them out of my head, even when I'm working. They're just ever-present." Miranda echoed this unremitting nature of motherhood: "I'm forever trying to do what is best for my children. I forever am questioning things that happened on a daily basis, whether I discuss it with other mothers, whether I discuss with my mother, whether I discuss with my children.”

Not every mother acknowledged the reprioritization of her needs as a sacrifice. Hailey recognized changes in her life after her children were born, but struggled to categorize them: "Sacrifices? I don't know. I'm one of those born wanting to be a mom, so things that others think of as sacrifices, I say no, I don't feel that. I really like the way [things] are." Hailey hypothesized that mothers who fiercely guard their pre-motherhood independence grapple with their transition to motherhood. She offered insight into why this might happen: "[Being a mother] is very humbling, very. I mean, it's a gamechanger. It really is. I feel like some moms are scared to embrace motherhood and they just...it's terrifying to think of having a kid and not having it to change you."

Overall, mothers talked about self-sacrifice in a way that extended beyond making child(ren)'s needs a priority; they agreed that self-sacrifice was a necessary component of good mothering. But beyond this, mothers demoted their own statuses within their families, specifically in relation to their child(ren) and partners or spouses. While most mothers acknowledged the importance of attending to themselves, the very act of doing so was diminished. Those without financial means, active co-parents, or reliable familial support systems were more often forced to sacrifice themselves to achieve consuming and competing demands of intensive mothering and other obligations (e.g., employment, 
school). As some mothers' narratives in Chapter VI reveal, intentionally engaging in selfcare becomes an act of resistance.

\section{Good Mothers and Self-Care}

Even though every mother admitted that self-care would be beneficial, how they defined it and whether they practiced it fluctuated. Some acknowledged that self-care was necessary to good mothering, but they failed to incorporate it into their lives. Others recognized it as a non-negotiable element of mothering. These women, set aside time and activities for themselves, or even a longer route home from work to face their unrelenting demands of work and family obligations. Race, class, and family structure influenced mothers' views and practices of self-care.

\section{Self-Care: Stay-at-home-mothers}

Even though they acknowledged the importance of self-care in maintaining their own mothering abilities, married mothers were more likely to let it slip to the end of their "to do" lists. When I ask Hailey about self-care, her response reflected the all-consuming nature of mothering several small children. Although she regularly pushed self-care aside, Hailey expressed her desire for a helping hand so she could tend to herself for a brief time:

[Self-care is] something that I hear a lot about, but I haven't really thought about it a lot... I probably should...having a required 30-minute shower a week would be super...I'll take showers while [my children and husband are] home and I'll leave the door open and watch [my husband] sit there and throw toys at me .... It's sometimes easier when [my husband's] not home. [At] times when I try to shower and [my husband] is home, he'll come in and say "[The baby] wants you!" And I'll say, "He's perfectly fine." ...I'd really like to have [my husband] help me when he's home. 
Beyond showering, however, Hailey was reticent to confess the need for time away from her mothering duties: "For me, I enjoy so much of my kids that when I do things on my own, that doesn't sound like fun.”

When stay at-home mothers (SAHMs) in this study practiced self-care, they were more likely to describe it as a luxury. Lisa expressed appreciation for her family's financial stability which allowed her to be a SAHM. She searched for a way to fit selfcare into her family's schedule to ensure that it did not impede upon her mothering duties:

My newfound thing is tennis. It's social. It's something I can do in an hour. It doesn't consume the entire day. I am blessed that I don't have to work, so I can get that done for an hour or two, a couple times a week while they're in school, and still do all of those other things, keep my household for the weekend. For me, that's good.

Staying connected to an online mothering community reminded Hailey that other mothers prioritize self-care: "Having somebody else tell me what they did [or self-care]. I'm like, 'That's a great idea. I would have never thought of that on my own.' And other moms sharing what works for them and what doesn't work for them." Hailey then shared an anecdote about a mother from her online forum in desperate need of a break from her infant. She told her husband that she wanted an hour to herself to take a walk. When he refused to take the baby, she "threw" the baby at him and walked out the door. She came home to find her husband upset with her for leaving the baby with him; she turned to her online community for support. Hailey empathized with this mother's predicament: "It's hard...there's so many times when you want to have a discussion...Just staying sane is important, however you make that work." 


\section{Self-Care: Working mothers}

Working mothers, especially those who derived an essential part of their identity from their careers, talked about practicing self-care to make them better mothers. Elise, for example, acknowledged that her career is part of her self-care. Despite craving more flexibility from her hectic counseling practice, Elise's career fulfilled a major facet of her life: "It's the other piece of who I am. I couldn't stay home. I don't know how people stay at home." She wrestled with the demands of full-time work and mothering, but needed both components of her identity to be a good mother: "I don't want to be with [my children] all the time, but I want to be with them more than I am.... I always had it in my head [that] I wanted a job that would be flexible with motherhood...I just knew that... whatever I did for a living, I would have to be able to have a family.”

Hanna, a 33-year-old, white, soon-to-be-divorced, lower-middle income mother to her three-year-old son, learned that defining boundaries around her mothering responsibilities helped her care for herself. "There's no real way to describe what [good mothering] is...for me, it is accepting that 'mother' is not my title. It's not my first title." She and her son's father were finalizing their divorce and child custody arrangements. As they partitioned their son's care, Hanna recognized how necessary it was for her to have regular breaks from mothering: 'I'm a student; I'm a theologian; I'm an activist; I'm a feminist; and I'm a mother. And kind of in that order-mother's down the line because that's not my identity. I'm still [Hanna]...[and] that, for me, makes me a good mother.... Part-time mothering works really well for me.” The single-mothers' online community through MV encouraged Hanna to maintain her focus on herself. The feedback from this community validated Hanna's approach to mothering as a facet of her identity. This 
message deviates from the all-consuming approach to mothering revered by the partnered mothers in MV's on-site and online communities.

Brenda's demanding career and practice of concerted cultivation could leave her depleted if not for her commitment to self-care: "I periodically go to counseling. I think it's good for people to do that." She and Yvonne were the only black mothers in this study to discuss mental-health care; Brenda was the only black mother to pursue it on it on her own. Brenda conceded that her occasional therapy sessions make some peopleincluding her own mother-very uncomfortable: "My mom, the first time I told her that, she was like, 'You can't go, they're going to blame me for everything that's wrong with you!'”

Brenda acknowledged that discussing her personal issues with a "stranger" breached a cultural norm among black mothers; self-care replenished her and fueled her exhaustive efforts. It allowed her to continue cultivating her daughter's cultural resources and establish her own path to financial and social success. Unlike other affluent black mothers, Brenda modeled the importance of self-care for her daughter:

I'm always trying to show [my daughter] that - as much as I love her and as important as she is to me- she's not the only thing to me. That there are other [things]. My job's important to me, her father's important to me, God is important to me. Not necessarily in that order, but that order changes every day and sometimes by the hour, depending on what's going on. I'm more than just one thing and...I get to pick what those are and it's not always going to be her.

Boundaries allowed Brenda to nurture her multifaceted identity and to maintain her allconsuming mothering duties. Striving to incorporate concerted cultivation, self-sacrifice, and self-care in her interpretation of good mothering required constant vigilance. As mothers' narratives revealed, this often led to an ongoing struggle. 


\section{Combining Self-Sacrifice and Self-Care}

Ultimately, most mothers talked about striving to "balance" self-sacrifice and self-care. Instead of balance, however, many narratives exposed an on-going battle in an internal zero-sum game. Instead of approaching self-care and self-sacrifice as two necessary components in the practice of mothering, most sounded conflicted, guilty, and apologetic about needing or wanting to invest in themselves. The exceptions in this study (e.g., Hanna and Elise) stemmed from substantial shifts in family structure (e.g., Hanna's divorce and custodial arrangement) or intentional adjustments in shared parental duties by pushing a partner to “step up" (e.g., Elise's arrangement to maintain her career).

For the other mothers in this study, their narratives often vacillated between selfcare and self-sacrifice. First, they upheld their decisions to prioritize their children above all else (especially themselves) as the most important aspect of good maternal practices; then, they emphasized the need for self-care to continue these exhaustive practices of good mothering. But when it came to putting the concept of self-care into action, mothers admitted that it was the first thing eliminated from their busy schedules. Talia drew from her personal and professional experience to illuminate this perpetual conflict:

I worked in child abuse. I think half of the reason why kids get abused is because mom is highly stressed and frustrated, and pressures of the world and just can't take it. They fly off the handle. Dads, too! It's a lot. You got to find that balance though. You got to. You've got to love yourself first. If you don't, then depression sets in, and other things set in to where you're not a good mother.

Finding this balance between sacrifice and care seemed imperative. While "bad mothers" "love themselves more than they love their child," Talia pointed out the need to temper self-sacrifice with self-care: “[A] bad mother doesn't care about herself. Doesn't care for 
herself well enough to know that you actually have to practice self-care in order for you to care for other people." Miranda echoed this sentiment; she explained the need to guard her time for self-care: "Yeah...I'm a better mom [when I take care of myself]."

Like Talia, single mothers in this study often lauded the benefits of self-care.

Some scheduled it and protected this time and ritual fiercely. Cara found a way—with the help of her father and the encouragement of the MV online community for single mothers - to incorporate self-care in her busy schedule:

On Thursday nights, my dad picks [my son] up from school and keeps him all night... [and] if I'm not falling asleep on the way home from school and work, then I go to ten o'clock yoga [class]. ... If I get it all out [at yoga], then [my head is] clear for [my son]. ...I need to be...[on] my best game to guide him and not be impatient and selfish and short-tempered. When I'm with him, [I can] be present with him.

For Cara, this ritual replenished her and gave her the energy and emotional focus necessary to tackle another week of solo-parenting her son. Like Hanna and other single mothers connected via MV's online community, self-care is often regarded as a nonnegotiable aspect of solo parenting.

Cara and Elise both recited the warning issued on airplanes about attending to one's own oxygen mask prior to helping a child — as if they were trying to persuade themselves that time alone is permissible. Elise even admitted to promoting two contradictory standards of good mothering between her counseling career and her own maternal practices; she encouraged clients to adopt parenting practices replete with selfcare and more attainable guidelines. Yet, she held herself to an impossible standard of mothering: "I talk about 'good enough' mothering all the time [to her clients]. ...I'm constantly telling people, 'You have to put "you" first'." When I asked Elise what it 
would look like to be the mother she thinks she "should" be, she sighed and described a

scenario in which she was always available to others, devoid of self-care:

I would not be exhausted all the time. Not needing to come from work and just lay on the couch and stare at the wall for a half an hour. That's kind of like a dream - can I just walk in, go upstairs, change my clothes, and then come downstairs ten minutes later without being followed? [My children] want to talk to me...I need to be there to hear that because that's so important. At that point, I have spent eight hours listening to people tell me about what's going on in their lives and I'm burnt.

Even mothers who accepted self-sacrifice and self-care as necessary elements of

mothering and strived to maintain both in harmony still struggled to do so. Lisa described

how tenuous this balance could be and how easy it was to disrupt this equilibrium.

I think [self-care is] different for everyone. I think it's one of the first things to go, and it's the hardest thing to regain. Even when we put our stake in the ground and go, "That's it. I am putting me at the top of the ladder again, it's crazy stuff," that there has to be a balance, because there has to be that mental health, spiritual health and emotional health that allows you to be all of those other things to the rest of your family. You've got to find something that picks those spirits up, whatever that is for you.

Talia wove her professional expertise into her rationale for maintaining personal care:

I can't love anybody else until I love myself. There is a great, great weight on self-care and acknowledging it. You're not a bad mother because you want to find a babysitter so you can go out and relax and have fun. We need that. Especially single mothers, you have to find time. Running to the bathroom don't always get you where you need to be, because your kid [will] find you. ...Do something you love and enjoy minus your kids and without feeling guilty about it. Put your child to bed at a decent time, so you can have some down time to yourself.... You have to ...[do] things that make you happy so that you can be happy.

Despite acknowledging the necessity of self-care, this tension between self-sacrifice and self-care some mothers face appeared constant. Like so many mothers, Cara recognized that she "should" make caring for herself a priority, but conceded that her son took precedence in her hierarchy of care: "In my head, I think that I should be first and then 
[my son], but I know that's not the case. Everything... in my life is tied to him. So, he's definitely one; I'm two."

Identifying and maintaining equilibrium between self-sacrifice and self-care fluctuated with mothers' perceptions of good mothering. Indefatigable neglect of these practices can be detrimental, and the maternal support offered by MHM and MV does not appeal to all mothers. For Angeline, a 26-year-old, lower-income, separated, Asian American mother, mothering was a combination of endless personal sacrifices and a total void of self-care. Eventually, these maternal practices manifested themselves in reckless behavior. Recently, they culminated in a serious and blatant disregard for her children's safety:

This is my fault, I'll admit this - my doctor prescribed Ambien, told me to lay down a little bit after I took it. ...I started feeling like I was a little drunk. I got dressed up ... put on make-up... taking pictures of myself...I went to the bar and I was like, "Hey, everybody!" They're like, "Where's your daughter?” And I was like, “Oh, fuck!” ...so I got CPS calling me for that.

While Angeline deemed CPS's prior involvement unwarranted, she conceded that this time it was warranted. Her unrelenting self-sacrifice and utter neglect of self-care culminated in a dangerous and irresponsible act that could have cost Angeline her children.

\section{Discussion}

Tenets of intensive mothering (Hays 1996) influenced all mothers in this study; how mothers defined "good mothering" practices to meet these standards varied by race, class, and family structure. Affluent mothers across racial groups practiced concerted cultivation (Lareau 2003), made possible by their husband's financial contributions, 
parenting support, and marital stability. Middle-income mothers modified stringent standards of good mothering to accommodate their economic and/or marital circumstances; some chose to practice versions of simple mothering (Bobel 2002), while other single mothers and lower- to lower-middle-income mothers modified their standards of good mothering by practicing "nurtured growth." Doing so allowed mothers to emphasize the resources they do have (e.g., time, emotional and physical availability) and augment their practices for the resources they lack (e.g., financial resources, coparenting support).

The practice of nurtured growth differs from Lareau's (2003) and Putnam's (2015) assessment of lower-income families' parenting practices. Both found that the stresses and frustrations facing lower-income families resulted in less parental interaction and negligible external activities for children. Instead, lower-income children remained detached from the networks and opportunities afforded to more affluent children. This resulting economic stagnation facing families today is a departure from the class mobility experienced in past generations (Putnam 2015). It could be that compared to Lareau's sample (2003), this sample of mothers is more tapped into resources available through schools or other local institutions given I found several mothers in this sample via their participation in these institutions. However, further research is needed to understand why some mothers engaged in nurtured growth while others practiced the accomplishment of natural growth (Lareau 2003), and how economic and familial forces intersect with race and other structures to influence these practices.

Mothers compensated for their limited resources and/or lack of a co-parent with an increased dependence on family (e.g., Hailey and Sandi's own parents' support and 
Talia's extended kin). Lower-income single mothers in this study echoed the mothers in Edin and Kefalas's (2005) study as they defined "being there" (physically and emotionally) as tantamount to good mothering. Unable to adhere to the privileged standards of good mothers practicing concerted cultivation and simple mothering, their limited resources and non-existent partners mean that physical and emotional availability represents the most precious commodity they can offer to their children.

But income was not the only factor accounting for differences in perceptions and practices of good mothering. Mothers' narratives illuminated the complexities embedded in the notions of good mothering, particularly as they attempted to reconcile these standards along with seemingly incompatible practices of self-sacrifice and self-care. Many echoed the ambivalence Rich (1976) identified among mothers who vacillate between maternal ecstasy and utter frustration. Practices varied between single mothers who fiercely guarded their self-care, partnered mothers who often let self-care slip to the end of their priorities, and working mothers and stay at-home mothers (SAHMs) who struggled to reconcile self-care's shifting position between a luxury and a necessity. Working mothers, especially those who derived an essential part of their identity from their careers, discussed self-care as something that made them better mothers. Economic and marital privilege often afforded mothers the resources and/or time needed to practice self-care. Self-care replenishes mothers' reserves of patience and well-being, both of which are essential to coping with the stresses and responsibilities of mothering (Balaji et al. 2007).

While SAHMs admitted that they, too, would benefit from self-care, they were less likely to make provisions for it or to seek activities to replenish their reserves. When 
asked why, SAHMs implied that mothering as an all-consuming venture was to be expected, or at least probable. As SAHMs, their maternal experiences—even the battles - were tolerated in exchange for the "privilege" of caring for their children fulltime. They signed up for the job-some even "choosing" to leave lucrative and successful careers to do so; they were not allowed to complain.

In many ways, these mothers echoed the mothers in Stone's (2007) study of women who left of the labor market and their rhetoric of "choice feminism." The women profiled by Stone—-financially and maritally stable, highly educated and successful professionals - chose to walk away from rewarding careers once becoming mothers. After struggling to reconcile the competing standards of the "ideal worker" at work with the "good mother" at home, they accepted these conflicts as personal failures, not structural incompatibilities. Their spouses lent "support" to the women's decisions to abandon their obligations outside the home without offering to sacrifice their own careers to meet increasing familial obligations. Faced with a lack of compatible options, the women cited feminism for empowering them to make this "choice" without recognizing the institutional rigidity that constrained their decisions. The financially and maritally privileged mothers in my study and the mothers in Stone's study were both willing to abandon self-care in exchange for exercising their "choice" to mother full-time as SAHMs, masking the lack of maternal support from co-parents, spouses, and the labor market. For them, this was an anticipated part of the package.

Race influenced mothers' narratives, especially discussions of public scrutiny of maternal practices. While Edin and Kefalas (2005) found that lower-income mothers across racial groups practiced image maintenance, my findings differed. In this study, 
black mothers from all income groups attended to image maintenance to deflect the public's judgement and to meet the standards of good mothering. While lower-income, single, white mothers responded empathically to other mothers' struggles, they were able to brush off the practice of image maintenance; their racial privilege protected them from critiques of negligence when out in public with unkempt children. Future studies need to explore in depth how higher-income black mothers discuss image maintenance, as this study's sample size may be too small to generate generalizations. However, in this study, race mattered more than class in mothers' image maintenance narratives.

Next, Chapter VI reveals how mothers interpret and implement maternal support. How women incorporated maternal support into their maternal practices to meet standards of good mothering varied by race, class, and family structure. Their narratives also demonstrated how some black mothers challenged these standards by incorporating "everyday acts of resistance" and chipping away at the white, middle-class norms of mothering (Collins 1990). Showing affection for one's children and oneself, for example, is not only a demonstrative act, but an act of rebellion (hooks 2007; Lorde 1998). By doing so, these black mothers constructed hooks' (2007) "homeplace" as a site of sanctuary and preservation for their children, and incorporated Lorde's (1998) use of selfcare as a revolutionary act. Chapter VI also delves more deeply into these racial variations by exploring how black mothers conformed to and resisted normative standards of mothering constructed by and for white, middle-class women.

As discussed in Chapter IV, Mothers Helping Mothers' (MHM) peer-based support group (PSG) programming encouraged mothers - especially those with limited financial and parenting resources - to incorporate peer-based, maternal support as a form 
of self-care, an approach that lacked relevance for black mothers and single mothers. Based on the narratives from single mothers and black mothers in this study, aligning PSG topic with black mothers' attention to image (their own and their children's), ways to respond to public scrutiny, and black mothers' and single mothers' struggles to incorporate self-care practices without compromising their self-sacrificing practices of good mothering may resonate more with MHM's desired participants. Yet, except for Janeesa (discussed in Chapter VI), only white mothers in this study discussed ongoing ties to MHM and/or MV's community.

Potential programming that could appeal to a more racially/ethnically diverse demographic includes: offering resources to clothing exchanges and affordable options for consigned clothing; hosting "naked lady" parties in which mothers swap clothing and accessories they no longer use for "new" items; partnering with local salons to provide costly hair and nail services pro bono or at greatly reduced prices; hosting meal preparation workshops through which mothers receive recipes and assemble ingredients for complete, freezable meals and slow-cookers to prepare them; legal clinics regarding mediation and negotiating custody arrangements; inviting case workers from county offices and counselors to provide tips and strategies for child support and communicating with ex-partners; and a guide to budget-friendly community activities for children.

Ultimately, this chapter demonstrated how mothers' narratives of good mothering reflected their privileged and/or less-privileged statuses and their use of self-sacrifice and self-care. Next, mothers' narratives reveal that maternal support is influenced by their interpretations of good mothering and maternal practices. Whether they perceived 
maternal support to be child-centric or mother-centric seems to be entwined with privilege and race- and class-based maternal norms. 


\section{CHAPTER VI: \\ WHAT IS MATERNAL SUPPORT?: HOW GOOD MOTHERS MOTHER}

Despite the benefits associated with social and emotional maternal support for both mothers' and children's well-being (e.g., Balaji et al. 2007), mother-centric maternal support is not an element of all mothers' maternal practices. Mothers most likely to lack mother-centric maternal support (including single mothers and lower-income mothers) are also most at-risk of social isolation, postpartum depression, and compromised parenting skills (Balaji et al. 2007). Mothers Helping Mothers (MHM) presumed that this was due to a lack of access: mothers were without mother-centric maternal support because of geographic gaps in support programming. In response, MHM expanded its peer-support group (PSG) programming to under-resourced neighborhoods. Even so, as Chapter IV revealed, black mothers and single mothers did not participate in PSG programming at the same rate as white mothers and partnered mothers.

This study used in-depth interviews with racially, economically, and maritally diverse mothers to learn how mothers talk about good mothering, maternal practices, and maternal support to understand why MHM's PSG programming did not attract black mothers and single mothers as anticipated. Chapter V revealed patterns in mothers' use of self-sacrifice and self-care to meet standards of good mothering. Black mothers and single mothers were more likely to employ self-sacrifice and eschew self-care practices that were often linked to mother-centric maternal support. 
This chapter examines how women perceived maternal support, and if and how they included it in their maternal practices. Narratives about maternal support aligned with mothers' previous rhetoric of self-sacrifice and self-care, ultimately reinforcing their perceptions of good mothering. Race (and class and family structure, as secondary factors) contributed significantly to these patterns, as well. Black mothers, regardless of class, were more likely to talk about maternal support as a child-centric resource, as were lower-income mothers; more white mothers talked about maternal support as a mothercentric resource. Race, class, and family structure also influenced whether mothers viewed maternal support as a form of self-care (as most white mothers in this study did), or if it contributed to self-sacrifice (as most black mothers, single mothers, and lowerincome mothers in this study did). Therefore, if black mothers, lower-income mothers, and single mothers perceived the support offered by MHM to be mother-centric and emphasizing self-care, it was incompatible with their maternal practices equating good mothering to self-sacrifice and child-centric use of support.

Based on mothers' narratives, I constructed two themes to structure the findings discussed in this chapter: "privileged" and "less-privileged" mothering and support; and "empowered mothering." In my discussion of these findings, I posit that the intersections of race, class, and family structure influenced mothers' perceptions of good mothering, their maternal practices, and whether maternal support was an ancillary or compensatory resource. I conclude by arguing that racial and maternal ideology are embedded in these perceptions and practices. 


\section{Privileged and Less-Privileged Mothering and Support}

Mothers' interpretations of intensive mothering ideology (Hays 1996) shaped their standards of good mothering and their maternal practices; to attain these standards, mothers discussed sacrificing their own needs for their children's, or combining selfsacrifice with self-care. To assist mothers in their intensive practices and in striving for stringent standards, mothers in this study employed maternal support. Mothers talked about maternal support in two ways. Those who viewed good mothering as self-sacrifice regarded maternal support as another child-centric resource. Mothers who tempered selfsacrifice with self-care sought support for its mother-centric, self-care benefits. Class influenced the types of maternal support mothers accessed; race contributed to mothers' interpretation of support as either mother-centric or child-centric support. All mothers in this study incorporated some version of support into their various maternal practices and pursuits of good mothering.

\section{Privileged Mothering and Support}

The tenets of intensive mothering ideology as an expensive, expert-driven, emotionally-, resource- and time-intensive endeavor (Hays 1996) are predicated on mothers' racial, economic, and marital privilege. White, middle-upper-class, married mothers are best equipped to perform intensive mothering in its various manifestations (e.g., Lareau's [2003] concerted cultivation, Bobel's [2002] simple mothering) and to achieve the standards of good mothering. These privileged locations serve as the default setting for intensive maternal practices; any deviation from these locations affects 
mothers' social, economic, and emotional resources and therefore, ability to achieve this elusive standard.

Molly, a 38-year-old, white, married, upper-class mother, did not describe the same pressure to practice concerted cultivation (Lareau 2003) as the affluent black mothers in this study (e.g., Lisa, Libby, and Brenda) did; her son was all but guaranteed the skills and resources to access and navigate networks to attain success. Molly's racially, economically, and maritally privileged status allowed her to "slack" on her maternal practices without fear of altering her son's life course. Occasionally, she wondered if she "should" structure her son's time more rigorously, but quickly rationalized her less regimented approach:

He's been in front of the iPad for an hour and a half and he's just zoned out .... And you know, what am I doing? ... I'm doing stuff around the house ...that's stuff that needs to be done, right? If I was on a farm hulling corn, that has to be done too, and I wouldn't be ... teaching him how to count to 100 , I'd be hulling corn. I think about that sometimes. ... it can't be quality time every single second and I try to remind myself of that.

Molly did not feel pressure to aggressively cultivate her son's cultural capital and expand his social contacts to provide him entrée into educational and professional networks. Through her own and her partner's successes and social support systems, those connections were all but guaranteed for her son.

Molly's privilege extended to her career choices which also revealed her marital and economic support. She chose a position with greater flexibility over one with a higher salary, allowing her to spend more time with her son and reap the financial and self-care benefits that her job provided. "My position also allows me to have flexibility...to me, [that] is priceless.... I could go somewhere [else] and make ... lots of money... [but] it's not as valuable as my time. I can do that when [my son is] $20 \ldots$ or 
not, you know."

Molly's privileged maternal practice was focused on fostering her son's emotional growth: "What's going to make me happy [as a mother] is [my son] not being a jerk kid and him being a loving, good being on the planet. That's what's going to make me happy. So as long as I have enough money to feed us and you know, pay the bills, that's what I'll do." Molly knew she could "pull back" from parenting with intensity, and instead "nurture" her son and his feelings. For Molly, maternal support was malleable. It provided mother-centric support in the form of self-care, such as her regular fitness classes or a child-free weekend away with her husband, and it provided child-centric resources, such as her five-year-old son's recreational teams and yoga classes. Molly's racial, economic, and marital privilege provided her the resources she needs to perform good mothering; support was extra.

\section{Less-Privileged Mothering and Support}

Many black mothers, lower-income mothers, and single mothers, and therefore, less privileged mothers, are less equipped to achieve the standard of good mothering as defined by intensive mothering ideology (Hays 1996). Instead, these less-privileged mothers often seek compensatory resources to augment their less-privileged position(s). In Chapter V, mothers talked about modifying maternal practices and standards of good mothering; they employed methods of self-sacrifice to funnel resources and emotional energy to their children. Less-privileged mothers in this study identified a third way to supplement their maternal practices: maternal support. Across class, black mothers in this study were more likely than white mothers to recognize maternal support as a child- 
centric resource. Black mothers talked about its value to subsidize their children's physical, professional, and emotional development. Among black mothers, class influenced the types of support mothers chose and how it was included in their practices.

Less-privileged mothering:

Affluent, married, black mothers and child-centric support

Unlike Molly, affluent black mothers practicing concerted cultivation (Lareau 2003) filled the potential down time in their schedules with private lessons and leadership opportunities for their children. Libby (the 38-year-old, upper-income, married, black mother to two daughters) directed her time, energy, and resources to foster and strengthen her child(ren)'s social capital. Child-centric external activities, private lessons, and programming enriched and advanced her daughters' potential for academic, professional, and social success.

Libby sacrificed her engineering career to "manage [her daughters'] entrepreneurial ventures." Libby described rigorous strategies to maintain her family's demanding schedules; she explained that external sources of support—beyond those offered by her daughters' schools-were important:

Well, because school is not everything. You can learn in so many different ways... whatever you have a special talent to do, then that's where you need to operate ... if you never do anything else out[side] of booklearning, then you won't know what you're gifted at. And so I strongly support [my children] to be what they want to be and [to discover] the dreams that they have for themselves... I want you to do what you're good at doing and excel in that area and then you can hire somebody for the rest of it.

Libby was raising her daughters to explore beyond their school-based offerings to discover and nurture their "special talents." She did not devalue the benefit of education; 
instead, Libby recognized that education alone would not equip her daughters with opportunities for success as adults. External maternal support helped Libby accomplish this.

Lisa, the 46-year-old, black, upper-income, married mother with two daughters, and her family recently relocated to the area after a lifetime in Florida. Their transition to a new home, new schools, and a new culture was exhausting, but Lisa emphasized the importance of creating support in her new town. Starting with school and church as entry points, establishing a social network for her children's benefit became Lisa's primary task: "I turned it into a job...We started looking at churches...I'm part of a moms' organization, Jack and Jill, so I made those connections and got involved in the PTA...from there, larger groups...create smaller groups, smaller networks. [The process] was definitely thoughtful and intentional and planned." Lisa started with school- and church-based groups, but rapidly expanded her system of child-centric maternal support to include elite club-based sports teams and a membership-based organization (Jack and Jill of America or JJA) for her daughters.

In fact, all three of the upper-income and two of the three upper-middle income black mothers in this study identified JJA as a means of child-centric maternal support. Jack and Jill of America (JJA) is an independent, membership-based service organization in operation since 1938. Mothers and children up to age nineteen attend local meetings, regional gatherings, social events, and participate in service projects "dedicated to nurturing future African-American leaders...through leadership development, volunteer service, philanthropic giving and civic duty" (www.jackandjillinc.org). JJA's mission 
reflected the very essence of maternal support for higher-income black mothers: the cultivation of their children's social capital.

Nina (the 44-year-old, upper-middle income, married, black mother with three daughters) recently retired from the military. Her career required several relocations, moving her family around the country while she was raising her oldest daughters. These transfers kept Nina and her family away from her hometown and familial support systems. Now that those daughters are out of high school and Nina is retired, she focused more time and resources on her 10-year-old daughter than she did with her older daughters. The family settled into its current neighborhood and school, and Nina looked forward to being a part of the community long term. I asked her about non-familial support: "In the military...you have no family and wherever you are, you latch on and lean on whoever helps you. That's your support system."

Now that Nina lived as a civilian and established roots in her community, she reestablished her maternal support. Adjusting to life away from a military base meant adapting to a more racially homogeneous population: "Whenever we've been close enough to go to school on the military installation, [my daughter] had that [racial] diversity and everything in one spot." The lack of racial diversity at her daughter's school ("maybe 95 percent Caucasian and five percent African-American") limited their schoolrelated options and motivated Nina to keep her daughter involved with JJA. According to Nina, the benefits of JJA were transferable to most children, but especially to African American girls: "It teaches [kids] to be leaders... a lot of moms that join-it's because your kids are missing something in their upbringing." For Nina, JJA's child-centric support contributed to her daughter's social capital. Nina explained that an extensive 
number of extracurricular activities were necessary for raising a black child: "We have too many [activities]...but it's needed." These maternal supports supplemented Nina's existing parenting resources.

While JJA was regarded as support for higher-income black mothers, its direct benefits were less apparent to some of these mothers. Miranda, the 45-year-old, uppermiddle income, divorced, black mother to two children, found her informal and online social supports more valuable: “Well, Jack and Jill wasn't really a resource. I mean, it was, but it wasn't...You had to know somebody and get into their clique...I feel like I have friends that are mothers [outside of these formal groups] ...[and] I've got the good ol' internet I can look up stuff!" JJA's exclusivity contributed to its cultural value: it was not socially accessible to all, and only provided benefits to its members.

The support JJA provided was not mother-centric; Nina cited its benefits in increasing her daughter's leadership skills and community connections. Despite her current involvement with JJA, Nina echoed Miranda's sentiments about the organization. She admitted that under different circumstances, their participation with the organization may have diminished: "I think that if we... had been allowed to go to a diverse school, there's a chance I may not have joined Jack and Jill because [my daughter] would have been around a diverse culture...I think if we were in a different area, I might not have joined it." But, given her family's racially homogenous surroundings, they remained involved:

I let her go to Jack and Jill so she can be among girls of her color, her body build... all of her friends [from school] are different and she needs to see other girls like her...so, stuff like that, that got me to Jack and Jill because there are girls that look like her and are going through the same things right now. 
For Nina, JJA provided child-centric support to her daughter comprised of physically and socially similar girls; JJA also cultivated her daughter's leadership skills and cultural acumen which she can translate into future connections and opportunities.

Less-privileged mothering:

Child-centric support and "nurtured growth"

Single mothers and lower-income mothers undoubtedly lacked the financial and cultural resources to practice the tenets of concerted cultivation (Lareau 2003) embraced by privileged and more affluent mothers. In this study, however, they did not ascribe to the laissez-faire "accomplishment of natural growth" that Lareau found amongst lowerincome families in her study (2003). Instead, lower-income mothers in this study talked about a modified, more hands-on approach to mothering that prepares their children to negotiate in middle-class environments. I conceptualized this practice as "nurtured growth" to reflect these adapted standards of good mothering that combined the physical and emotional accessibility of "being there" (Edin and Kefalas 2005) with the use of institutional, child-centric resources that provide budget-friendly modifications of intensive mothering ideology (Hays 1996).

Less-privileged mothers in this study depended on child-centric support to compensate for their compromised parenting resources. Single mothers and lower-income mothers attempted to supplement the lack of a co-parent and lower family income. On paper, for example, Sandi was severely impoverished. She was a full-time student; her only income (less than $\$ 10,000$ annually) was from a scholarship from her university’s women's center for single mothers pursuing undergraduate degrees. The father of her child had always been absent and did not contribute support of any kind. 
But Sandi's daughter, then in kindergarten, attended a private, parochial school. After Sandi graduated, she was entering law school. She and her daughter lived with her parents, as they have since Sandi was pregnant. Her parents provided housing, childcare, and financial resources, and helped to further Sandi's daughter's intellectual, social, and emotional skills. Without this expansive range of child-centric support, Sandi's maternal practice might have been more similar to the lower-income single mothers practicing "accomplishment of natural growth" (Lareau 2003) or "being there" (Edin and Kefalas 2005). Instead, Sandi provided her daughter with both the physical and emotional accessibility of being there (Edin and Kefalas 2005), and the supplemental resources (parental, social, and financial) provided by her family to practice "nurtured growth."

Less-privileged mothering:

Single, lower-income, black mothers and child-centric support

Although a single, lower-income mother, Sandi's racial privilege grants her an edge over single, lower-income, black mothers. Unlike their more affluent counterparts who strategically draw from private organizations and traveling sports clubs to equip their children with social capital and cultural acumen, lower- and lower-middle income, single black mothers in this study turned to public institutions (e.g., community, school, church) for child-centric support. With limited financial means, Rhonda, Talia, and Jodi each discussed how these financially and socially accessible resources contributed to their maternal practices. In doing so, they revealed their own versions of good mothering. These mothers also reinforced that this child-centric support was an extension of selfsacrifice. 
Jodi, the 29-year-old, lower-income, divorced, black mother of two, found costconscious ways to nurture her son's (age seven) and daughter's (age five) physical, social, and emotional growth. Her children's father refused to help with the expenses, but Jodi felt strongly about the positive influence of these activities on her children's development. Their school provided some of their low-cost extra-curricular activities:

[The activities are] a great opportunity for [my son], in particular because he needs a social connection. He struggles so much socially that I feel like if I don't put him in something extracurricular, he won't get [social interaction]. It's also something physical because he is not a physical child, in the least. He will watch a movie, play a video game, read a book all day long if you let him.... [My son] needed something extra.

Beyond the physical and social benefits associated with the school's athletic options, Jodi saw the effect they had on her son's autism. When she was married, her son received professional treatment (e.g., physical therapy, occupational therapy) to support his development. As a single mother on a limited budget, school-based sports and a couple of community-based programs rounded out her children's activities:

We used to do therapy and now [sports] is cheap therapy. [My son] needed something, he needed the discipline. With my daughter, I feel like she needs an outlet. ... She's full of energy and life and that's why we chose dance and gymnastics. She needs an outlet for all that, that's why she's in extra-curricular [activities].

Like other less-privileged mothers, Jodi's use of support compensated for her low income and limited social network. She depended most on the resources the school provides for her children's physical, social, and emotional development. Her children were also involved with a local musical program, but her limited financial means rendered participation cost-prohibitive. Instead, Jodi volunteered (upwards of 20 hours a week) with the organization in exchange for her children's enrollment fees. Jodi worked 50 or 
more hours a week in her job at the local grocery store in addition to volunteering to continue providing her children these social and cultural opportunities.

Talia, the 33-year-old, lower-middle income, single, black mother to a nine-yearold boy and a daughter due imminently, pieced together support from her neighbors in her tight-knit community:

I know my block. I know the people who live around me. I know that they're looking out for my kid. I can't say that for everywhere.... [There's] power in numbers. I love community so much. I lean on the village that it takes to raise a child. That is a big influence in my world. I love being able to go places, and me feel comfortable letting my child run amok. Because I know there's twelve people [here] that love him just as much as I do.

Often serving as "othermothers" (Collins 1990), communal childcare in communities of color offer support networks comprised of extended and fictive kin. For single mothers, like Talia, and families with limited financial resources, this network is empowering for Talia (by allowing her to work full-time to support her family and to develop a career aligned with her identity and ideology), and to her child(ren) by offering "homeplace" (hooks 2007), a site of nurturance and support to shield loved ones from oppression and to replenish reserves to continue fighting. The safety and care provided by this communal support outcome may have offered Talia some mother-centric assistance, but as a single mother, she revered the network of trustworthy, loving adults as a purely child-centric benefit for her son.

Talia's neighbors' child-centric support compensated for the hands-on parenting assistance that a partner or co-parent might have provided. Her community offered social and emotional resources for her son, not simply a form of childcare. However, Talia chose to divert a significant portion of her single-mother salary to pay for her son to 
attend on-site afterschool care; her new daughter would be enrolled in daycare when Talia returned to work, as well. Foregoing free childcare from neighbors and extended kin imposed a financial burned on Talia, yet it was worth the sacrifice to expose her children to diverse settings and adults. The social interactions that both daycare and her community provided were compensatory resources to supplement her son's social, emotional, and physical development.

Rhonda, a 42-year-old, lower-middle income, single, black mother to two sons (ages 12 and 19) has always turned to church to provide child-centric support. She was raised in a religious family, so this institution has been a continuous presence in her life and a constant source of support:

For me, I cannot imagine - especially being a single mother, being a single parent - raising children and not be going to church. That is frightening.... I have two sons, [and] if they ever needed anything or had a question, whatever. ...I can't imagine myself saying that [my sons are being raised in a single-parent household because] of all the men that have surrounded me in the faith. Whatever you need, whatever. They're there.

Church members provided Rhonda and her sons with tangible resources (e.g., furniture, employment, clothing) and helped with her children's emotional and spiritual development, as well: "[T]he values that [church] teaches—-first and foremost about family—about forgiveness, about responsibility towards other mankind. ...I cannot imagine not being actively involved in a church." As a site of communal mothering and social activism, the church has served as a hub for black mothers, both motherhood and the church functioning as sites of resistance within communities of color (Collins 1990; O’Reilly 2004a:9). Yet, while Rhonda herself may have also benefitted from these more tangible forms of support, she recognized the child-centric benefits to her sons' social and emotional development above all else. 
These single, lower-income, black mothers may have lacked the financial resources needed to practice concerted cultivation (Lareau 2003) like more affluent black mothers, but they continued to prioritize their children's social, emotional, and cultural development by substituting low- and no-cost sources of support via institutions. For these mothers, school, community, and church offered child-centric resources; beyond these affordable solutions, mothers practiced self-sacrifice to pay for fee-based programs. The long-term value of these resources for their children outweighed the short-term sacrifices mothers make.

As an adaptive maternal practice, nurtured growth provides less-privileged mothers with child-centric resources to supplement their limited financial, social, and emotional capacities. Their sacrifices - most often in the form of financial resources and mother-centric support—are investments in their children's future. Less-privileged mothers practicing nurtured growth turned to lower-cost resources to attempt the improbable standards of good mothering revered by affluent black mothers and privileged mothers.

Local groups, social media, and online communities offer free and low-cost mothering resources. I asked each woman about the use of mother-centric support offered locally and online (e.g., Facebook pages, community groups, MHM's peer-based support groups), but these self-care resources did not resonate with them. Instead, mothers exerted their limited time, money, and energy on their children's endeavors; self-care was often brushed off as a non-essential practice.

Just as Jodi's interview was coming to an end, however, she remembered an online community of mothers she used to turn to for pregnancy-related support. "I 
actually joined an online community...It was like a group. ... and oh my god, those women were life savers... I would go and ask questions or where I could just go and talk about being pregnant and not get on anyone's nerves. We were all pregnant, so we could all talk about it together." Despite the social and emotional benefits Jodi referenced from this online community, she no longer participates. She explained that her need for support ended with her first pregnancy; even if that support were still needed, she now invests all of her time and resources in her children: "I don't have the energy to complain about how I don't have energy. I'm just done." But after a brief pause, Jodi's face lit up:

I do have a girlfriend that I'll call...she's the only one where I can say, "[My daughter] is being an asshole today." She's the only one where I'm comfortable calling my daughter an asshole. She gets it. She's fine. She realizes I'm not that mom and that I'm really not going to look at [my daughter] and say she's an asshole. But dammit, I think it.

Jodi may not have been able to prioritize her friendship like before, but this mothercentric form of self-care provided her with social and emotional support. While limited, it offered Jodi a modicum of self-care amidst her unrelenting practice of self-sacrifice for her children's benefit.

For most black mothers in this study, intensive mothering ideology (Hays 1996) and good mothering translated into the practice of Lareau's (2003) concerted cultivation (for affluent, married, black mothers) and nurtured growth (for lower-income, single, black mothers) of their children. Based on their financial means, they incorporated childcentric resources as supplementary support in their children's social, emotional, and cultural development. Affluent, married, black mothers turned to private organizations and exclusive clubs for these forms of support; lower-income, single, black mothers turned to public, no-cost, and low-cost institutions. 


\section{Challenging Racial and Maternal Ideologies}

Narratives from three black mothers in this study, however, diverged from other less-privileged mothers' interpretations of intensive mothering ideology (Hays 1996). Steph, Janeesa, and Valerie are single, lower-income, black mothers whose good mothering scripts did not include the familiar refrains of intensive mothering. Instead, their narratives focused on self-care and mother-centric support (similar to the maternal support promoted by Mothers Helping Mothers) in their maternal practices. They constructed their maternal support systems from various social networks: Janeesa's came exclusively from MV's on-site and online communities; Valerie's came from another nonprofit organization and MHM's PSG programming; and Steph's was a result of personal and work contacts. Despite these diverse approaches, their resulting support systems helped them to challenge racial and maternal ideologies by emphasizing mothercentric supports and self-care.

These mothers acknowledged that their use of mother-centric support contested "acceptable" forms of maternal practices amongst black mothers. They endure family members' critiques about their mothering styles and accusations of forsaking their racial ideologies. But these less-privileged mothers were still willing to eschew the dominant maternal practices and tolerate personal attacks to justify their maternal ideology. The self-sacrificial practices of concerted cultivation (Lareau 2003), simple mothering (Bobel 2002), being there (Edin and Kefalas 2005), and even "nurtured growth" did not appeal to them. Their maternal practice, disapprovingly labeled "parenting white" by their family members, served as more than just a vehicle for self-care. For them, good mothering with self-care was an intentional act of resistance. 
Less-Privileged Mothering:

Self-care as resistance and "parenting white"

Steph is a 28 -year-old, single, lower-middle income, black mother to a five-yearold daughter. Her family (comprised of her mother, grandmother, aunt, her daughter's father, and his mother) assisted with many daily parenting demands and provided childcentric support. Where Steph's maternal practice deviated from the other less-privileged mothers in this study was her extensive mother-centric support system. Made up of friends, fictive kin, and colleagues from her social activism community, this group provided Steph social and emotional support and encouraged her commitment to selfcare.

As Steph tried to make sense of her family's disapproval of her non-familial support system, she illustrated how racial ideology and maternal ideology were connected in regards to her maternal practice: "White women whine, cry, complain, and ask for help," her family told Steph when she told them that she was struggling with her transition into motherhood; "strong black women" do not exhibit their frustrations or vulnerabilities. They underscored that needing social, emotional support was a sign of weakness and threatened the "strong black woman" narrative: "[M]ental [health issues] ...whether it's counseling, depression, any of those things, it's always brushed off as, 'Oh, that's what white people do.' ... when there are moments of weepiness or...weakness or...fear, it's: 'You sound like a white woman."'

This emotional vulnerability was especially forbidden in regards to mothering challenges which called one's maternal abilities into question: "They credit [being emotional] to being something lesser or to being racial versus, 'Hey, [becoming a mother] has been a major change in [your] life.'...I do think it's definitely a racial thing." 
To her family, it said, “'You weren't ready for kids if you have to ask that [parenting] question." Steph's mother and her daughter's father struggled to understand her use of mother-centric support and self-care, and even questioned her racial ideology: "You're that 'new black.' And I'm like, 'I don't know what "new black" is!' ... 'Is there a card for that? [laughs] Do I get a purse?' [laughs]." According to Steph's family, a black mother needing emotional support was tantamount to betraying one's racial and maternal ideologies.

Single, black mothers face unrelenting emotional and physical demands. Steph recognized that her grandmother's, her mother's, and her own experiences as single, black mother were simultaneously devalued and valorized; tending to one's own needs was not an option: "As a young, black woman raised by single, black women, they're the deity. ... you know, they grind. They make things happen. They just, they DO. So, you [are expected] to just DO." Without her mother-centric emotional support and self-care, however, Steph admitted that her own physical and emotional resources for mothering would be depleted. With financial means or a co-partner, Steph might have had assistance with daily child-care demands and chores. As a less-privileged mother, however, she lauded mother-centric support and self-care as supplemental parenting resources.

De-stigmatizing mother-centric support and self-care for black mothers was a form of activism for Steph. She surrounded herself with like-minded friends and fictive kin who comprised her mother-centric support system. Together, they deconstructed their culture's confining rhetoric by expressing feelings in the face of ongoing disapproval from family members. Steph provided a recent example in which she and her support system members talked each other through the emotional first day of school for their 
children: "Because that was a big faux pas. [My family was] like, 'I know you didn't cry like a white woman dropping her off!' 'Yes. Yes, I did. And I cried the whole way there, I cried walking her in, and I cried when I got in my car. And I called my friends and I cried on the phone with them, too."”

Steph's intentional steps to destigmatize mother-centric support and self-care for black mothers resonated with Collins' (1990) writings on resistance among mothers of color. By adopting a "both/and" approach (Collins 1990), black mothers can broaden the boundaries of maternal and racial ideologies to encompass both aspects of strength and emotional vulnerability. As Steph explained: "I have my posse — the 'I-am-a-strongblack-woman"-and-“we-cry-when-we-drop-our-kids-off' group." Without examples of mother-centric, self-care to mimic, Steph and her support system members were feeling their way: “[We] just try to give each other that space: 'It's okay. You're totally valid in your feelings. It's okay. Cry and tell me all of the terrible things your two-year-old did.' Sometimes, it's just that." Through their "small acts of resistance" (Collins 1990), Steph and her support system were rewriting the "strong, black, mother" script to create space for mother-centric support.

\section{Less-Privileged Mothering:}

Formal mother-centric support and "parenting white"

Janeesa, a 30-year-old single, lower-income, black mother to her seven-year-old daughter, has also incorporated mother-centric support into her mothering practices. Instead of the hand-picked members of Steph's support system, Janeesa connected with Mama's Village (MV), an established community for mothers with online and in-person options for support. Unlike Steph, Janeesa did not have a child-centric support system; 
her family lived hours away and she and her daughter's father were estranged. Janeesa's sole source of support was the mother-centric social and emotional resource provided by the MV community.

Janeesa was a full-time nanny for an upper-income family; the mother introduced her to the predominately white, middle-class, MV community. Her initial encounter with the in-person group was not welcoming, but she soon discovered the online community and joined a sub-group for single mothers. She tried visiting another in-person gathering, but still felt unwelcomed. She voiced her frustration in a message to her online group: "I was like, 'I don't know if it's because I'm a nanny or because I'm black, but nobody will talk to me!"' This message led to online connections, which led to in-person connections: "Then I just started coming here all the time, and it's become, like, a second home." Now that Janeesa is familiar with MV's culture and the group's supportive nature, she defends their hesitations to let her into their tight-knit community: “I don't think they knew I was a mama, they just saw me as a nanny. So, it was like, 'Well, she doesn't know our struggles, she's not a mama, she's just a nanny.' I think once it was known that I had a kid, too, and I was a mama, I think that maybe that kinda changed."

Like Steph's family, Janeesa's family disapproved of her association with this non-familial form of support. Her mother, sisters, and grandmother admonished her for seeking help outside of her family and for adopting parenting practices that were not aligned with their racial ideology. Her decision to not spank her daughter, for example, was a departure from many black mothers' maternal practices. This decision created tension with Janeesa's family. Voicing their disapproval, her family not only questioned her maternal practices, but also her racial ideology: 
There's a big difference in parenting [by] social classes or even different racial classes... my family says, 'Oh, you're parenting like a white person!' It's like, 'What's parenting like a white person?'...They say I read too many books and I'm around too many white people, and that's why [I parent this way]. ...They don't agree with [my parenting style]. But...that's fine.

Janeesa's family vocalized their objections to her support network of "strangers" and critiqued her "white" parenting style.

Her family's critiques of her maternal practices kept Janeesa from turning to them for support. This offended her family, but they continued urging Janeesa and her daughter to move back home:

...[T] his community is part of the reason that I don't [move home]. ...My sister's like, 'But this is your family!' and I'm like, 'Yeah, this is too, though.' You know? I mean, I live [here and] I love it. Sometimes I get homesick and I miss my family, but the friends and family that I've made here make it okay to stay. If I ever had another kid, I wouldn't want to be anywhere else but here.

Janeesa understood her family was insulted by her decision: her maternal practices rejected not only their maternal practices but the practices most often associated with lower-income, single-mother black families. Her MV-based mother-centric support was self-care; it violated the standards of good mothering based on child-centric support and self-sacrifice. But MV provided child-centric support for Janeesa's daughter, too. Over the years, MV's support has been mother-centric (e.g., a car, driving lessons, money for insurance, furniture) and child-centric (e.g., childcare, clothing, housing, referrals to child-based programs). Like Steph, Janeesa encouraged other single mothers to connect to this source of mother-centric support to fill the dearth of social and emotional self-care many experience: “...solo moms, [we] have a lot of different hardships and feeling lonely and stuff like that. ...I'll see a mom struggling...And I'm like, 'Hey, come join [our 
group]! We're like a family.' So, yeah, I'm always telling mamas about [Mama's Village]." Janeesa found all the support she and her daughter needed through this formal community.

As a single, lower-income, black mother, Janeesa understood that some lessprivileged mothers were apprehensive to turn to a group of white, middle-class mothers, for social and emotional support. Janeesa promoted the opportunity to be exposed to different parenting styles as one of MV's benefits: “'They're just going to judge my parenting style; they're not going to understand.' And, I get it. I totally understand where that mentality could come from...[But], I mean, it's nice to be around people of different, you know, backgrounds." Eventually, Janeesa conceded that MV's membership might make less-privileged mothers reluctant to join: "Even for me... there's still that thought that they're going to look at me differently, or they're going to treat me differently. So, I think it's definitely intimidating. It still is sometimes [a challenge] for me when I'm at certain places [with MV] or certain [MV] events." In the end, the benefits that Janeesa reaped from this formal source of mother-centric support far outweighed any racial, economic, or cultural obstacles she encountered.

\section{Less-Privileged Mothering:}

Normalizing mother-centric support and self-care

Valerie (the 41-year old, single, lower-middle income, black mother to six children) bridged Janeesa and Steph's mother-centric support systems: her family's childcentric support is combined with a formal mother-centric support system. As an older mother, Valerie's role in this formal mother-centric group was one of a mentor, modeling self-care for younger less-privileged mothers (mostly single, lower-income, black 
mothers). Valerie's mother-centric support complemented the child-centric support afforded by her family. Her father and cousins provided child care, housing, and financial assistance with school-based extracurricular activities. Her self-care came from Possibilities $^{24}$ in the form of mother-centric social and emotional support. Like Steph and Janeesa, Valerie encouraged other less-privileged mothers to reap the benefits of mothercentric support and self-care.

Valerie first sought mother-centric support as a 21-year-old single mother pregnant with her second child. Faced with a lack of support from her partner at the time, she constructed an informal system of friends and fictive kin to complement her meager familial support: “[I did] not really [feel supported] by the [baby's father], but I have a lot of friends and family, and family that's not really blood family, but family just because. My chosen family. I got a lot of support from them." This fictive kin system's mothercentric support sustained Valerie through emotionally turbulent times: moves away from her home town, the births of her children, and the dissolution of her long-term romantic relationship. Valerie eventually decided to return to her home town. Coping with an unplanned pregnancy that would produce her sixth child, she was single, unemployed, and diverting all of her energy and resources to her children. Valerie decided to supplement her sacrificial practices and child-centric support from her family with selfcare and social and emotional support that she found at Possibilities. Valerie credited Possibilities' mother-centric resources with sustaining her through pregnancy and the subsequent year - an emotionally desolate and bleak period. With the groups' support

\footnotetext{
${ }^{24}$ Possibilities is a nonprofit organization providing services and programs to low-income women facing unplanned pregnancies. By agreeing to carry their pregnancies to term, the local charity offers mothers professional counseling (e.g., mental health, spiritual, referrals), programs (e.g., job training, GED classes, academic tutoring), and material goods (e.g., baby clothes, diapers, car seats, cribs).
} 
and encouragement, she decided to earn a nursing degree to provide better pay and increased stability for her family.

Possibilities' staff members and group of mothers remained an integral part of Valerie's support system. She received social and emotional support, and taught others about the benefits of mother-centric support and self-care that proved so crucial to her as an informal mentor for younger mothers at Possibilities. In her unofficial capacity, she spoke to the young mothers more bluntly than "official" representatives of the organization did, yet was careful to ensure that the mothers never felt judged for their decisions. Valerie said that the young mothers benefitted from her candid approach and were receptive to incorporating self-care and mother-centric support into their maternal practices. She relayed her own experiences as a less-privileged mother and encouraged others to take advantage of the opportunities being offered: “I don't mind giving people, anybody, those [self-care] resources because I feel like they weren't given to me [as a young mother]. I went and looked for them. I'm trying to pass it on. I feel like that's part of my purpose is to pass it on, and that's what I do." Valerie hoped her story would destigmatize mother-centric and self-care among black mothers. Even those with childcentric support sought out Valerie as a mentor on self-care and mother-centric support. She "walk[s] with them through motherhood," and demonstrated that good mothers could temper self-sacrifice with self-care.

\section{Less-Privileged Mothering: Redefining good mothering}

As seen in Chapter V and mothers' quotes above, most mothers in this study valued self-sacrifice and child-centric support as good mothering practices. Valerie, however, rejected society's standard of good mothering as unattainable: "[The good 
mother has] got to work and she's got to come home and cook a cooked meal every day. Just take care of the kids and that's all that a mom is 'supposed' to do. That's not what a mom is supposed to do!" These unrealistic expectations failed to consider the familial and resource-based constraints that less-privileged mothers encounter, forcing them to make concessions in their maternal practices: "The mom and the dad are supposed to do that when you have a family. You're supposed to do it together. Home cooked meals are good, but time doesn't give all the time. You have to improvise; you have to do other things." As she identified the challenges facing so many mothers, Valerie's rationale for augmenting her maternal practice to include both self-sacrifice and child-centric support and self-care and mother-centric support reiterated Collins' (1990) "both/and" position to empower marginalized groups:

I don't think it should just be on the mom because when the children do stuff ... whatever it is they're doing... people want to point the finger at the mom. 'The mom's not doing a good job.' Well, I disagree. What's the dad doing? What is the neighbor doing? From what I know, it takes a community. It takes a village to raise a child, it's not just me. If I see that my sister over here is having difficulty with her kids, I'm going to step in and help her. I'm not going to just let her linger and get deep in her mess and not help her out.

Merging child-centric and mother-centric support encouraged communal mothering and eschewed socially and emotionally isolating mothers. This approach echoed hooks' (2007) and Collins' (1990) themes of "other-mothering" and community-based parenting in which family members, fictive kin, and peers cared for children and mothers, creating space for self-care in good mothering practices.

Intensive mothering (Hays 1996) tropes herald self-sacrifice, encouraging good mothers to funnel all their time, energy, and resources into their children. Incorporating self-care and mother-centric support diverts mothers' resources and attention, violating 
good mothering practices. Valerie instead argued that the lack of mother-centric support and self-care can lead to poor maternal practices. She was quick to discount the notion of bad mothers and emphasized why she mentored less-privileged mothers:

A bad mom...to me, I don't really think there is a bad mom. I just think there are moms that are uneducated. I think there are moms that have not learned how to be a person themselves, so if they haven't learned to be a person themselves, how can they teach someone else to be a person? That's where guidance comes in. That's where mentoring comes in. That's where the helping hand comes in.

Valerie knew that if she — a seasoned mother of six — struggled to access social, emotional, mother-centric support, other mothers may have been unaware of this valuable resource, too.

Steph and Janeesa agreed with Valerie's sentiment that mother-centric support and self-care lead to "better" mothering. Janeesa's mother-centric support system introduced her to new resources and maternal practices, expanding her perceptions of acceptable mothering. Instead of devaluing mothering that did not align with a narrow scope of maternal practices and stringent standards, Janeesa appreciated that mothering with self-care and mother-centric support validated the myriad paths that led to good mothering: 'I hate seeing moms say, 'I'm a bad mom.' [or] 'Oh, I'm a horrible mother!' ...I'm like, 'No, you're not! Is your kid alive?' ...I mean, I just feel like a good mom is somebody who...their kids are happy and alive and...you're doing all you can...there's no wrong way to do it ... Like, there's just not." This approach encouraged lessprivileged mothers to avoid linking their maternal identity to the often disparaging institution of motherhood (Rich 1976), maternal practices, and acts of mothering so readily critiqued in society. Janeesa provided an example of shifting this rhetoric through her own struggle to stay off her phone when she spent time with her daughter: "[T]hat is 
definitely something I'm working on. It doesn't make me a bad mom, but goodness, I wish I could do better with that."

Child abuse was one criterion that Janeesa originally linked to bad mothers, but as we talked, she reconsidered her stance:

I don't think they're bad moms, I just think they need a lot of help with better choices. They're making really bad choices. ... I won't say that they don't love their kid...they just don't maybe know how. Because...that could have easily been me, but I just made a different choice.

Janeesa attributed her ability to parent differently to her use of self-care and mothercentric support: "Yeah. [I] probably could have [been a mother who hits and spanks] ...around my family and... around people that were doing it." Instead, she surrounded herself with other mothers whose maternal practices align with hers, and turned to them for parenting resources, advice, and support.

As less-privileged mothers, Steph, Janeesa, and Valerie knew how difficult mothering could be without familial, spousal, and financial support; their mother-centric support systems provided them with social and emotional support and maternal resources and advice. Drawing attention to mother-centric support and self-care reinforced their commitment to challenging existing maternal norms that shunned these practices. If the benefits of self-care and mother-centric support were more visible to other less-privileged mothers with limited resources - especially black mothers, single mothers, and lowerincome mothers - it could lessen the financial and emotional pressures associated with intensive mothering, concerted cultivation, nurtured growth, and relentless self-sacrifice, and make mothering more manageable. MHM's efforts to expand maternal support to mothers with limited resources may have been aligned with mothers' needs, yet the approach failed to resonate with mothers' interpretations of self-care and mother-centric 
support. Janeesa, Valerie, and Steph's narratives provide insight into the ways in which this support can be framed to match mothers' perceptions and ideologies of good mothering. For mothers without support, circumstances can rapidly unravel, with irreversible repercussions.

\section{Less-Privileged Mothering: Accepting mother-centric support}

Understanding the benefits of mother-centric support and self-care in their various forms may elude the neediest mothers, but perceptions of good mothering can expand to include these elements. Mother-centric support and self-care could have helped Yvonne, the 29-year-old, partnered, lower-middle income, stay-at-home, black mother caring for six children when she was younger. As a struggling single mother, her lack of mothercentric support led to potentially fatal consequences. As a result of that experience, Yvonne learned to incorporate elements of mother-centric support; her most recent pregnancy had a significantly better outcome.

When we talked, Yvonne resided with her boyfriend, the father of her threemonth-old daughter, along with his son, her nephew, and her three children from previous relationships (ages 10, 12, and 14 years). Yvonne first became a mother three weeks after turning 15 -years-old; her next two children were born when she was 16 - and 18 -yearsold. Through the years, Yvonne lost custody of her children (both willingly surrendered and forcibly removed), regained custody, married, divorced, re-partnered and decoupled, held various jobs to provide for her children, and even served time in jail. Her childcentric support system is well-established. Comprised of her own immediate and extended family members and members of her children's fathers' families, this system 
provides ongoing financial- and resource-based support for the children in her family, ranging from childcare to clothing to tangible goods and financial assistance for activities.

After her third child was born, Yvonne struggled with severe postpartum depression: "It was really, really bad. I tried to kill both of us. Good thing I didn't succeed. ... I felt like I went through that because his father, he was there, but he was no help. I had to do everything on my own." When Yvonne finally admitted that she needed social and emotional help and mother-centric support, her existing child-centric support system was ill-equipped to respond: "I told my mom [that something was wrong] and she was no help. She was no help.”

Asking for help was difficult for Yvonne. To her, resources should be directed to children; good mothering is self-sacrifice and being there (Edin and Kefalas 2005), a total emotionally and physically availability to her children: "You just do what you have to do. Whenever [her infant] calls, you just run. That's what I do...Whenever she needs something, you have to go." When Yvonne was struggling emotionally, her mother offered advice, but it violated Yvonne's good mothering standard: “'You've got to let him cry.' You don't have to let them cry. ... they're crying for a reason. They want something, even if it's just to be held. They want something." For Yvonne, good mothering required child-centric support, self-sacrifice, and utter devotion to her children; self-care and mother-centric support were antithetical.

During her most recent pregnancy, however, Yvonne received mother-centric support. A Medicaid case worker ensured that she was connected to social and emotional resources, if needed. Just knowing that someone was there to support her helped Yvonne: 
"I had a lot of help. They called me every day and made sure everything was good... They told me that after she was born, that I could go see a psychiatrist on their behalf and everything, but everything was good. I just needed someone to talk to, somebody to be in my corner." Even though Yvonne's interpretation of good mothering may not have emphasized self-care and mother-centric support, just knowing it was an option - that somebody was "in her corner" to provide emotional support—gave Yvonne the boost she needed to persevere through a potentially challenging time.

\section{Less-Privileged Mothering: Maternal support and skepticism}

While Yvonne's support system was predominantly child-centric, she learned that mother-centric, emotional support was available. Her experience illustrated the limitations of child-centric support in providing the emotional mother-centric support and self-care that can buoy less-privileged mothers through difficult times. One mother in this study lacked both child-centric and mother-centric support and talked about mothering as an unbearable endeavor. Angeline (the 26-year-old lower-income, Asian American mother of three children ${ }^{25}$ ), was estranged from her partner and lived alone with her two youngest children (six-years-old and eight-months-old) in her tiny government subsidized studio apartment. She and her daughters slept together on a mattress on the floor. She had no car nor access to reliable public transportation. Her older daughter was severely autistic and non-verbal; she attended the exceptional child program at the local public school. Angeline was too scared to leave her tiny apartment; she believed that the neighbors called Child Protective Services (CPS) on her whenever she did.

\footnotetext{
${ }^{25}$ Angeline lost custody of her oldest child to his father and paternal grandmother.
} 
Angeline was overwhelmed caring for her infant and was visibly frustrated with her other daughter's disability. She often escaped to her tiny porch to get away from her daughters' crying. Angeline was initially reluctant to meet with me; she worried that divulging her challenges would give CPS another reason to remove her children.

Ultimately, Angeline decided that her story might help other mothers who are also alone and feeling judged; she seemed relieved to have someone listen to her.

CPS was a regular presence in Angeline's life, and has been since she was a child. They intervened several times recently to investigate claims of abuse and neglect, but she had not been charged. Angeline was raised by her mother and step-dad, both of whom battled drug and alcohol addiction. She and her sister were separated and cycled in and out of foster care. By the time she aged-out of the foster care system, Angeline had one child of her own and no remaining familial ties. Through a series of bad relationships and custody battles, she ended up alone, save for her two daughters from two different fathers. Angeline and her infant's father had a turbulent relationship that included physical and emotional abuse. He provided minimal financial support for his daughter (her six-year-old daughter's father is absent), and no parenting support. For all intents and purposes, she was a single mother: "I don't have help...Just because you're getting money [from the government and from her daughter's father] no one is there with you when your baby is crying for four hours at night. You just feel like going to find a cliff and jumping off of it."

Angeline's link to the outside world was online communities. The cracked television served as a monitor for her dilapidated computer; the internet was opened to a Facebook page for mothers. For Angeline, these pages and occasional dialogue with other 
less-privileged mothers coping with isolation, neglect, depression, anxiety, and fear, offered a modicum of mother-centric support. The anonymity that online interactions provide appealed most to Angeline: "I usually talk to people on Facebook. We have a secret group that I created for myself and I have five people there that I can trust. I just write whatever I want and they'll comment or they'll call me." Angeline visited the Mama's Village's (MV) Facebook page. Unlike Janeesa, she was hesitant to share too much in that forum: “I don't really know people who are in that group [well enough] to vent like that...like I can with my friends." Angeline thought that the MV mothers were actively judging her and reporting her to CPS.

When asked about forms of mother-centric support, she conceded that she had only two friends who were often unavailable: "It seems like they can never really help. They offer to help, but it's either they are too busy or they can't help, so I just gave up [asking]." As a result, she was forced to mother in social, emotional, and physical isolation: "It gets really hard at night...around 4:00 [in the afternoon] and then it just goes to shit from there." CPS's most recent response (the Ambien-induced incident discussed in Chapter V), yielded a benefit, however: Angeline was assigned to a therapybased group for substance abuse and mental health issues. She liked the emotional, mother-centric support that this group provided: "It's not like you're in trouble. It's just like someone to help you manage your mental health...It was optional. They were like, 'You can either take it but you don't have to. We're not forcing you to, you know.' I was like, 'Sure, I'll take it. [The counselor] helped out a lot." Angeline appreciated the emotional and social mother-centric support and the break from parenting that the group required, allowing her to practice self-care. 
The absence and presence of child-centric and mother-centric support shaped Yvonne and Angeline's maternal practices. Both were less-privileged mothers; both grappled with maintaining custody of their children. Even though the bulk of parenting duties fell to Yvonne, however, her extended family provided child-centric support (e.g., childcare, financial resources, etc.). Without family support, Angeline would have been forced to seek child-centric and mother-centric support externally, making her vulnerable and at risk of public scrutiny and CPS interference. To avoid this, she pieced together a meager support system comprised of anonymous online communities and her assigned therapy group.

As less-privileged mothers, Yvonne and Angeline demonstrated how varying degrees of support may shape — or even reflect - their interpretations of intensive mothering ideology (Hays 1996) and perceptions of good mothering. They both equated good mothering with self-sacrifice and emotional and physical attentiveness, similar to the practice of being there defined by lower-income mothers in Edin and Kefalas's study (2005). Yvonne attributed her improved mothering to her use of sacrificial practices: "Now, yes [I am a good mother]. I do [consider myself one] now." Despite sharing a similar view of being there as good mothering, Angeline amended her standard to compensate for her current circumstances: "I like to view myself as a good mom because I don't give up on my kids and they're not neglected, struggling or anything. I do blame myself for [her older daughter] being non-verbal because I didn't really talk to her, read books to her, or play with her." The tenets of being there outlined her aspirations for her future maternal practices: "For me, [good mothering] would be getting my shit together... doing fun stuff with the kids every night instead of just sitting here...like 
going on walks and cooking good meals. ...It would be spending more time with [her older daughter] ...I just don't have the energy." Angeline's less-privileged circumstances were exacerbated by her nonexistent child-centric support and negligible mother-centric support, but she was hesitant to give up hope.

\section{Discussion}

For racially, economically, and maritally privileged mothers in this study, maternal support was supplemental and malleable. It could provide additional childcentric resources or create options for mother-centric, social and emotional support and self-care. Nearly all less-privileged mothers in this study, however, described pressure to supplement their caregiving with resources derived from child-centric support. Many mothers seemed to fear that mother-centric support and self-care could compromise children's outcomes. The three less-privileged mothers who embraced self-care and mother-centric support did so to intentionally challenge the restrictive parameters of good mothering and its unsustainable emphasis on self-sacrifice. They adopted self-care and mother-centric support as a vehicle for resisting confining racial and maternal ideologies.

\section{Privileged Mothering, Less-Privileged Mothering, and Concerted Cultivation}

Hays (1996) found intensive mothering, the current ideology shaping maternal practices, to be evident across economic and racial groups, but most detectible in white, middle-class, married mothers' practices. Consistent with this, I found intensive mothering ideology (Hays 1996) to be visible in mothering standards across racial, economic, and marital groups. According to Lareau (2003) class - not race-accounts for 
differences in maternal practices. Affluent black mothers in this study confirmed this through their exhaustive use of exclusive groups and private clubs to develop and enrich their children's cultural capital, supporting Lareau's claim that class trumps race in the practice of concerted cultivation (2003).

Privileged mothers (white, middle- and upper-middle-class, married mothers) in this study, however, were less likely than affluent black mothers to discuss the pressures of concerted cultivation (Lareau 2003), but still engaged in concerted cultivation practices for their children. Their racial, economic, and marital privilege afforded sufficient maternal resources, making white, middle- and upper-class, married mothers the most equipped to accomplish this maternal practice successfully. External forms of support (e.g., elite sports teams, music lessons, co-parenting support, mental health counseling) therefore, provide extra benefits, either enhancing already abundant childcentric reserves or creating mother-centric supports and opportunities to practice selfcare. Affluent, married, black mothers—lacking racial privilege—employed these external child-centric resources to help close the gap between their children and the children of privileged mothers. As a result, privileged mothers can invest external resources in self-care and mother-centric support without compromising their children's outcomes. Less-privileged mothers described pressure to channel any external support into their children's future, sacrificing their own needs. Doing so could deplete their child-centric supports and risk jeopardizing their children's opportunities for success.

Mothers' narratives from this study revealed not only who practices concerted cultivation (Lareau 2003), but how. The use of maternal support reflects mothers' racial, economic, and marital privilege. Maternal support allows privileged mothers to either 
embellish their children's abundant social and financial reserves, or to enhance their maternal reserves with self-care practices and mother-centric support. Alternatively, most less-privileged mothers in this study employed self-sacrifice and maternal supports to accrue compensatory resources and support to increase their children's cultural capital.

Edin and Kefalas (2005) found that even mothers with minimal means practice intensive mothering through "being there" for their children. By being emotionally available and physically present to their children at all times, poor mothers compensate for their lack of economic and cultural resources by dedicating their time and care to mothering. This study, like Edin and Kefalas's (2005), found that the lowest-income mothers practiced tenets of "being there" across racial groups, but it was more prevalent for the lower-income, non-white mothers. For the mothers of the residential treatment facility (Urban Site 2), "being there" was one of the only forms of good mothering practices available. Due to court-mandated programming, a complete lack of income and financial resources, and residential separation from their families, mothers could only offer their physical presence and emotional availability to their newborn children.

Less-Privileged Mothering:

Simple mothering, being there, and nurtured growth

Without financial and cultural means, Lareau (2003) asserts that mothers are more likely to recognize accomplishment of natural growth, a hands-off, less demanding form of parenting than concerted cultivation. However, in this study I found that when race and class intersected with family structure, lower-income mothers, especially single, lowerincome, black mothers, practiced "nurtured growth." This maternal practice combines the emotional and physical intensity of being there (Edin and Kefalas 2005) with external, 
child-centric resources to add onto mothers' limited means. Despite a status that deviates from that of the white, middle-class, married mother, less-privileged mothers draw from various sources of maternal support to boost their parenting capital. Unlike their affluent counterparts' use of elite organizations and private clubs, less-privileged mothers turned to established institutions (e.g., schools, church, community), at times even sacrificing their own needs to accumulate the resources required to perform this modified form of intensive mothering.

Alternatively, lower- and lower-middle income, married, white mothers in Chapter V—and including some of the mothers who participated in MHM's PSG programming in Chapter IV—were more likely to employ simple mothering practices (Bobel 2002), instead. Simple mothering often requires fewer financial resources than concerted cultivation (Lareau 2003), making it more accessible to lower-income mothers; yet, it retains the exhaustive practices of intensive mothering and self-sacrifice, resonating with mothers' interpretations of good mothering. Since the mothers in MHM's PSG programming were more likely to be partnered as well, their racial and marital privilege are assets to their simple mothering practices. By constructing the mothercentric support systems promoted by MHM, these white, lower-income, partnered mothers can access additional resources and self-care techniques to maintain the stringent practices of simple mothering even with their minimal resources.

As I entered this study through organizations providing maternal support (MV and MHM), I focused on maternal support (in all its forms) throughout this study of motherhood. Edin and Kefalas' (2005) findings defined the value of motherhood (along with relationships and perceptions of marriage) for lower-income mothers. Lareau (2003) 
focused on childrearing practices, socialization, and variations across economic class. By asking mothers more about maternal support, therefore, my findings offer insight into mothering practices across race, class, and family structure. Specifically, I contribute a nuanced understanding of the practice of mothering and how different kinds of support matter for different groups of women.

\section{Empowered Mothering:}

Self-care as racial and maternal resistance

Intensive mothering (Hays 1996) in its various maternal practices, including concerted cultivation (Lareau 2003); simple mothering (Bobel 2002); being there (Edin and Kefalas 2005), and "nurtured growth" each call for all-consuming maternal concentration, constant self-sacrifice, and infusions of child-centric resources to attempt the rigorous standards of good mothering. A small group in this study—comprised of lower-income, single, black mothers - rejected these intensive mothering practices. Instead, they promoted self-care and mother-centric support, and redefined their standards of good mothering.

For these mothers - Steph, Janeesa, and Valerie - using mother-centric supports and committing to self-care not only challenges these norms. These are acts of empowerment. This theme, "empowered mothering," combines attributes of fictive kinbased support systems (e.g., Stack 1974), communal mothering and "othermothers" (Collins 1990; hooks 2007); "homeplace" as a site of resistance (hooks 2007); and selfcare as a radical act (Lorde 1992). For these mothers to accomplish their practice of "empowered mothering," mother-centric support systems are crucial. Their use of these supports demonstrates a potential bridge between other black mothers and Mothers 
Helping Mothers' (MHM) community-based programming promoting self-care and mother-centric support. MHM and other maternal support groups might employ this frame to connect with black mothers, aligning with Valerie's "empowered mothering" work as a mentor for mothers needing help.

"Empowered mothering" challenges cultural, racial, and maternal norms. Family members' disapproval of this maternal practice illustrates how deeply the elements of racial and maternal ideologies are intertwined. Critiques of the mothers' practices of selfcare questioned their racial identities and their mothering abilities. This can be seen in Steph's family, who criticized her for "parenting white" when relying on emotional support from othermothers. Self-care is construed as an indulgent (and irresponsible) act afforded to those with financial and cultural resources; mother-centric support and selfcare diverts time, energy, and resources away from child-centric ventures. Good mothers sacrifice themselves for their children; mother-centric support—especially emotional support-implies weakness and an inability to handle the demanding acts of mothering, posing a threat to the iconic strong, black mother. In contrast, empowered mothers' emphasis on self-care challenges the norm of self-sacrifice and emotional stoicism held by black mothers; self-care is synonymous with "parenting white."

For black mothers practicing empowered mothering, however, acts of self-care may be motivated by various forces. While Steph identified self-care as a vehicle for resisting isolated racial and maternal norms, Janeesa and Valerie's acts of self-care seemed to be a necessity. Both were physically and emotionally detached from their families and previous support systems. Further research is needed to better understand the motivating factors for empowered mothering. Ultimately, these empowered mothers 
modeled a commitment to self-care and mother-centric support for other mothers in hopes of redefining maternal standards for black mothers.

The maternal practice of "nurtured growth" also reveals why MHM's efforts to reach lower-income, single mothers often fell short. By turning to public resources and institutions (e.g., church, school), these mothers have constructed their own child-centric support systems. MHM's focus on mother-centric support and self-care, therefore, seems irrelevant or time-consuming for mothers practicing nurtured growth. In Chapter VII, I discuss the cultural mismatch between MHM and its intended participants, and offer suggestions to assist MHM and other organizations offering maternal support to reach black mothers, lower-income, and single mothers practicing nurtured growth and empowered mothering. 


\section{CHAPTER VII: DISCUSSION AND CONCLUSION}

This intersectional study of maternal standards, maternal practices, and maternal support revealed several key findings. The program evaluation of Mothers Helping Mothers' (MHM) peer-based support group (PSG) in Chapter IV produced two noteworthy findings to understand why MHM faced challenges attracting participants of color and single mothers. First, MHM's staff's own maternal practice of simple mothering (Bobel 2002) informed its PSG programming curriculum. Simple mothering as a maternal practice benefits from economic and marital privilege to achieve its intensive standards of good mothering, rendering it incompatible with single mothering, especially lower-income single mothers. Second, MHM's staff members' difficulty in recognizing this ideology's incompatibility with its targeted participants' attributes suggests a level of cultural incompetency. Together, the program evaluation findings indicate that the PSG program's curriculum and approach reflected the white, middle-class, married mothers' maternal practices of MHM's staff. Thus, their approach did not resonate with racially, economically, and maritally diverse participants' perceptions of good mothering and maternal practices.

Next, I found that race, class, and family structure influenced mothers' definitions of good mothering, which informed both maternal practices and approaches to maternal support. Narratives revealed that perceptions of good mothering — self-sacrifice for most, self-sacrifice tempered by self-care for few-shaped maternal practices and defined their 
maternal standards. For mothers with some economic and marital privilege, perceptions of good mothering often reflected their interpretation of intensive mothering ideology (Hays 1996). Less privileged mothers adapted maternal standards and practices to accommodate lower incomes or single parenting.

Finally, mothers' scripts about good mothering also revealed that perceptions of maternal support are affected by race, class, and family structure. Mothers' views of good mothering - whether it is synonymous with sacrifice or if it can include elements of selfcare-influence their definitions and uses of maternal support. Those aligning good mothering with sacrifice incorporate maternal support as a child-centric resource; maternal support as a mother-centric resource appears to be reserved for mothers practicing self-care. Mothers use maternal support to supplement their maternal practices and achieve their standards of good mothering. These findings offer a deeper understanding of mothering perceptions and can inform recommendations for organizations working to support diverse groups of mothers.

This study illuminated the challenges mothers encounter as they make sense of maternal standards, practices, and support; the intersections of race, class, and family structure complicates this process for many. Privileged maternal support (defined by mothers' racial, economic, and marital privilege) can supplement existing child-centric resources and/or provide mother-centric care without compromising children's outcomes. Less-privileged maternal support is almost always child-centric; the less-privileged mothers in this study used it to equip their children with as many resources as possible. Assimilation and adaptation are additional strategies employed by black mothers to increase the likelihood of their children's physical and emotional well-being and survival. 
With the addition of the multi-institutional politics (MIP) approach to examining social movements (Armstrong and Bernstein 2008), these findings clarify why MHM and its PSG programming resonated with white mothers and partnered mothers, but did not appeal to black mothers and single mothers as MHM had intended. Racial, economic, and marital privilege not only benefit the practice of simple mothering - the ideology embedded in MHM's PSG curriculum, but also provides parenting support and resources to better equip children for success. Examining the organization and its programming from a systems-centered intersectional perspective (Choo and Ferree 2010:133) revealed how institutional inequalities informed the lived experiences of the marginalized mothers MHM was trying to reach.

Next, I offer two themes constructed from mothers' narratives to explain their various experiences and strategies to construct support: "nurtured growth," "empowered mothering," I apply these themes to discussions within the context of the sociological literature on mothering and family support. I demonstrate how maternal support reinforces both racial and maternal ideologies, especially for black mothers practicing concerted cultivation (Lareau 2003), nurtured growth, and empowered mothering, and how understanding mothers' strategies for maternal support underlie the cultural mismatch between MHM's programming and its targeted demographics.

These findings can help organizations like MHM working to extend culturally competent support to all mothers, especially mothers from racially, economically, and maritally marginalized groups. I contend that MHM's cultural mismatch can be alleviated by reframing its PSG programming through empowered mothering and nurtured growth, and offers MHM an opportunity to attract more participants of color and single mothers. 
Repositioning MHM's mother-centric version of support through the lens of empowered mothering promotes a form of self-care that resonates with some black mothers and single mothers. At the same time, MHM's staff's strengths_-building community networks and making referrals to child-centric resources—can connect black mothers, lower-income mothers, and single mothers practicing nurtured growth to these benefits. Customizing its PSG programming to incorporate less-privileged maternal supports positions MHM to become the "bridge" it desires to be to these communities.

\section{Discussion}

Maternal Practices, Maternal Support, and Child Outcomes

How mothers in this study interpreted good mothering informed their maternal practices and usage of maternal support; these were influenced by race, class, and family structure. Children's physical and emotional development, and their future successes framed mothers' decisions. For black mothers, especially mothers of sons, survival underscored this motivation (Dow 2016b). Life expectancy (Olshansky et al. 2012), physical health (Anderson, Bulatao, and Cohen 2004), emotional well-being (McLeod and Owens 2004; Balaji et al. 2007), and incarceration rates (Western and Pettit 2010) in the United States vary significantly by race, income, and educational attainment, each influencing children's outcomes.

Socioeconomic status (SES) contributes (Anderson et al. 2004) to the racial disparity and stratification of life expectancy, quality of life, and risk of imprisonment (Anderson et al. 2004); race and class combine to create a cumulative disadvantage for lower-income black children and well-being over the life course (McLeod and Owens 
2004). Alternatively, educational attainment contributes to increases in income and lifetime earning potential, economic stability, marital stability, neighborhood safety, and physical and emotional well-being (McLeod and Owens 2004; Olshansky et al. 2012; Anderson et al. 2004), decreases the risk of imprisonment (Pettit and Western 2004), and lessens the effects of incarceration over the life course (Western and Wildeman 2009; Pettit and Western 2004; Western and Pettit 2010). To improve black children's outcomes, less-privileged mothers provide protective forms of preservation that are embedded in their maternal practices (e.g., concerted cultivation, nurtured growth, and empowered mothering).

\section{Culturally Mismatched Uses of Maternal Support}

As the program evaluation of MHM's PSG programming (Chapter IV) showed, racial, economic, and marital privilege are embedded within simple mothering (Bobel 2002) ideology and practices. I expand on Bobel's work and argue that race, class, and family structure is embedded in maternal support; these integral factor(s) affect mothering in ways MHM and the PSG programming failed to take into account. For example, simple mothering (Bobel 2002) practices—-such as those promoted in MHM's PSG programming — encourage mothers to trust that they are all that their child needs to thrive. Expensive equipment and excessive external advice interferes with the "intuitive" process of parenting. But this stripped down approach to mothering involves upfront and on-going investments of time (e.g., attachment parenting, extended breast-feeding) and money (e.g., cloth diapering, baby wearing) that make simple mothering inaccessible to 
women without economic and spousal supports-elements often connected to racial privilege - to implement and sustain these intensive acts.

Ideally, simple mothers have the financial means, resources (e.g., stay-at-homemothering, flexible work schedules), and support (e.g., spouse, familial support systems) needed to practice this intensive form of mothering. Yet, many simple mothers with these financial and parenting supports seek mother-centric, social and emotional support for this all-consuming practice. Mothers possessing economic and marital privilege are at an advantage for practicing this (and other) forms of good mothering. Investing their remaining energy and resources in constructing mother-centric support systems, and receiving the benefits of this support as self-care do not compromise children's outcomes.

Racial oppression has financially and maritally marginalized black mothers throughout history, making it necessary for black mothers to divert available resources to children. This sacrificial approach to mothering is embedded within racial perceptions of good mothering ideology and practices (Collins 1990): as black mothers in this study confirmed, good mothering is often synonymous with sacrifice. Self-care and mothercentric support, therefore, may contradict the cultural and racial ideologies of parenting held by black mothers. For example, Steph, Janeesa, and Valerie's practice of empowered mothering drew accusations of "parenting white" from their families; their use of selfcare weakened their maternal abilities and their racial identity, from the perspective of their families. 
Amended Maternal Practices: Nurtured growth and maternal support

A lack of social, emotional, and economic means may make the practice of concerted cultivation unattainable. Mothers in this study demonstrated that good mothering can be adapted through the use of nurtured growth. Nurtured growth allows less-privileged mothers to amend standards and practices of good mothering to align with fewer resources. Mothers in this study practicing nurtured growth turned to maternal support as a child-centric resource to accomplish this maternal practice. Whereas higherincome black mothers sought private clubs and prestigious organizations to accumulate their children's resources, lower-income mothers and single mothers invested the childcentric benefits of less-privileged maternal support.

Because mothers practicing nurtured growth most often identified maternal support in the form of accessible institutional resources (e.g., church, school), public programs (e.g., community centers, libraries), and community (e.g., neighbors, extended and fictive kin) to supplement their child-centric practices, MHM could partner with these institutions and established public resources. Connecting mothers practicing nurtured growth to additional community-based programs would position MHM as a conduit to existing resources, allowing its staff to use its racial and economic privilege to assist marginalized mothers in navigating the various institutions and structures that are often barriers to black mothers and lower-income mothers. In doing so, the founders of MHM could also revisit an original goal of their grassroots activism: being a bridge between existing resources and people who need them. This approach would help MHM overcome its cultural mismatch — not by working to avoid it, but by making the 
imbalance of power (via racial, economic, and marital privilege) work for its programming and its participants.

\section{Empowered Mothering and Maternal Support}

"Caring for myself is not self-indulgence, it is self-preservation, and that is an act of political warfare."-Audre Lorde (1992)

The maternal practice of empowered mothering incorporates elements of communal mothering and "othermothers" (Collins 1990; hooks 2007); "homeplace" as a site of nurturance and resistance (hooks 2007) and love and mothering through "motherwork" (Collins 1990); and self-care as a radical act (Lorde 1992). Beyond accomplishing this practice for themselves and their children - for which maternal support systems are crucial - empowered mothers and their maternal support systems are engaged in redefining maternal ideologies, standards, and practices to empower other mothers. While their activist-inspired ideologies and manners diverge from other black mothers in this study, the goal for their children is the same: preservation.

Through activism, empowered mothering challenges dominant maternal standards, practices, and outcomes. "Small acts of resistance" (Collins 1990) redefine and reshape measures of good mothering, such as emphasizing self-care over self-sacrifice and constructing mother-centric, social and emotional support systems. Replacing “either/or" (Collins 1990) mothering (e.g., either invest in one's children or invest in oneself) with "both/and" (Collins 1990) approaches (e.g., performing acts of self-care and nurturing children) become radical acts of preservation for black mothers and black children. 
The practice of empowered mothering contests racial and maternal ideologies, as does MHM's programming. Some mothers may be reluctant to employ empowered mothering; indeed, the empowered mothers in this study faced their families' critiques of their maternal practices and racial identity may compromise much-needed support systems. But it is because of empowered mothers' self-care and their well-established, non-familial, mother-centric support systems that they are able to withstand accusations of "parenting white" and risk losing the support provided by their familial systems to continue their maternal practices. For other black mothers without mother-centric support, the loss of their familial support would be too great.

MHM's programming proved to be a cultural mismatch for mothers practicing empowered mothering, but not for the same reasons as mothers practicing nurtured growth. Instead, I argue that MHM's incompatibility with empowered mothers is tied to their similarities. Both are challenging institutional and structural forces of power to expand definitions of good mothering. Both are expanding support to mothers through radical self-care. To reach mothers practicing empowered mothering, I recommend that MHM align its practices with these mothers, revering them for the positions of leadership they already occupy within their support networks. Turning to empowered mothers - as coaches, advisors, and leader - provides MHM with advocates for maternal support and ambassadors to the very communities it seeks to serve. Aligning their forces, MHM and empowered mothers could expand the grassroots effort underway to expand maternal support. 


\section{Implications for Maternal Support Programs and Mother-Centric Self-Care}

Within this study's exploration of mothering standards and practices, race was pervasive. Elements of racial privilege and subjugation were evident in one-on-one interviews with participants, in participants' accounts of their own maternal standards, experiences, and perceptions, and in the notable presence and absence of Mothers Helping Mothers' (MHM) peer-support group (PSG) participants. Race informed findings from the program evaluation, the focus group, and in-depth interviews.

Altogether, these findings demonstrated the intersecting effects of race, class, and family structure on maternal standards and practices; race is specifically embedded in mothercentric maternal support.

Mothers in this study were most likely to practice simple mothering (Bobel 2002), concerted cultivation (Lareau 2003), being there (Edin and Kefalas 2005), and nurtured growth. ${ }^{26}$ Each practice incorporates elements of intensive mothering ideology (Hays 1996) and/or self-sacrifice to achieve its standards of good mothering. While MHM and its white participants worked to construct peer-based maternal support to provide mothercentric self-care, black mothers and lower-income mothers in this study were less likely to discuss self-care ${ }^{27}$ and rarely considered maternal support a mother-centric resource.

Becoming "that bridge" for mothers:

Systems-centered intersectionality and frame bridging

In the focus group with the founders of Mothers Helping Mothers' (MHM), a collective desire to "be that bridge" between maternal support/resources and less-

\footnotetext{
${ }^{26}$ The exception to these maternal practices, "empowered mothering," is discussed above.

${ }^{27}$ Affluent mothers of color occasionally incorporated self-care measures to replenish themselves, immediately resuming their exhaustive practices of concerted cultivation (Lareau 2003).
} 
privileged mothers motivated the creation of peer-based support group (PSG) programming. Employing Choo and Ferree's (2010) system-centered intersectional approach in this study, however, provides a deeper understanding of the incompatibility between MHM's programming and its targeted communities. To authentically connect with racially, economically, and/or maritally disadvantaged mothers, MHM must consider how race, class, gender, and other forms of oppression are both embedded within multiple institutions (e.g., family, work, government, etc.), and how this institutionalization of oppression affects mothers differently.

Without understanding how these various forms of oppression influence mothers' perceptions and practices, MHM encouraged mothers - especially those with limited financial and parenting resources - to incorporate peer-based, mother-centric support as a form of self-care. For many black mothers, lower-income mothers, and single mothers, this use of privileged maternal support was incompatible with their good mothering practices emphasizing self-sacrifice and child-centric support. This culturally mismatched form of maternal support echoed the cultural incompetency embedded in MHM's simple mothering-based curriculum.

MHM's PSG programming rhetoric — rooted in simple mothering (Bobel 2002) ideology — also required economic and marital privilege to attain good mothering and did not resonate with many lower-income mothers, single mothers, and black mothers. The curriculum's discussion of cloth diapering and extended breastfeeding, for example, demonstrated MHM's oversight of the multiple intersections of power (e.g., race, class, family structure) across several institutions (e.g., family, work, policy). For the mothers at Urban Site 2, the residential facility's strict policies were antithetical to many of the 
practices promoted in the PSG programming. As participants in a court-ordered, residential treatment facility for drug and/or alcohol abuse, the mothers faced the threat of permanently losing custody of their children and lacked any power to contest these restrictive policies.

Empowered mothering, however, demonstrated how some lower-income, single, black mothers actively redefine maternal ideologies, standards, and practices to empower themselves and other mothers; they emphasize preservation via self-care and turn to maternal support as mother-centric resources. Decoupling simple mothering from the PSG programming reveals how the tenets of empowered mothering and simple mothering overlap. I suggest that MHM's mother-centric peer-based support group programming could resonate with some black mothers if reframed as empowered mothering.

People construct frames — mental shortcuts or ways of knowing — to make sense of the world around them and to inform behaviors, as illustrated by the various perceptions of good mothering and maternal acts in mothers' narratives. MHM, as a social movement organization (SMO), employs its own frames about mothering, as do its participants or members (Snow, Rochford, Worden, and Benford 1986; Snow and Benford 1988; Snow and Benford 1992; Johnston 1995). The act of challenging norms and contesting frames is most successful when the SMO and its members align frames, providing a shared language and view; often, however, adaptation is required to facilitate interaction between the groups. Bridging these multiple frames incorporates aspects of each to construct a common platform for collective action (Snow et al. 1986:467). Frame bridging would allow MHM to present its maternal support curriculum and social change agenda to the targeted demographic in a culturally familiar format and language. Doing 
so would help the MHM attract new participants, demonstrate its reverence to maternal ideologies and practices beyond its own, and increase membership for its movement.

Like empowered mothering, MHM's simple mothering approach does not require excessive financial means and excessive resources; both practices reject consumerism and the commodification of mothering. Like empowered mothering, MHM is working to redefine standards of good mothering and reshape maternal practices to create space for maternal support and self-care. Reframing its PSG programming as preservation via selfcare and self-acceptance, and promoting mother-centric support systems through maternal activism informed by homeplace (hooks 2007) and small acts of resistance (Collins 1990; Collins 1994) demonstrates its transferability to black mothers.

Incorporating tenets of nurtured growth into the PSG programming could reach other racially diverse mothers, as well. The elements of the PSG programming focused on connecting mothers to community resources would resonate with lower-income, single, black mothers seeking child-centric public and institutional resources to supplement their limited resources. In lieu of simple mothering demonstrations, MHM should focus on access to existing institutions and low- and no-cost community programs to enhance these mothers' child-centric practices.

Image maintenance (to stave public scrutiny) proved to be another shared practice for black mothers and lower-income mothers. In Chapter V, I recommended potential programming for MHM to connect with these mothers (e.g., clothing swaps, spa days, meal preparation workshops, and other acceptable — and budget friendly-forms of selfcare) to introduce MHM to new groups. Engaging participants through these forms of self-care without compromising their good mothering practices could foster peer-based 
connections organically through MHM's social gatherings. Additional forms of acceptable mother-centric support (e.g., pro bono legal clinics, case worker/counselor workshops, low-cost or free activities for children) could attract this demographic, as well. Ultimately, however, participants and mothers from the targeted communities should be asked to provide input and MHM's programming should reflect this feedback.

MHM can increase its efficacy in extending support to mothers across racial, economic, and maritally diverse groups by incorporating this study's primary findings (empowered mothering, nurtured growth, and less-privileged maternal support). Despite this study's findings and these recommendations, MHM's founders will continue to face challenges in their intersectional approach to expanding support to less-privileged mothers. Their emphasis on privilege and power - their own and the participants'-is laudable, as is their valiant commitment to social justice via expanded maternal support. Yet, as white, middle-class, married mothers mobilizing intersectional efforts, microscale corrections and macro-scale social justice will continue to be difficult. Because MHM is limited in its ability to increase the larger social and/or economic power of its participants (Luft and Ward 2009:33), lasting and larger impacts of their programming remain elusive.

Regardless, this study's findings deepen our understanding of how mothers define and recognize good mothering and apply maternal standards to their practices. This understanding can bolster MHM's local efforts to construct programming that supports mothers with racially, economically, and maritally diverse perceptions of good mothering practices, and position MHM at the forefront of broader cultural contestations to expand maternal practices. These findings can assist other community based organizations 
working to support mothers, as well. Traditionally top-down organization (e.g., government agencies) would benefit from incorporating client feedback to garner which types of resources and programming is needed; presuming a one-size-fits-all approach to serving diverse populations will continue to clash with maternal ideologies and practices, and reinforce a lack of support for mothers who may need it. Grassroots organizations (e.g., church and civic groups) could find that this participatory-based outreach increases interest from the targeted communities and serves to empower under-supported mothers, as well. Recognizing the diverse interpretations of good mothering and mechanisms to support it are essential to reaching the very women who may benefit most from bolstered networks of support.

\section{Study Limitations and Future Research}

\section{Study Limitations}

Findings from this study may apply to other similar mothers. The quantitative aspects of the evaluation of Mothers Helping Mothers (MHM)'s peer-based support group (PSG) programming (Chapter IV) - based on the population of PSG participants instead of a statistical sample - offer the potential for generalizable findings. My observations of MHM's programming may be based on specific interactions, yet the themes of cultural incompetency and mismatched perceptions of maternal ideologies are likely consistent with other groups using a simple mothering ideology to reach diverse mothers.

My study was also limited by time- and resource-based constraints. I originally intended to conduct several focus groups: with mothers who participated regularly in 
MHM's programming; mothers who attended MHM's PSG programming once, but no more; and mothers who did not attend any MHM gatherings. Ultimately, I conducted only one focus group (with MHM's founders-Chapter IV). Through the focus group, I gathered the standpoints of MHM's staff members and triangulated the findings from the individual interviews as a way of engaging in feminist research methodologies.

Due to the size and scope of this study, I intentionally focused my in-depth interviews with participants who varied by race, class, and family structure. Given a broader scope and timeline, I would have conducted additional in-depth interviews with participants from additional groups, including ethnically diverse mothers, foreign-born mothers, and sexually-diverse mothers. Narratives from these-and other-groups are necessary to construct a comprehensive understanding of mothers' experiences and the social forces shaping them. Time constrained my collection of in-depth interviews (in number and duration) as most interactions were limited to one meeting per participant. More time could have permitted me to foster more authentic connections with participants, potentially resulting in deeper insight into mothers' perceptions and experiences.

Race played an enormous part in this study. In this study's location, black mothers comprised the largest non-white population; thus, I based my interview collection and interpretations of non-white mothers on these (only two participants identified as neither white nor black — one Latina mother and one Asian American mother). My own racial, economic, and marital privilege may have affected how comfortable less privileged mothers were in sharing their stories. The candor of their 
stories, however, make me somewhat confident that most were open about their views on and experiences of motherhood.

Gift cards may have increased participation among low-income participants, allowing for more participants from racially and maritally diverse low-income mothers. Even without compensation, however, mothers in this study were extremely gracious with their limited time and balanced competing demands to create space to talk. Funding to pay additional researchers, especially those from racially, economically, and maritally diverse backgrounds, to collect in-depth interviews, could have increased the number of interviews performed, established entrée into additional participant groups, and provided insight and context to improve this study's cultural competency.

\section{Future Research}

Additional research is needed to continue expanding knowledge about maternal practices, experiences, limitations, and perceptions, and how mothers' perceptions are influenced by social locations. The intersections of race, class, and family structure account for extensive variations in these experiences, and future research must continue to address these differences. Subsequent studies must examine maternal practices across additional racially and ethnically diverse groups to ascertain how privileged and lessprivileged maternal support accounts for variations in other maternal practices.

Heteronormativity is rampant in this study; no participants identified as lesbian, bisexual, or transgender mothers. Expanding an intersectional analysis of maternal practices to address this is crucial to include narratives that reflect alternative family formation and structural constraints. Examining mothers' paths to motherhood- 
including fertility treatments, adoption, surrogacy, and foster care-will provide insight into if and how these mothers practice simple mothering (Bobel 2002), given cultural feminism's emphasis on biologically divined knowledge and practices. Learning from mothers who have lost children (to miscarriage, stillbirth, death, and custody) would show if and how maternal ideologies and experiences shape women's perceptions of mothering and if this maternal status is a permanent or conditionally-dependent one. Incorporating fathers' narratives would demonstrate how paternal ideologies and practices are assumed and how these experiences vary across race, class, and family structure. As fathers become increasingly (albeit, still marginally) involved with childrearing, racial and gender ideologies - and their intersection with class, sexuality, and other social locations - may provide insight into engaging more hands-on parenting by fathers and why some fathers might be reticent to embrace paternal practices. How fathers make sense of paternal ideologies, paternal practices, and especially the limited standards of "good fathering," could demonstrate ways to increasing fathers' involvement in marital and non-marital families.

Finally, additional research on the grassroots maternal activism evident in this study is imperative. Cumulatively, the mothers in this study practicing empowered mothering; the organizations involved (Mothers Helping Mothers and Mama's Village); the women who established and lead these groups; and the mothers who participated in MHM and MV programming (online and in person) represent shifting perceptions of motherhood. I argue that these collective efforts - especially those spearheaded by MHM and MV—constitute a social movement to reshape institutional, extra-institutional, and cultural norms influencing maternal practices and maternal support. 
The cumulative efforts of MHM and MV's staff and volunteers are redefining maternal support systems to shift mothering from an isolated endeavor to a communal one. Institutionally, MHM identifies public and private resources to support mothers, and encourages the expansion of social, emotional, and financial services for disadvantaged mothers at-risk of social isolation and postpartum depression. Using the multiinstitutional politics (MIPs) approach (Armstrong and Bernstein 2008) to evaluate these collective efforts will center these cultural contestations and their abilities to affect social change. By examining MV and MHM's resources, frames, activities, and outcomes, research into organizations' grassroots strategies and outcomes could determine if these collective efforts warrant recognition as a legitimate social movement.

\section{Conclusion}

The themes of privileged and less-privileged maternal support, nurtured growth, and empowered mothering help explain how diverse mothers in this sample approached mothering differently. Race and class influenced mothers' interpretations of intensive mothering ideology (Hays 1996), with the intersections of race, class, and family structure shaping how most mothers incorporated maternal support to perform concerted cultivation (Lareau 2003), simple mothering (Bobel 2002), and nurtured growth. These practices reflected mothers' maternal and racial ideologies, racial, economic, and marital privilege and marginalization. A small group of mothers diverged from these most common practices, and rejected the standards of good mothering and maternal practices associated with intensive mothering ideology (Hays 1996). Instead, these mothers incorporated maternal support as a mother-centric form of self-care and a form of 
empowerment. Understanding how mothers' race, class, and family structure contribute to maternal standards, practices, and usage of maternal support can aid Mothers Helping Mothers and other grassroots organizations working to support mothers. Increasing the efficacy of mother-centric, social and emotional support systems can improve well-being for mothers at an increased risk of emotional and social isolation due to a lack of community-based resources and maternal support systems (Balaji et al. 2007). 


\section{REFERENCES}

Alcoff, Linda. 1988. "Cultural Feminism Versus Post-Structuralism: The Identity Crisis in Feminist Theory." Signs: Journal of Women in Culture and Society 13(3):405436.

Ampofo, Akosua Adomako. 2008. “In My Mother's House: Mothering, Othering, and Resisting Racism." In Mothering in the Third Wave. Amber E. Kinser, Ed. Demeter Press: Toronto, ON.

Anderson, N.B., R.A. Bulatao, and B. Cohen (Eds.). 2004. "Critical Perspectives on Racial and Ethnic Differences in Health in Late Life." National Research Council (US) Panel on Race, Ethnicity, and Health in Later Life. National Academies Press (US): Washington, DC. http://www.ncbi.nlm.nih.gov/books/NBK25532/. Retrieved March 26, 2016.

Armstrong, Elizabeth A. and Mary Bernstein. 2008. "Culture, Power, and Institutions: A Multi-Institutional Politics Approach to Social Movements.” Sociological Theory 26(1):74-99.

Avishai, Orit. 2007. "Managing the Lactating Body: The Breast-Feeding Project and Privileged Women.” Qualitative Sociology, 30: 135-152.

Balaji, A.B., A.H. Claussen, D.C. Smith, S.N. Visser, M.J. Morales, and R. Perou. 2007. "Social Support Networks and Maternal Mental Health and Well-Being." Journal of Women's Health 16(10):1386-96.

Bartley, Tim and Curtis Child. 2014. "Shaming the Corporation: The Social Production of Targets and the Anti-Sweatshop Movement." American Sociological Review 79(4):653-679.

Bernstein, Mary. 2008. “The Analytic Dimensions of Identity.” In Identity Work in Social Movements, Jo Reger, Rachel Einwohner, and Daniel Myers (Eds.), 277301. University of Minnesota Press: Minneapolis, MN.

Bernstein, Mary, and Marcie De la Cruz. 2009. "What Are You? Explaining Identity as a Goal of the Multiracial Hapa Movement." Social Problems 56(4):722-745.

Bernstein, Mary and Kristine A. Olsen. 2009. "Identity Deployment and Social Change: Understanding Identity as a Social Movement and Organizational Strategy." Sociological Compass 3(6):871-883. 
Bernstein, Mary. 2013. "Power, Politics and Social Movements: A Multi-Institutional Politics Approach.” Politics, Groups and Identities 1(1): 87-93.

Bianchi, Suzanne M., Liana C. Sayer, Melissa A. Milkie, and John P. Robinson. "Housework: Who Did, Does or Will Do It, and How Much Does It Matter?" Social Forces 91(1):55-63.

Bledsoe, Katrina L. and James A. Graham. 2005. Using multiple evaluation approaches in program evaluation. American Journal of Evaluation, 26:302-319.

Bobel, Chris. 2002. The Paradox of Natural Mothering. Temple University Press: Philadelphia, PA.

Bobel, Chris. 2007. "Resisting, But Not Too Much: Interrogating the Paradox of Natural Mothering." In Maternal Theory: Essential Readings. Andrea O’Reilly, Ed. Demeter Press: Toronto, ON.

Bureau of Labor Statistics. 2016. "Employment Characteristics of Families, 2015." http://www.bls.gov/news.release/famee.nr0.htm. Retrieved August 29, 2016.

Choo, Hae Yeon, and Myra Marx Ferree. 2010. "Practicing Intersectionality in Sociological Research: A Critical Analysis of Inclusions, Interactions, and Institutions in the Study of Inequalities.” Sociological Theory 28(2):129-149.

Christopher, Karen. 2012. "Extensive Mothering: Employed Mothers' Constructions of the Good Mother." Gender \& Society, 26, 1: 73-96.

Collins, Patricia Hill. 1990. Black Feminist Thought: Knowledge, Consciousness, and the Politics of Empowerment. Routledge: New York, NY.

Collins, Patricia Hill. 2007. "Shifting the Center: Race, Class and Feminist Theorizing About Motherhood." In Maternal Theory: Essential Readings. Andrea O'Reilly, Ed. Demeter Press: Toronto, ON.

Copeland, Debra Beach and Bonnie Lee Harbaugh. 2004. "Transition of Maternal Competency of Married and Single Mothers in Early Parenthood," Journal of Perinatal Education. 13(4): 3-9.

Correll, Shelley J., Stephen Bernard, and In Paik. 2007. "Getting a Job: Is There a Motherhood Penalty?" American Journal of Sociology 112(5):1297-1339.

Dillaway, Heather E. 2008. "Mothers for Others: A Race, Class, and Gender Analysis of Surrogacy." International Journal of Sociology of the Family. 34, 2: 301-326.

Douglass, Susan J. and Meredith W. Michaels. 2007. "The New Momism." In Maternal Theory: Essential Readings. Andrea O’Reilly, Ed. Demeter Press: Toronto, ON. 
Dow, Dawn Marie. 2016a. "Caring for Them Like Family: How Structure and Culture Simultaneously Influence Contemporary African American Middle- and UpperMiddle-Class Mothers' Kin and Community Child Care Choices." Sociology of Race and Ethnicity 2(1):72-86.

Dow, Dawn Marie. 2016b. "The Deadly Challenges of Raising African American Boys: Navigating the Controlling Image of the 'Thug'." Gender \& Society 30(2):161188.

Dow, Dawn Marie. 2016c. "Integrated Motherhood: Beyond Hegemonic Ideologies of Motherhood." Journal of Marriage \& Family 78(1):180-196.

Edin, Kathryn and Maria Kefalas. 2005. Promises I can keep: Why poor women put motherhood before marriage. University of California Press: Berkeley, CA.

Fine, Michelle and Lois Weis. 1996. "Writing the 'Wrongs' of Fieldwork: Confronting Our Own Research/Writing Dilemmas in Urban Ethnographies." Qualitative Inquiry 2(3):251-274.

Fine, Michelle, Lois Weis, Susan Weseen, and Loonmun Wong. 2003. "For Whom?: Qualitative Research, Representations, and Social Responsibilities." In The Landscape of Qualitative Research, Norman K. Denzin and Yvonna S. Lincoln (Eds.) Sage Publications: Thousand Oaks, CA.

Fletcher, Richard, G. Vimpani, G. Russell, and D. Keating. 2008. "The evaluation of tailored and web-based information for new fathers." Child: Care, Health and Development. 34, 4: 439-446.

Fominaya, Cristina Flesher. 2010. "Collective Identity in Social Movements: Central Concepts and Debates," Sociology Compass 4(6):393-404.

Giuffre, Katherine. 2013. Communities and Networks: Using Social Network Analysis to Rethink Urban and Community Studies. Polity Press: Cambridge, UK.

Glenn, Evelyn Nakano, Grace Chang, and Linda Rennie Forcey (Eds.). 1994. Mothering: Ideology, Experience, and Agency. Routledge: New York, NY.

Goldberg, Abbie E. and Katherine R. Allen. 2015. "Communicating Qualitative Research: Some Practical Guideposts for Scholars." Journal of Marriage and Family 77:3-22.

Gore, Ariel. 2007. "High Risk: Who a Mother Should Be." In Maternal Theory: Essential Readings. Andrea O’Reilly, Ed. Demeter Press: Toronto, ON. 
Gürbüz, Mustafa E. 2015. "Ideology in Action: Symbolic Localization of Kurdistan Workers' Party in Turkey.” Sociological Inquiry 85(1): 1-27.

Gürbüz, Mustafa E., and Mary Bernstein. 2012. “"Thou Shall Not Protest!': MultiInstitutional Politics, Strategic Nonconfrontation and Islamic Mobilizations in Turkey.” Pp. 63-91 In Nonviolent Conflict and Civil Resistance. Emerald Group Publishing Ltd: Bingley, UK.

Hallstein, D. Lynn O’Brien. 2008. “Second Wave Silences and Third Wave Intensive Mothering." In Mothering in the Third Wave. Amber E. Kinser, Ed. Demeter Press: Toronto, ON.

Harding, Sandra G. 1987. "The Method Question,” Hypatia 2(3):19-35.

Harding, Sandra G. 1991. Whose Science? Whose Knowledge?: Thinking from Women's Lives. Cornell University Press: Ithaca, NY.

Hatchett, Bonnie and Daniel A. Duran. 2002. "An Approach to Community Outreach Practice in the 21st Century." Journal of Community Practice 10 (2):37-52.

Hays, Sharon. 1996. The Cultural Contradictions of Motherhood. New Haven: Yale University Press.

Hays, Sharon. 2007. “Why Can't a Mother Be More Like a Businessman?” In Maternal Theory: Essential Readings. Andrea O’Reilly, Ed. Demeter Press: Toronto, ON.

Hesse-Biber, Sharlene Nagy and Patricia Leavy. 2006. The Practice of Qualitative Interviewing. Sage Publications, Inc.: Thousand Oaks, CA.

Hewett, Heather. 2008. "Of Motherhood Born." In Mothering in the Third Wave. Amber E. Kinser, Ed. Demeter Press: Toronto, ON.

Hochschild, Arlie Russell. 1989. The Second Shift: Working Parents and the Revolution at Home. Viking: New York, N.Y.

hooks, bell. 1984. Feminist Theory: From Margin to Center. South End Press: Cambridge, MA.

hooks, bell. 2007a. "Revolutionary Parenting." In Maternal Theory: Essential Readings. Andrea O’Reilly, Ed. Demeter Press: Toronto, ON.

hooks, bell. 2007b. "Homeplace: A Site of Resistance." In Maternal Theory: Essential Readings. Andrea O'Reilly, Ed. Demeter Press: Toronto, ON. 
Huisman, Kimberly. 2008. “'Does This Mean You're Not Going to Come Visit Me Anymore?': An Inquiry into an Ethics of Reciprocity and Positionality in Feminist Ethnographic Research,” Sociological Inquiry 78(3):372-396.

Jadresic, E., R. Araya, and C. Jara. 1995. "Validation of the Edinburgh Postnatal Depression Scale (EPDS) in Chilean Postpartum Women," Journal of Psychosomatic Obstetrics and Gynecology 16(4):187-191.

Johnston, Hank. 1995. "A Methodology for Frame Analysis: From Discourse to Cognitive Schemata" in Social Movements and Culture, Hank Johnston and Bert Klandermans, eds. University of Minnesota Press: Minneapolis, MN.

Lareau, Annette. 2003. Unequal Childhoods: Class, Race, and Family Life. University of California Press: Berkeley, CA.

Levitt, Mary J., Ruth A. Weber, and Cherie M. Clark. 1986. "Social network relationships as sources of maternal support and well-being." Developmental Psychology 22(3):310-316.

Long, D. Adam and Douglas D. Perkins. 2003. "Confirmatory Factor Analysis of the Sense of Community index and Development of a Brief SCI," Journal of Community Psychology 31(3):279-296.

Lorber, Judith. 2010. Gender Inequality: Feminist Theories and Politics. Oxford University Press: New York, NY.

Lorde, Audre. 1992. A Burst of Light: Essays. Women's Press: Toronto, ON.

Luft, Rachel E. and Jane Ward. 2009. "Toward an Intersectionality Just Out of Reach: Confronting challenges to intersectional practice," Pp. 9-37 in Perceiving Gender Locally, Globally, and Intersectionally. Vasilike Demos and Marcia Texler Segal (Eds.). Emerald Group: Bingley, UK.

Luthar, Suniya. 2015. "Mothering Mothers." Research in Human Development 12 (3-4): 295-303.

Luthar, Suniya S. and Lucia Ciciolla. 2016. "What It Feels Like to Be a Mother: Variations by Children's Developmental Stages." Developmental Psychology 52(1):143-154.

Kinser, Amber E. (Ed.). 2008. Mothering in the Third Wave. Demeter Press: Toronto, ON.

Kuumba, M. Bahati. 2001. Gender and Social Movements. AltaMira Press: Walnut Creek, CA. 
Mama to Mama. 2014. "Updates from Mama to Mama.” Electronic newsletter. Received April 10, 2014.

Mann, Susan Archer. 2012. Doing Feminist Theory: From Modernity to Postmodernity. Oxford University Press: New York, NY.

Maxwell, Joseph A. 1996. Qualitative Research Design: An Interpretive Approach. Sage Publications, Inc.: Thousand Oaks, CA.

McKenzie, Cameron. 2016. "Love, Lust, and Loss in the Early Age of AIDS: The Discourse in the Body Politic from 1981 to 1987." Journal of Homosexuality 116.

McLeod, Jane, and Timothy Owens. 2004. "Psychological Well-Being in the Early Life Course: Variations by Socioeconomic Status, Gender, and Race/Ethnicity." Social Psychology Quarterly 67 (3):257-278.

Mental Health America. http://www.mentalhealthamerica.net/conditions/postpartumdisorders. Retrieved March 28, 2015.

Miller, Amy Chasteen. 2006. "Like a Natural Woman: Negotiating Collective Gender Identity in an Alternative World." Sociological Spectrum: Mid-South Sociological Association 27(1):3-28.

Moraga, Cherríe and Gloria Anzaldúa. 1983. This Bridge Called My Back: Writings by Radical Women of Color. Kitchen Table, Women of Color Press: New York, NY.

Morgan, David L. 1997. Focus Groups as Qualitative Research. Sage Publications, Inc.: Thousand Oaks, CA.

Naples, Nancy A. 1998. Grassroots Warriors: Activist Mothering, Community Work, and the War on Poverty. Routledge: London, UK.

Olshansky, S.J., T. Antonucci, L. Berkman, R.H. Binstock, A. Boersch-Supan, J.T. Cacioppo, B.T. Carnes. 2012. "Differences in Life Expectancy Due to Race and Educational Differences Are Widening, and Many May Not Catch Up." Health Affairs (Project Hope) 31(8):1803-13.

O’Reilly, Andrea. 2004a. Toni Morrison and Motherhood: A politics of the heart. SUNY Press: Albany, NY.

O'Reilly, Andrea. 2004b. From Motherhood to Mothering: The Legacy of Adrienne Rich's of Woman Born. SUNY Press: Albany, NY.

O’Reilly, Andrea (Ed.). 2007. Maternal Theory: Essential Readings. Demeter Press: Toronto, ON. 
O’Reilly, Andrea (Ed.). 2008. Feminist Mothering. SUNY Press: Albany, NY.

O'Reilly, Andrea (Ed.). 2010. 21st Century Motherhood: Experience, Identity, Policy, Agency. Columbia University Press: New York, NY.

O'Reilly, Andrea (Ed.). 2012. What Do Mothers Need? Motherhood Activists and Scholars Speak Out on Maternal Empowerment for the $21^{\text {st }}$ Century. Demeter Press: Bradford, ON.

O'Reilly, Andrea (Ed.). 2014a. Mothers, Mothering and Motherhood Across Cultural Differences: A Reader. Demeter Press: Bradford, ON.

O’Reilly, Andrea. 2014b. "African American Mothering: 'Home is Where the Revolution Is'." In Mothers, Mothering and Motherhood Across Cultural Differences: A Reader. Andrea O’Reilly, Ed. Demeter Press: Bradford, ON.

Pettit, Becky, and Bruce Western. 2004. "Mass Imprisonment and the Life Course: Race and Class Inequality in U.S. Incarceration." American Sociological Review 69 (2): 151-169.

Putnam, Robert D. 2015. Our Kids: The American Dream in Crisis. Simon \& Schuster: New York, NY.

Raley, Sara, Suzanne M. Bianchi, and Wendy Wang. 2012. "When Do Fathers Care? Mothers' Economic Contribution and Fathers' Involvement in Child Care." American Journal of Sociology 117(5):1422-1459.

Reich, Jennifer A. 2014. "Neoliberal Mothering and Vaccine Refusal: Imagined Gated Communities and the Privilege of Choice." Gender \& Society 28, 5:679-704.

Reich, Stephanie M. and Jennifer A. Reich. 2006. "Cultural Competence in Interdisciplinary Collaborations: A Method for Respecting Diversity in Research Partnerships," American Journal of Community Psychology 38(1):51-62.

Reinharz, Shulamit and Lynn Davidman. 1992. Feminist Methods in Social Research. Oxford University Press: New York, NY.

Rich, Adrienne. 1976. Of Woman Born: Motherhood as Experience and Institution. Norton: New York, NY.

Rich, Adrienne. 2007. "Anger and Tenderness." In Maternal Theory: Essential Readings. Andrea O'Reilly, Ed. Demeter Press: Toronto, ON.

Roberts, Dorothy. 2011. "Killing the Black Body: Race, Reproduction and the Meaning of Liberty." In Shifting the center: Understanding contemporary families. Susan J. Ferguson, ed. McGraw-Hill: New York, NY. 
Rothman, Barbara Katz. 2007. "Beyond Mothers and Fathers: Ideology in a Patriarchal Society.” In Maternal Theory: Essential Readings. Andrea O’Reilly, Ed. Demeter Press: Toronto, ON.

Snitow, Ann. 2007. "Feminism and Motherhood: An American Reading.” In Maternal Theory: Essential Readings. Andrea O'Reilly, Ed. Demeter Press: Toronto, ON.

Snow, David A., E. Burke Rochford, Jr., Steven K. Worden, and Robert D. Benford. 1986. "Frame Alignment Processes, Micromobilization and Movement Participation," American Sociological Review 51(4): 546-481.

Snow, David A. and Robert D. Benford. 1988. "Ideology, Frame Resonance, and Participant Mobilization" in International Social Movement Research: From Structure to Action, Bert Klandermans, Hanspeter Kriesi, and Sidney Tarrow, eds. JAI Press: Greenwich, CT.

Snow, David A. and Robert D. Benford. 1992. "Master Frames and Cycles of Protest" in Frontiers in Social Movement Theory, Aldon D. Morris and Carol McClurg Mueller, eds. Yale University Press: New Haven, CT.

Sprague, Joey. 2005. Feminist Methodologies for Critical Researchers: Bridging Differences. Rowman \& Littlefield: Walnut Creek, CA.

Springer, Kristen W. 2010. "The Race and Class Privilege of Motherhood: The New York Times Presentations of Pregnant Drug-Using Women.” Sociological Forum 25(3): 476-499.

Stack, Carol B. 1974. All Our Kin: Strategies for Survival in a Black Community. Harper \& Row: New York, NY.

Stone, Pamela. 2008. Opting out? Why women really quit careers and head home. University of California Press: Berkeley, CA.

Story, Kaila Adia (Ed.). 2014. Patricia Hill Collins: Reconceiving Motherhood. Demeter Press: Bradford, ON.

Stufflebeam, Daniel L. 2001. “CIPP Evaluation Model Checklist,” NYLC Resource Center. Retrieved March 3, 2014 from www.wmich.edu/evalctr/checklists.

Taylor, Ronald D. and Debra Roberts. 1995. "Kinship Support and Maternal and Adolescent Well-Being in Economically Disadvantaged African-American Families." Child Development, 66:1585-1597.

Taylor, Verta and Leila J. Rupp. 1993. "Women's Culture and Lesbian Feminist Activism: A Reconsideration of Cultural Feminism." Signs: Journal of Women in Culture \& Society 19(1):32-61. 
Taylor, Verta A. 1996. Rock-a-by Baby: Feminism, Self Help, and Postpartum Depression. Routledge: New York, NY.

Taylor, Verta, Katrina Kimport, Nella Van Dyke, and Ellen Ann Andersen. 2009. "Culture and Mobilization: Tactical Repertoires, Same-Sex Weddings, and the Impact on Gay Activism.” American Sociological Review 24(6):865-890.

Thornton, Patricia H., William Ocasio, and Michael Lounsbury. 2012. The Institutional Logics Perspective: A New Approach to Culture, Structure, and Process. Oxford University Press: Oxford, UK.

Tucker, Judith Stadtman. 2008. "Mothering in the Digital Age: Navigating the Personal and Political in the Virtual Sphere." In Mothering in the Third Wave. Amber E. Kinser, Ed. Demeter Press: Toronto, ON.

Walker, Alice. 2007. "In Search of Our Mothers' Gardens." In Maternal Theory: Essential Readings. Andrea O’Reilly, Ed. Demeter Press: Toronto, ON.

Walker, Rebecca. 2008. "How my mother's fanatical views tore us apart," DailyMail.com. Retrieved October 17, 2016. http://www.dailymail.co.uk/femail/article-1021293/How-mothers-fanaticalfeminist-views-tore-apart-daughter-The-Color-Purple-author.html

Weiss, Robert Stuart. 1994. Learning from strangers: the art and method of qualitative interview studies. New York: Free Press.

Western, Bruce and Becky Pettit. 2010. "Incarceration and Social Inequality." Daedalus 139 (3): 8-19.

Western, Bruce and Christopher Wildeman. 2009. "The Black Family and Mass Incarceration." The Annals of the American Academy of Political and Social Science 621 (1): 221-242.

Williams, Joan. 2010. Reshaping the Work-Family Debate: Why Men and Class Matter. Harvard University Press: Cambridge, MA.

Williams, Charlotte and Mekada Graham. 2016. Social Work in a Diverse Society: Transformatory Practice with Black and Minority Ethnic Individuals and Communities. Policy Press: Bristol, UK.

Wilson-Mitchell, Karline and Vincia Herbert. 2014. "Black Motherhood and The Power of the Intersectionality Framework: A Midwifery Perspective on the 'New Racism'.” In Patricia Hill Collins: Reconceiving Motherhood. Kaila Adia Story, Ed. Demeter Press: Bradford, ON. 


\section{APPENDIX I: \\ MOTHERS HELPING MOTHERS PROGRAM EVALUATION SURVEYS}

1. Comprehensive Survey-Administered to all participants at baseline, third, and sixth visits.

a. Parenting Self-Efficacy Subscale-Administered to all participants at baseline, third, and sixth visits.

b. Edinburgh Postpartum Depression Scale-Administered to all participants at baseline, third, and sixth visits.

c. Sense of Community Index-Administered to all participants at third and sixth visits.

2. Topic-specific Parenting Self-Efficacy Subscale-Administered to all attendees of monthly peer-based support group gathering; pre- and post-test.

3. Participant Contact Form-Administered to all attendees at first visit.

4. Confidential Demographic Form-Administered to all attendees at first visit. 
1. Peer-based Support Group Comprehensive Survey

Please respond to the following statements by circling a number on the scale of 1 (strongly disagree) to 5 (strongly agree).

\author{
Strongly \\ Disagree \\ Strongly \\ Agree
}

1. I would make a fine model for a new mother to follow in order to learn what she would need to know to be a good parent. (SE1)

2. The problems of taking care of a baby are easy to solve once you know how your actions affect your baby, an

$\begin{array}{lllll}1 & 2 & 3 & 4 & 5\end{array}$
understanding I have acquired. (SE2)

3. Being a parent is manageable, and any problems are easily solved. (SE3)

4. I meet my own personal expectations for expertise in caring for my baby. (SE4)

5. If anyone can find the answer to 1

23

3

45 (SE5)

6. Considering how long I've been a mother, I feel thoroughly familiar with the role. (SE6)

7. I honestly believe I have all the skills $\begin{array}{lllll}1 & 2 & 3 & 4 & 5\end{array}$ necessary to be a good mother to my baby. (SE7) 
Please read the following statements that people might make about this support group. After each statement, please check "true" if it is mostly true or "false" if it is mostly false. [OBß]'

8. I think this support group is a good place for me to participate. (SC1) TRUE FALSE

9. People on this support group do not share the same values. (SC2) TRUE FALSE

10. My peers and I want the same things from the support group. (SC3) TRUE FALSE

11. I can recognize most of the people who participate in this support group. (SC4) TRUE FALSE

12. I feel at home in this support group. (SC5) TRUE FALSE

13. Very few of my peers in this support group know me. (SC6) TRUE FALSE

14. I care about what my peers in this support group think of my actions. (SC7) TRUE FALSE

15. I have no influence over what this support group is like. (SC8) TRUE FALSE

16. If there is a problem in this support group, people who participate can get it solved. (SC9) TRUE FALSE

17. It is very important to me to participate in this particular support group. (SC10) TRUE FALSE

18. People in this support group generally don't get along with each other. (SC11) TRUE FALSE

19. I expect to participate in this support group for a long time. (SC12) TRUE FALSE 
As you are pregnant or have recently had a baby, we would like to know how you are feeling. Please check the answer that comes closest to how you have felt in the past 7 days, not just how you feel today. Here is an example, already completed:

I have felt happy:

$\square$ Yes, all the time.

Yes, most of the time.

No, not very often.

No, not at all.

This would mean: "I have felt happy most of the time" during the past 7 days. Please complete the other questions in the same way.

In the past 7 days:

20. I have been able to laugh and see the funny side of things

As much as I always did.

Not quite so much now.

Definitely not so much now.

Not at all. (PD1)

24. I have felt scared or panicky for no very good reason

$\square$ Yes, quite a lot.

$\square$ Yes, sometimes.

$\square$ No, not much.

21. I have looked forward with

enjoyment to things

$\square$ As much as I ever did.

Rather less than I used to.

$\square$ Definitely less than I used to.

Hardly at all. (PD2)

22. I have blamed myself unnecessarily when things went wrong

$\square$ Yes, most of the time.

Yes, some of the time.

Not very often.

No, never. (PD3)

23. I have been anxious or worried for no good reason

$\square$ No, not at all.

Hardly ever.

No, not at all. (PD5)

25. Things have been getting on top of me

Yes, most of the time I haven't been able to cope at all.

$\square$ Yes, sometimes I haven't been coping as well as usual.

$\square$ No, most of the time I have coped quite well.

$\square$ No, I have been coping as well as ever. (PD6)

26. I have been so unhappy that I have had difficulty sleeping

$\square$ Yes, most of the time.

$\square$ Yes, sometimes.

$\square$ Not very often.

No, not at all. (PD7)

Yes, sometimes.

Yes, very often. (PD4)

27. I have felt sad or miserable

Yes, most of the time.

Yes, quite often.

Not very often.

No, not at all. (PD8) 
28. I have been so unhappy that I have been crying

Yes, most of the time.

$\square$ Yes, quite often.

Only occasionally.

$\square$ No, never. (PD9)

29. The thought of harming myself has occurred to me

Yes, quite often.

Sometimes.

Hardly ever.

Never. (PD10)

Thank you so much for taking the time to complete this survey. Your feedback is so important to the success of this program.

We always want to hear your comments and suggestions. 
2. Peer-based Support Group Topic-specific Parenting Self-Efficacy Survey.

Please respond to the following statements on the topic of PREGNANCY SELF-CARE by circling a number on the scale of 1 (strongly disagree) to 5 (strongly agree).

1. I would make a fine model for a new

mother to follow in order to learn what she would need to know about pregnancy self-care. (SE1)

2. The problems pregnancy self-care are easy to solve once you know how your actions affect your pregnancy, an understanding I have acquired. (SE2)

3. Pregnancy self-care is manageable, and any problems are easily solved. (SE3)

4. I meet my own personal expectations for expertise in pregnancy self-care. (SE4)

5. If anyone can find the answer to pregnancy self-care, I am the one. (SE5)

6. Considering how long I've been pregnant/a mother, I feel thoroughly familiar with pregnancy self-care. (SE6)

7. I honestly believe I have all the skills necessary to be a good mother to my baby. (SE7)
Strongly

Disagree

Strongly

Agree

$\begin{array}{lllll}1 & 2 & 3 & 4 & 5\end{array}$

$\begin{array}{lllll}1 & 2 & 3 & 4 & 5\end{array}$

$\begin{array}{lllll}1 & 2 & 3 & 4 & 5\end{array}$

$\begin{array}{lllll}1 & 2 & 3 & 4 & 5\end{array}$

$\begin{array}{lllll}1 & 2 & 3 & 4 & 5\end{array}$

$\begin{array}{lllll}1 & 2 & 3 & 4 & 5\end{array}$

$\begin{array}{lllll}1 & 2 & 3 & 4 & 5\end{array}$




\section{Peer-based Support Group Participant Contact Form}

Welcome! Please help us respond to your needs by providing the following information.

\section{All information is confidential.}

Name (first, last):

Preferred name or nickname:

Mailing address:

Phone number:

Email address:

What is the best way to communicate with you?

$\begin{array}{ll}\square \text { Phone } & \square \text { Mail } \\ \square \text { Text } & \square \text { Facebook } \\ \square \text { Email } & \\ \square \text { Other: } & \end{array}$
(D1)

Your date of birth:

(D2)

Are you a first-time mama? (D3) If not, how many children do you have?

Your new baby's birthday or due date:

If you are currently pregnant, are you currently receiving prenatal care from a nurse, doctor, or midwife?

$\square$ Yes

$\square$ No

Other:

$\square$ Sometimes

(D6)

Over, please $>$ 
If you have already delivered, have you attended or are you planning to attend a six-week post-partum visit with a nurse, doctor, or midwife?
$\square$ Yes
$\square$ Maybe
$\square$ No
$\square$ Other:

How did you hear about this group? (Please check all that apply.)
Friend
WellCare Case Manager
Relative
$\square$ Other:

What is your current relationship status?

$\square$ Single

It's complicated.

In a relationship

Other:

Married

Thank you so much. We're so happy you're here! 


\section{Peer-based Support Group Participant Confidential Demographic Form}

The following information is confidential.

Please do not put your name anywhere on this paper.

1. Which race(s) do you identify as? (Please check all that apply.)

$\square$ Hispanic/Latina

African American

White

Asian

More than one race

Other:

2. What is the highest level of education you have completed?

Some high school (still going to school)

Some high school (no longer going to school)

$\square$ Graduated high school (earned a high school diploma)

GED (passed the high school equivalency exam)

Some community or technical college (like JCTC)

Finished community or technical college (earned an Associate's degree)

Some 4-year college (like UofL)

Finished 4-year college (earned a Bachelor's degree)

Other: (D10)

3. What is your annual income range? Please include all sources of support.

$\square \$ 0-\$ 4,999$ per year.

$\$ 5,000$ - $\$ 9,999$ per year.

$\square 10,000$ - $\$ 14,999$ per year.

$\square \$ 15,000$ - $\$ 19,999$ per year.

$\$ 20,000$ - $\$ 29,999$ per year.

$\$ 30,000$ or more per year. (D11)

4. Where are you currently living?

My own apartment or house

Relative's apartment or house

Friend's apartment or house

A group home or shelter

Other: (D12) 
5. Who are you currently living with? Please check all that apply.

$\square$ I live alone.

$\square$ I live with relatives.

Mother

$\square$ Father

$\square$ Step-mother

Step-father

Grandmother(s)

Grandfather(s)

Sister(s)

Brother(s)

$\square \operatorname{Aunt}(\mathrm{s})$

$\square$ Uncle(s)

Niece(s)

Nephew(s)

Cousin(s)

$\square$ My own children

Step-children

Other

I live with a romantic partner.

Husband

$\square$ Boyfriend

$\square$ It's complicated

I live with a friend/friends.

$\square$ It depends.

Other:

6. Do you have a people who emotionally support you?

YES

NO (D14)

7. If you answered yes, who is in your support system? Please check all that apply.

My friends

My relatives

My romantic partner

My children

A teacher or pastor

Other

Over, please -> 
8. Do you currently have health insurance?

YES NO (D16)

9. If you answered yes, who is your provider?

WellCare-Medicaid

$\square$ Passport-Medicaid

$\square$ Humana-Medicaid

$\square$ Anthem-Medicaid

$\square$ Coventry/Aetna-Medicaid

$\square$ Medicare

$\square$ Commercial plan (Employer)

$\square$ Commercial plan (Health Exchange/Individual)

Other

Your feedback helps to improve this and future programs.

Thank you so much. 


\section{APPENDIX II: \\ MOTHERS HELPING MOTHERS PROGRAM EVALUATION OUTCOME REPORT FORMS}

1. Program Evaluation Outcome Report Form-Urban Sites

2. Program Evaluation Outcome Report Form-Rural Site 
1. Outcome Report Forms-Urban Locations (Urban Site 1; Urban Site 2; and Urban Site 3)

\begin{tabular}{|c|c|c|c|}
\hline $\begin{array}{l}\text { EXPECTED } \\
\text { OUTCOMES }\end{array}$ & INDICATORS & RESULTS TO DATE & $\begin{array}{l}\text { CHALLENGES AND } \\
\text { LESSONS LEARNED }\end{array}$ \\
\hline $\begin{array}{l}\text { Increased self- } \\
\text { confidence in } \\
\text { parenting skills } \\
\text { and resources. }\end{array}$ & $\begin{array}{l}\text { Parenting Self- } \\
\text { confidence } \\
\text { Pre- and post-tests } \\
\text { Referrals/resource } \\
\text { packets }\end{array}$ & $\begin{array}{l}12.62 \% \text { increase in parenting } \\
\text { self-efficacy and confidence in } \\
\text { parenting skills across all urban } \\
\text { sites, all classes, all participants. } \\
\text { Making referrals and } \\
\text { disseminating resource packets. }\end{array}$ & $\begin{array}{l}\text { Class topics resonate with } \\
\text { participants and address areas of } \\
\text { information that increase } \\
\text { confidence in parenting skills. } \\
\text { Peer-discussion and access to } \\
\text { resources and referrals are } \\
\text { hypothesized to contribute, as } \\
\text { well. }\end{array}$ \\
\hline $\begin{array}{l}\text { Increase peer-to- } \\
\text { peer support for } \\
\text { expecting and new } \\
\text { mothers. }\end{array}$ & $\begin{array}{l}\text { High, increasing Sense } \\
\text { of Community (SCI) } \\
\text { scores } \\
\text { Attendance/engagement } \\
\text { Referrals/resource } \\
\text { packets }\end{array}$ & $\begin{array}{l}\text { SCI average score of } 91.7 \% \text { for } \\
\text { the two urban sites where } \\
\text { administered; } 16.7 \% \text { increase in } \\
\text { SCI from baseline to } 3^{\text {rd }} \text { visit for } \\
\text { Urban Site } 2 \text {. } \\
\text { Solid group attendance; Making } \\
\text { referrals and disseminating } \\
\text { resource packets. }\end{array}$ & $\begin{array}{l}\text { The peer-to-peer support and } \\
\text { structure of program fostered a } \\
\text { strong sense of community for } \\
\text { participants. Increasing } \\
\text { consistency of attendance } \\
\text { amongst participants is } \\
\text { hypothesized to strengthen SCI } \\
\text { scores over time. }\end{array}$ \\
\hline $\begin{array}{l}\text { Decreased risk of } \\
\text { postpartum } \\
\text { depression due to } \\
\text { isolation. }\end{array}$ & $\begin{array}{l}\text { Decreased scores on } \\
\text { Postpartum Depress. } \\
\text { Scale } \\
\text { Referrals/resource } \\
\text { packets }\end{array}$ & $\begin{array}{l}\text { Changes in EPDS over time } \\
\text { were mixed; the overall change } \\
\text { was an increase of } 109.52 \% \text {. The } \\
\text { presence of high baseline EPDS } \\
\text { scores ( }>13) \text {, however, was } \\
\text { significantly lower at only } \\
12.5 \% \text {. } \\
\text { Making referrals and } \\
\text { disseminating resource packets; } \\
\text { Postpartum safety pledges. }\end{array}$ & $\begin{array}{l}\text { Baseline scores indicate fewer } \\
\text { participants at-risk for PPD; } \\
\text { impact of programming on those } \\
\text { at-risk are inconclusive. Instead, } \\
\text { emphasis on awareness, safety } \\
\text { pledges }(93 \%) \text {, and referrals } \\
\text { remain most significant influence } \\
\text { on PPD amongst participants. }\end{array}$ \\
\hline
\end{tabular}


2. Outcome Report Forms-Rural Location

\begin{tabular}{|c|c|c|c|}
\hline $\begin{array}{l}\text { EXPECTED } \\
\text { OUTCOMES }\end{array}$ & INDICATORS & RESULTS TO DATE & $\begin{array}{l}\text { CHALLENGES AND } \\
\text { LESSONS LEARNED }\end{array}$ \\
\hline $\begin{array}{l}\text { Increased self- } \\
\text { confidence in } \\
\text { parenting skills and } \\
\text { resources. }\end{array}$ & $\begin{array}{l}\text { Parenting Self- } \\
\text { confidence } \\
\text { Pre- and post-tests } \\
\text { Referrals/resource } \\
\text { packets }\end{array}$ & $\begin{array}{l}14.61 \% \text { increase in } \\
\text { parenting self-efficacy } \\
\text { and confidence in } \\
\text { parenting skills across all } \\
\text { classes, all participants; } \\
\text { Making referrals and } \\
\text { disseminating resource } \\
\text { packets. }\end{array}$ & $\begin{array}{l}\text { Class topics resonate with } \\
\text { participants and address areas of } \\
\text { information that increase } \\
\text { confidence in parenting skills. } \\
\text { Peer-discussion and access to } \\
\text { resources and referrals are } \\
\text { hypothesized to contribute, as } \\
\text { well. }\end{array}$ \\
\hline $\begin{array}{l}\text { Increase peer-to-peer } \\
\text { support for expecting } \\
\text { and new mothers. }\end{array}$ & $\begin{array}{l}\text { High/increasing Sense of } \\
\text { Community (SCI) scores } \\
\text { Attendance/engagement } \\
\text { Referrals/resource } \\
\text { packets }\end{array}$ & $\begin{array}{l}\text { SCI average score of } \\
91.7 \% \text { on } 3^{\text {rd }} \text {-visit } \\
\text { surveys; remained } 100 \% \\
\text { on } 3^{\text {rd }} \text {-visit to } 6^{\text {th }} \text {-visit } \\
\text { surveys. } \\
\text { Consistent group } \\
\text { attendance. } \\
\text { Making referrals and } \\
\text { disseminating resource } \\
\text { packets. }\end{array}$ & $\begin{array}{l}\text { The peer-to-peer support and } \\
\text { structure of program fostered a } \\
\text { strong sense of community for } \\
\text { participants. Consistency of } \\
\text { attendance amongst participants is } \\
\text { hypothesized to strengthen SCI } \\
\text { scores over time. } 79 \text { participants } \\
\text { engaged over course of rural } \\
\text { location-based programming. }\end{array}$ \\
\hline $\begin{array}{l}\text { Decreased risk of } \\
\text { postpartum depression } \\
\text { due to isolation. }\end{array}$ & $\begin{array}{l}\text { Low/decreasing } \\
\text { Postpartum Depression } \\
\text { Scale scores } \\
\text { Referrals/resource } \\
\text { packets }\end{array}$ & $\begin{array}{l}\text { Changes in EPDS over } \\
\text { time were mixed, but } \\
\text { predominantly decreases. } \\
\text { Overall, the average } \\
\text { change decreased } 21.3 \% \text {. } \\
\text { The presence of high } \\
\text { baseline EPDS scores } \\
(>13) \text { was } 7.4 \% \text {; Making } \\
\text { referrals and } \\
\text { disseminating resource } \\
\text { packets. } \\
\text { Postpartum safety } \\
\text { pledges. }\end{array}$ & $\begin{array}{l}\text { Baseline EPDS scores indicating a } \\
\text { small number of participants at- } \\
\text { risk for PPD; impact of } \\
\text { programming on participants } \\
\text { suggests a decreased risk. } \\
\text { Emphasis on awareness, safety } \\
\text { pledges ( } 79 \% \text { ), and referrals } \\
\text { remain most significant influence } \\
\text { on PPD amongst participants. }\end{array}$ \\
\hline
\end{tabular}




\section{APPENDIX III: PARTICIPANT DEMOGRAPHICS}

1. Peer-based Support Group Participant Demographics and Discussion

2. In-depth Interview Participant Demographics 
1. Peer-Based Support Group Participant Demographics by Location

\begin{tabular}{|l|c|c|c|c|c|}
\hline & $\begin{array}{c}\text { Avg. of all } \\
\text { Locations }\end{array}$ & $\begin{array}{c}\text { Urban site } \\
1\end{array}$ & $\begin{array}{c}\text { Urban site } \\
2\end{array}$ & $\begin{array}{c}\text { Urban site } \\
3\end{array}$ & Rural site \\
\hline Average age & 27 years & 26 years & 28 years & 27 years & 25 years \\
\hline First-time mothers & $42.4 \%$ & $46.4 \%$ & $75.0 \%$ & $20.0 \%$ & $57.1 \%$ \\
\hline Average number of children & 3.0 & 3.7 & 3.0 & 3.0 & 2.3 \\
\hline Relationship status & & & & & \\
\hline Married & $45.6 \%$ & $32.1 \%$ & $75.0 \%$ & $10.0 \%$ & $42.9 \%$ \\
\hline In a relationship & $31.6 \%$ & $46.4 \%$ & $0.0 \%$ & $30.0 \%$ & $33.3 \%$ \\
\hline Single/other & $22.0 \%$ & $21.4 \%$ & $12.5 \%$ & $60.0 \%$ & $23.8 \%$ \\
\hline Race/ethnicity & & & & & \\
\hline Hispanic/Latina & $10.2 \%$ & $7.1 \%$ & $12.5 \%$ & $0.0 \%$ & $4.8 \%$ \\
\hline Black/African Am. & $20.3 \%$ & $32.1 \%$ & $0.0 \%$ & $20.0 \%$ & $0.0 \%$ \\
\hline White/non-Hispanic & $71.2 \%$ & $64.3 \%$ & $100.0 \%$ & $80.0 \%$ & $92.5 \%$ \\
\hline Asian/mixed/other & $0.0 \%$ & $0.0 \%$ & $0.0 \%$ & $0.0 \%$ & $0.0 \%$ \\
\hline Annual income & & & & & \\
\hline Less than $\$ 10,000$ & $40.7 \%$ & $39.2 \%$ & $25.0 \%$ & $100.0 \%$ & $42.9 \%$ \\
\hline \$10,000-19,999 & $15.3 \%$ & $17.8 \%$ & $0.0 \%$ & $0.0 \%$ & $28.6 \%$ \\
\hline \$20,000-29,999 & $15.3 \%$ & $21.4 \%$ & $0.0 \%$ & $0.0 \%$ & $9.5 \%$ \\
\hline \$30,000 or more & $23.7 \%$ & $14.3 \%$ & $75.0 \%$ & $0.0 \%$ & $19.0 \%$ \\
\hline Education & & & & & \\
\hline Less than HS & $16.9 \%$ & $17.8 \%$ & $0.0 \%$ & $40.0 \%$ & $9.5 \%$ \\
\hline High school/GED & $23.7 \%$ & $28.6 \%$ & $12.5 \%$ & $20.0 \%$ & $23.8 \%$ \\
\hline Some postsecondary & $39.0 \%$ & $32.1 \%$ & $50.0 \%$ & $40.0 \%$ & $47.6 \%$ \\
\hline College degree or + & $22.0 \%$ & $21.4 \%$ & $37.5 \%$ & $0.0 \%$ & $19.0 \%$ \\
\hline
\end{tabular}

Mothers Helping Mothers (MHM) devised the Peer-based Support Group (PSG) to provide support to mothers at risk for social isolation, postpartum depression, and lower parenting self-confidence; programs were offered in resource-poor communities. MHM succeeded in serving low-income women, with $40.7 \%$ of urban mothers and $42.9 \%$ of rural mothers living in households with less than $\$ 10,000$ annual income. The majority of the women obtain healthcare services through Medicaid (67.9\% in urban location, $68.4 \%$ in rural location); MHM's resource referrals was beneficial for participants.

The typical PSG participant for the urban locations was 27 years old, married (45.6\%) or in a relationship (31.6\%), not a first-time mother (57.6\%), and had an average of three children already. She was white/non-Hispanic (71.2\%), attended a community 
and technical college or participated in a postsecondary certification program (39.0\%), and reported an annual income less than $\$ 10,000(40.7 \%)$. She was insured (92.9\%), most likely on Medicaid (67.9\%). The typical rural location participant was 25 years old, married (42.9\%) or in a relationship (33.3\%), and a first-time mother (57.1\%). Those not first-time mothers had an average of two children already. She was white/non-Hispanic (95.2\%), attended a community and technical college or participated in a postsecondary certification program (47.6\%), and reported an annual income less than $\$ 10,000(42.9 \%)$. She was insured (89.5\%), most likely on Medicaid (68.4\%).

In all four locations, most participants were white. Urban Site 1 attracted the most racially diverse participants, while Urban Site 3 and the rural site were exclusively white (the only non-white participant at Rural Site was a Latina attending the one-time baby shower event). MHM's urban baby shower event included Latina mothers (25.0\%) and Black mothers (8.3\%) to this one-time event; Urban Site 1 PSG participants were the most racial diverse (39.2\% non-white). Urban Site 3 reported the highest average educational attainment (37.5\% of mothers with a college degree) and highest average income range ( $75 \%$ of with annual household income of $\$ 30,000$ or more). This suggested that Urban Site 3 mothers already have access to resources and/or support compared to Urban Site 1 and Urban Site 2 mothers.

While the PSG program's singular focus on mothers could be viewed as a limitation for supporting at-risk mothers [research echoes the need to incorporate new and expecting fathers in classes to prepare them for parenting responsibilities (e.g., Fletcher, Vimpani, Russell, and Keating 2008)], it reflected an intentional decision by MHM's leadership. Mother-centric programming acknowledged the reality of this 
demographic: Many of these participants entered parenthood alone (22.0\% of Urban Sites 1, 2, and 3; 23.8\% of Rural Site) or in informal relationships (31.6\% of Urban Sites 1, 2, and $3 ; 33.3 \%$ of Rural Site). The lack of curriculum for fathers in the program, therefore, was not an oversight but an accurate recognition of the specific needs facing these mothers and their circumstances. MHM committed to providing the most tangible and relevant resources to its participants; they designed this program to do just that. 
2. In-depth Interview Participant Demographics $(n=41)$

\begin{tabular}{|c|c|c|c|}
\hline & Percentage & Number & Range \\
\hline Average current age & 35.3 years & 35.3 years & $24-47$ years \\
\hline Average age entered motherhood & 26.6 years & 26.6 years & $15-37$ years \\
\hline Mothers Helping Mothers participant & $43.9 \%$ & 18 & \\
\hline \multicolumn{4}{|l|}{ Current Living Situation } \\
\hline Reside with own children & $90.2 \%$ & 37 & \\
\hline Reside with spouse/partner & $56.1 \%$ & 23 & \\
\hline Reside with extended family (permanent) & $13.3 \%$ & 8 & \\
\hline Staying with friends/family (temporary) & $7.3 \%$ & 3 & \\
\hline Average no. children in household (own) & 2.0 & 2.0 & $0-6$ children \\
\hline Average no. children in household (all) & 2.3 & 2.3 & $0-6$ children \\
\hline Raising step-children & $19.5 \%$ & 8 & \\
\hline Raising niece/nephew/other & $14.6 \%$ & 6 & \\
\hline \multicolumn{4}{|l|}{ Relationship status } \\
\hline Partnered & $56.1 \%$ & 23 & \\
\hline Married (first marriage) & $39.0 \%$ & 16 & \\
\hline Remarried & $14.6 \%$ & 6 & \\
\hline In a relationship & $2.4 \%$ & 1 & \\
\hline Not partnered & $43.9 \%$ & 18 & \\
\hline Single (never married) & $26.8 \%$ & 11 & \\
\hline Divorced & $17.1 \%$ & 7 & \\
\hline \multicolumn{4}{|l|}{ Race/ethnicity } \\
\hline Non-white & $53.7 \%$ & 21 & \\
\hline White/non-Hispanic & $48.8 \%$ & 20 & \\
\hline \multicolumn{4}{|l|}{ Non-white participants: } \\
\hline Black/African-American & $46.3 \%$ & 19 & \\
\hline Hispanic/Latina & $4.9 \%$ & 2 & \\
\hline Biracial & $4.9 \%$ & 2 & \\
\hline Asian & $2.4 \%$ & 1 & \\
\hline \multicolumn{4}{|l|}{ Annual income } \\
\hline Less than $\$ 30,000 /$ Lower-income & $14.6 \%$ & 6 & \\
\hline$\$ 30,000-59,999 /$ Lower-middle income & $41.5 \%$ & 17 & \\
\hline$\$ 60,000-99,999 /$ Upper-middle income & $26.8 \%$ & 11 & \\
\hline$\$ 100,000$ or more/Upper-income & $17.1 \%$ & 7 & \\
\hline \multicolumn{4}{|l|}{ Residence } \\
\hline Own apartment/home & $61.0 \%$ & 25 & \\
\hline Rent apartment/home & $31.7 \%$ & 13 & \\
\hline Other & $7.3 \%$ & 3 & \\
\hline \multicolumn{4}{|l|}{ Education } \\
\hline High school diploma/GED & $9.8 \%$ & 4 & \\
\hline Some postsecondary school & $36.6 \%$ & 15 & \\
\hline College degree or higher & $56.1 \%$ & 23 & \\
\hline Bachelor's degree only (BA or BS) & $29.3 \%$ & 12 & \\
\hline Graduate or Professional degree & $26.8 \%$ & 11 & \\
\hline \multicolumn{4}{|l|}{ Employment } \\
\hline Working outside the home & $75.6 \%$ & 31 & \\
\hline Part-time (1-30 hrs. per week) & $17.1 \%$ & 7 & \\
\hline Full-time $(31+$ hrs. per week $)$ & $58.5 \%$ & 24 & \\
\hline Not working outside the home & $24.4 \%$ & 10 & \\
\hline Looking for work & $7.3 \%$ & 3 & \\
\hline Not looking for work & $17.1 \%$ & 7 & \\
\hline
\end{tabular}




\section{APPENDIX IV: \\ IN-DEPTH INTERVIEW GUIDES}

1. Interview guide for all mothers, regardless of involvement with Mothers Helping Mothers and/or Mama's Village.

2. Supplemental interview questions for mothers involved with Mothers Helping Mothers and/or Mama's Village.

3. Focus group interview guide. 
1-The following IRB-approved guide was used for all in-depth interviews participants:

1) What is your current age? What was your age at first pregnancy?

2) Are you partnered? For how long? Divorced/separated? For how long? How old were you when you coupled/separated? If separated from child's father, are you co-parenting?

3) Some women describe identifying as/feeling like mothers during pregnancy. Can you remember/tell me about when you first felt/identified like/as a mother? How did you know? Could you walk me through your thoughts/feelings when you experienced this?

4) Tell me about the choices you made during your pregnancy and birth? Did the idea of being a good mother influence your pregnancy and/or your birth? If yes, please tell me about your experience. What would you have liked to change about your birth? Did your experience mirror/challenge your views as a mother? Pregnancy/infant loss? How did this impact your feelings about motherhood?

5) How do your views about breastfeeding support your standards of mothering?

6) Do/did you have a clear image of what constitutes "good mothering"? Please describe it. Tell me about a time when you felt like a good mother? How did you know (you'd achieved that standard)? What/who influences your standards? Can you tell me about a time when you thought you or someone else was not being a good mother? Did you talk to anyone about this? Do you experience these feelings of good or bad mothering frequently/infrequently?

7) How do your views on mothering contribute to your decision to work/to not work outside the home?

8) How do your views on mothering contribute to your decisions regarding your child's education, extracurricular activities?

9) Do you consider yourself to be religious? How do these views contribute to your ideas of mothering?

10) Does your child have any developmental/physical disabilities? How have you navigated these as a mother? What is required?

11) Overall, how would you describe your experience as a mother?

12) What would you like to add that I have not touched on? 
2-In addition to the questions from the general interview guide, participants involved with any aspect of Mothers Helping Mothers' peer-support group (PSG) programming and/or Mama's Village were asked these additional questions, informed by Collom and Mitchell's (2005) work on culture- and quality of life-focused social movements:

1) Tell me about the Mothers Helping Mothers' (MHM) and/or Mama's Village (MV) groups/classes you've attended.

2) What role does $\mathrm{MHM} / \mathrm{MV}$ play in creating maternal support and expanding options for mothers?

3) How do you view local efforts and action to expand maternal support?

4) How do you feel your participation in MHM/MV's programming has influenced your mothering?

5) How important is it to create maternal support for local mothers?

6) Do you believe that change is needed for mothers to feel supported? Why is that? If so, how would this look?

7) Do you think MHM/MV is able to effect maternal support and social change for mothers?

8) How satisfied are you with your participation with MHM/MV? How do you talk about this organization and/or your participation with other mothers/parents? How do you encourage/discourage participation?

9) How has your mothering experience influenced your participation with MHM/MV? Why is that?

10) Why did continue to participate in MHM's PSG/MV's programming? OR

Why didn't you return to MHM's PSG/MV's programming? What was missing from your experience with the group? Why is that? What would need to change for you to re-visit the group? 
3-The following questions were used for the semi-structured, in-depth focus group interview with the founders and facilitators of Mothers Helping Mothers (MHM) and its local efforts to expand support for mothers. These questions were informed by Bobel's (2007a) research on grassroots activism:

1) How does your work with Mothers Helping Mothers (MHM) reflect your views of mothering?

2) How does this local maternal action to expand support for mothers reflect your views of mothering?

3) What motivates you to expand options for mothers?

4) How do you view your local efforts in terms of social norms about mothering?

5) How important is it that mothers like you identify with the work you're doing? Mothers who are different than you? How do you talk about the work you do? How do you explain the purpose of MHM and the peer-support group program?

6) How has your personal mothering experience shaped your involvement with MHM? Why is that?

7) How important is it that mothers who participate in MHM share an overall view of mothering? How do mothers with different identities (e.g., race, class, marital status, parenting philosophies) fit into the community? Is MHM strengthened or weakened by mothers with different views? Why do you think that is?

8) How do you know when MHM is successful? How do you know you've accomplished your goals? Have those goals changed since its inception? In what way? How does success look moving forward? Why is that?

9) How would your efforts and action look ideally? How would your previous efforts have gone ideally? Where would MHM be now ideally? What would that look like? Who would be involved? What would its impact have been, so far? In the future?

10) Where have you deviated from this ideal? Why do you think that is? Has this altered your projected course? In what way?

11) What is social change? Why is creating social change for mothers locally important to you? Have you created social change for mothers?

12) Would you classify your efforts locally as a social movement? Why is that?

13) Are you an activist? Why do you say that? Why do you think that is? 


\title{
CURRICULUM VITAE
}

\author{
Cheryl Lynn Crane \\ 2706 Cameron Court \\ Louisville, Kentucky 40205 \\ cheryl.crane@louisville.edu•502-296-8382
}

\section{EDUCATION \\ 2012 - 2016 (exp.)}

$1996-1998$

$1992-1996$

\section{Ph.D., Applied Sociology, University of Louisville}

Dissertation defense: November 17, 2016; ABD, 2015; Internship completed, 2015. Dissertation: "We Weren't Created To Do It By Ourselves": Good Mothering and Maternal Support Across Race, Class, and Family StrFucture

Committee: Karen Christopher (chair), Gül Aldikaçti Marshall, Patricia Gagné, Robin Högnäs, and Nancy Theriot (Women and Gender Studies) Comprehensive Examinations: Social Movements Theories; Feminist Theories; Qualitative Methodologies; Sociology of Motherhood

M.A., Human Geography, University of Washington, Seattle Thesis: Therapeutic Landscapes: A case study of feminist health care Committee: Lucy Jarosz (chair), Richard Morrill

B.A. with Honors, Human Geography, University of Washington Honors Thesis: Why Abortion Rates Vary in the U.S.

\section{AREAS OF INTEREST}

Race, Gender, and Class/Intersectionality; Collective Behavior and Social Movements; Feminist Theories; Inequality, Poverty, and Movement; Family; Resistance and Social Change;

Motherhood, Birth, and Reproduction.

\section{ACADEMIC POSITIONS}

2016-2017 Visiting Assistant Professor

Department of Sociology, Franklin College (Indiana)

2014-2016 Graduate Teaching Assistant

Department of Sociology, University of Louisville

2012-2014 University Fellow

School of Interdisciplinary Graduate Studies, University of Louisville

2004 Instructor, World Geography

Red Rocks Community College, Lakewood, Colorado

2002 Instructor, Human Geography

Green River Community College, Auburn, Washington

1998-1999 Research Assistant, Dean of Instruction

Highline Community College, Des Moines, Washington

1997-1998 Graduate Teaching Assistant, Department of Geography

University of Washington, Seattle

1996-1997 Director, Writing Center, Department of Geography

University of Washington, Seattle 


\section{PROGRAM EVALUATION}

Mama to Mama, Louisville, Kentucky

2014 - 2015 The Best Intentions: A Program Evaluation of Mama to Mama's

Prenatal/Postpartum Wellness and Peer Support Groups Program. A formative program evaluation of programing for new and expecting mothers in at-risk communities. Mixed-methods analysis incorporated parenting self-efficacy; post-partum wellness; and sense of community instruments; pre- and post-test topic-based surveys; and extensive participant observation. Final report and recommendations submitted to organization and Medicaid contractor (funding agency).

\section{PUBLICATIONS}

\section{Manuscripts in Preparation}

Crane, Cheryl. (To be submitted to Family Relations). "Mothers Helping Mothers: How race and class affect peer-based maternal support."

Crane, Cheryl and Gül Aldikaçti Marshall. (In process). "'Helping them find that voice': Privilege, power, and supporting mothers through collective action."

Bergman, Mathew J., Jacob Gross, and Cheryl Crane. (In process). "'I Don't Know How She Does It': An Examination of Variables that Impact Working Mothers' Ability to Complete Baccalaureate Degrees."

\section{Other Publications}

Crane, Cheryl L. 2001. “Taking the Pulse: Women's health care doesn't just mean offering OB/GYN services anymore." Puget Sound Business Journal. http://www.bizjournals.com/seattle/stories/2001/08/06/focus $1 . h t m l$ ?page=all

\section{TEACHING EXPERIENCE} Franklin College (Franklin, Indiana)

Courses taught: Introduction to Sociology

Social Problems \& Nonprofit Responses

Gender \& Sexualities

Research Methods I and II

Evolution of Feminism through Music, Film, and Text: Riot Grrrls to Queen Bey

University of Louisville (Louisville, Kentucky)

Courses taught: Introduction to Sociology

Social Problems

Diversity \& Inequality

Social Theory (Classical and Contemporary)

\section{Red Rocks Community College (Lakewood, Colorado)}

Course taught:

Introduction to World Geography

\section{Green River Community College (Auburn, Washington) \\ Course taught: Introduction to Geography}

\section{Teaching Assistantships (University of Washington, Seattle)}

Courses assisted: Introduction to Human Geography, Prof. Michael Brown Introduction to Human Geography, Prof. Stephen Frenkel 


\section{SCHOLARSHIPS, GRANTS, \& AWARDS}

Awards and Scholarships

2014-2016

2016

2014-2015

Graduate Teaching Assistantship (full tuition and stipend), UofL

2012-2014

Publishing Academy

2015

Graduate Teaching Assistant Academy

2015,2016

University Fellowship (full tuition and stipend), UofL

Graduate Student Council, Conference Travel Grant, UofL

2014

Selected as a Faculty Mentor for Red \& Black Scholar reception recognizing student athletes with cumulative GPA of 3.25 or higher

2014

Graduate Student Council, Research Grant, UofL

Graduate Student Council, Conference Travel Grant, UofL

Graduate Student Union, Conference Travel Grant, UofL

Graduate Student Council, Conference Travel Grant, UofL

2013

Society of Professional Journalists, Western Washington chapter, Excellence in Journalism

1998 Distinguished Teaching Assistant, Department of Geography, UW

1997-1998 Graduate Teaching Assistantship (full tuition and stipend), UW

1997 Glenda Laws Undergraduate Award, Urban Specialty Group, Association of

American Geographers

Federal Grants*

2004-2006 Retired \& Senior Volunteer Program/Corporation for National \& Community Service $(\$ 99,740$ per year for two years, on behalf of Eagle County Health \& Human Services)

2003-2004 Federal Community Block Grant, Jefferson County, Co. $(\$ 25,000$ per year for two years, on behalf of Refugee \& Asylee Programs, Lutheran Family Services of the Rockies)

2002-2004 Office of Refugee Resettlement/Department of Health and Human Services (\$119,688 per year for three years, on behalf of Refugee \& Asylee Programs, Lutheran Family Services of the Rockies)

*Funding secured and managed to launch or renew program and operating support for nonprofit organizations.

\section{Private Grants*}

2008-2012 Private/corporate donation support of various nonprofit programming $(\$ 3 \mathrm{M}+)$

2006-2008 Corporate/private foundation support of multiple sclerosis programming $(\$ 1.2 \mathrm{M}+)$

*Funding secured and managed to launch or renew program and operating support for nonprofit organizations.

\section{PRESENTATIONS}

Conference Panels

2016 "Do community programs make "better" mothers?" (Panel organizer and presenter). Annual Winter Meeting of the Sociologists for Women in Society. Memphis, Tn.

2004 "Best practices for advocacy." (Panel chair and presenter). Lutheran Immigration \& Refugee Service, Immigration Management Project-Advocacy and Networking Conference. Milwaukee, Wis.

\section{Conference Papers}

2015 "The Best Intentions: 'Helping' at-risk mothers." Annual Winter Meeting of the Sociologists for Women in Society. Washington, D.C. 
2014 "Women, Birth, and Resistance: Emerging Research." Annual Winter Meeting of the Sociologists for Women in Society. Nashville, Tn.

2013 "Birth in the Bluegrass: Emerging Research." Annual Meeting of the Mid-South Sociological Association. Atlanta, Ga.

\section{Conference Presentations and Workshops}

2010 "Overcoming fundraising obstacles for academic libraries." Academic Library Advancement and Development Network Annual Conference, Santa Monica, Ca.

2005 "Team approach to volunteer management and best practices." The Corporation for National and Community Service, Colorado Senior Corps Grantees Annual Conference, Denver, Co.

2005 "Cultural diversity and increasing cultural competency." The Literacy Project, Cultural Diversity Training for Volunteers, Avon, Co.

2004 "Local advocacy efforts and best practices." Lutheran Immigration \& Refugee Service, Immigration Management Project Advocacy and Networking Conference, Milwaukee, Wis.

2004 "Advocacy efforts and best practices for serving refugees and asylees." Lutheran Services in America National Conference, Chicago, Ill.

2004 "Working with refugees and asylees as social work practitioners in the human service arena." Metropolitan State College, Practices in Social Work course. Denver, Co.

2003 "Identifying and service victims of human trafficking." Global Trafficking in Humans, International Conference, Denver, Co.

2003 "Working with refugees and asylees as social work practitioners in the human service arena." Metropolitan State College, Practices in Social Work course. Denver, Co.

\section{ACADEMIC SERVICE}

2015-2016

2013-2015

2012-2013

2012

1997-1998
Secretary, Sociology Graduate Student Association

Student representative to faculty meetings, Sociology Graduate Student Assoc.

Student co-representative, faculty meetings, Sociology Graduate Student Assoc.

Reviewer, Contemporary Journal of Anthropology and Sociology, Ryan

Schroeder, editor

Graduate Student Senate Representative, Geography, University of Washington

\section{MEMBERSHIP}

American Sociological Association

Society for the Study of Social Problems

Sociologists for Women in Society 2012-present

2012-present

2013-present

\section{PROFESSIONAL DEVELOPMENT}

2008-2014 Certified Fundraising Executive, CFRE International

2004

2003

Board of Immigration Appeals accredited representative, BIA

The Grantsmanship Center, Inc.

\section{RELATED PROFESSIONAL SERVICE}

2011-2012 Director of Advancement, Kentucky Science Center, Louisville, Ky.

2008-2011 Director of Development, University Libraries, University of Louisville, Ky.

2006-2008 Director of Development, Can Do Multiple Sclerosis, Edwards, Co.

2004-2006 Director, Retired \& Senior Volunteer Program federal grant, Health \& Human Services, Eagle, Co.

2002-2004 Community Services Administrator, Refugee \& Asylee Program, Lutheran Family Services of the Rockies, Denver, Co. 
1999-2002 Research Director, Puget Sound Business Journal, Seattle, Wa.

\section{COMMUNITY SERVICE}

2013-present Advisory Board Member, Camp Piomingo, YMCA Greater Louisville, Ky. 2008 Executive Board Member, Eagle Valley Child Care Association, Vail, Co.

\section{ACADEMIC REFERENCES}

\section{Karen Christopher, Ph.D.}

Associate Professor, Sociology and Gender \& Women's Studies

University of Louisville

502-407-8161

k.christopher@louisville.edu

\section{Patricia Gagné, Ph.D.}

Professor, Sociology

University of Louisville

502-767-6930

gagne@,louisville.edu

\section{Gül Aldikaçti Marshall, Ph.D.}

Associate Professor, Sociology

University of Louisville

502-852-8027

gul.marshall@,louisville.edu

\section{PROFESSIONAL REFERENCES}

\section{Bob Hughes, Ed.D.}

Associate Dean, Research and Online/Professional Learning, Adult Education and Training Associate Professor, Adult Education

Seattle University

206-296-2147

rhughes@,seattleu.edu

\section{Jennifer Rackow}

Management Analyst

Corporation for National \& Community Service

267-252-7944

jrackow@cns.gov

\section{James Horan}

Vice President, Refugee \& Community Services

Lutheran Family Services, Rocky Mountains (Denver, Colorado)

720-837-8802

james.horan@1fsrm.org 